\title{
WAVE TRANSMISSION AND MOORING-FORCE CHARA CTERISTICS OF PIPE-TIRE FLOATING BREAKWATERS
}

Volker W. Harms

Joannes J. Westerink

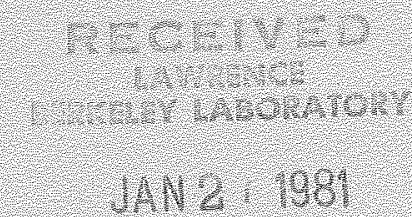

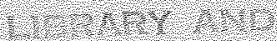

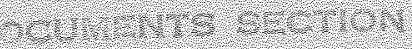

\section{October 1980}

TWO-WEEK LOAN COPY

This is a Library Circulating Copy which may be borrowed for two weeks.

For a personal retention copy, call Tech. Info. Division, Ext. 6782.

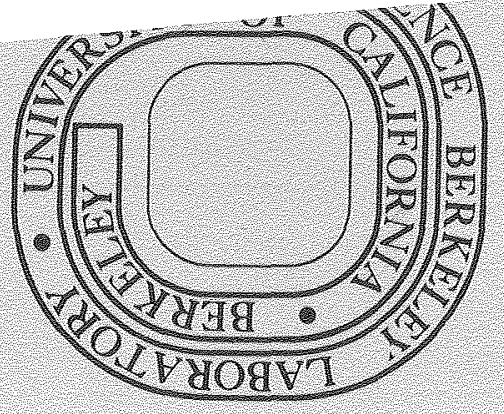

Prepared for the U.S. Deparment of Energy under Contract W-7405ENG 4.8 and the New York Sea Grant Instifute under a grant from the National Oceanic Armospheric Administra. tion and for the U.S. Army Corps of Engineers Coastal Engineering Research Center. 


\section{DISCLAIMER}

This document was prepared as an account of work sponsored by the United States Government. While this document is believed to contain correct information, neither the United States Government nor any agency thereof, nor the Regents of the University of California, nor any of their employees, makes any warranty, express or implied, or assumes any legal responsibility for the accuracy, completeness, or usefulness of any information, apparatus, product, or process disclosed, or represents that its use would not infringe privately owned rights. Reference herein to any specific commercial product, process, or service by its trade name, trademark, manufacturer, or otherwise, does not necessarily constitute or imply its endorsement, recommendation, or favoring by the United States Government or any agency thereof, or the Regents of the University of California. The views and opinions of authors expressed herein do not necessarily state or reflect those of the United States Government or any agency thereof or the Regents of the University of California. 
LBL -11778

WAVE TRANSMISSION AND

MOORING-FORCE CHARACTERISTTCS OF

PIPE-TTRE FLOATING BREAKWATERS

Volker W. Harms

Joannes $J$. Westerink

October 1980

This work was partially sponsored by New York Sea Grant Institute under a grant from the office of Sea Grant, National Oceanic and Atmospheric Administration (NOAA), U.S. Department of Commerce.

The experiments were conducted at the United States Army Corps of Engineers Coastal Engineering Research Center, Fort Belvoir, Virginia.

This work was also supported by the United States Department of Energy under contract W-7405-ENG-48 to the Lawrence Berkeley Laboratory, University of California, Berkeley, California. 


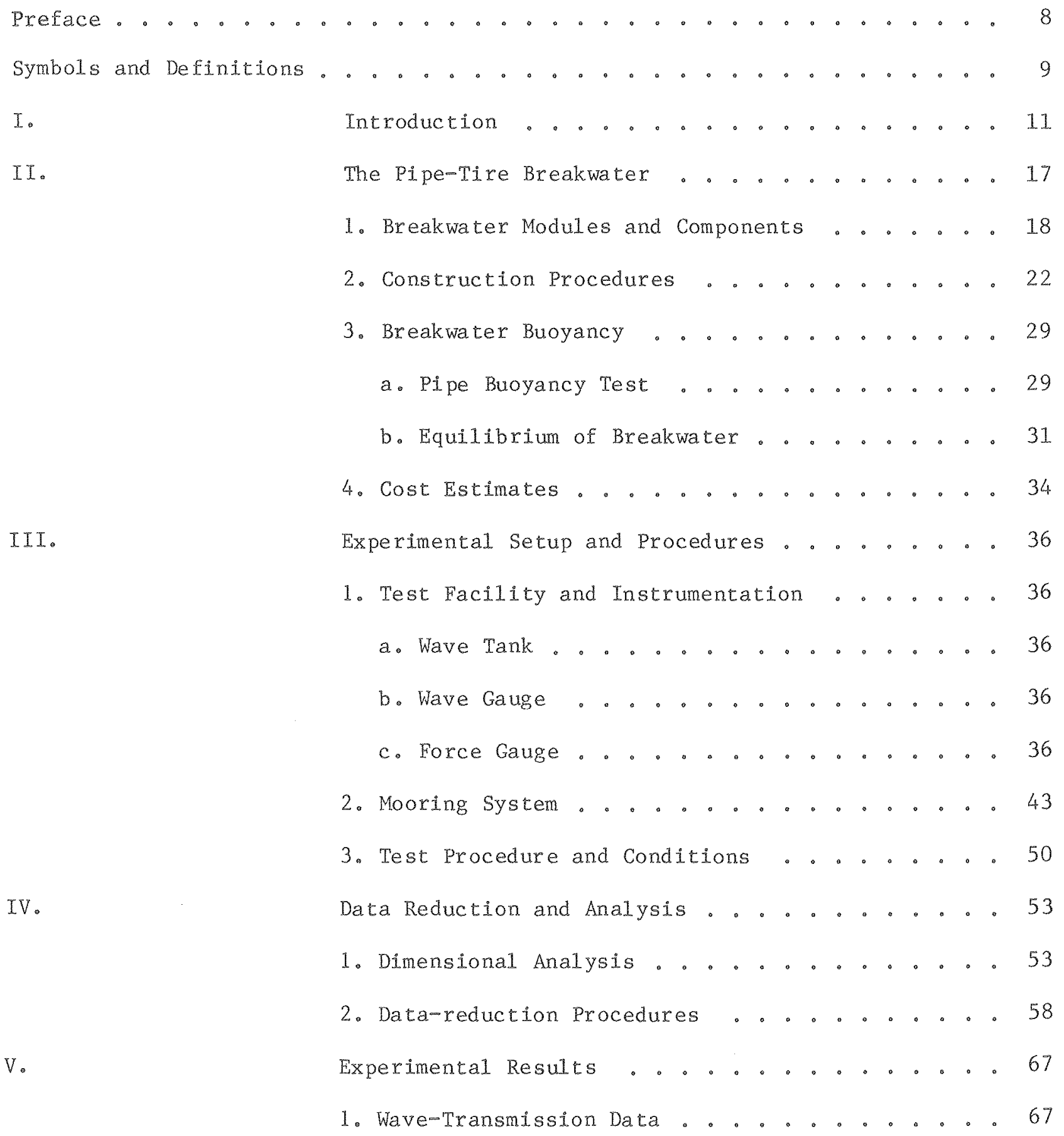


a. PT-1 Breakwater ........... 69

b. PT-2 Breakwater ......... 74

c. Goodyear Breakwater ......... 79

2. Mooring-Force Data .......... 85

a. $\mathrm{PT}-1$ Breakwater ........... 85

b. PT-2 Breakwater ........... 92

c. Goodyear Breakwater ..........995

VI。 Summary and Conclusions . . . . . . . 98 Literature cited ..............102 Appendix A - Test Results in Tabular Form. . . . 104 Appendix B - Force-leasurement Correlation (PT-1).112 Appendix C - Detailed Wave-Transmission Diagrams . 121 
List of Figures

Figure

Title

Page

1. Pipe-Tire Breakwater Field Installation at Mamaroneck, New York (misalignment due to transitional mooring)。. . . . . . . 15

2. Typical PT-Breakwater Module with Tire-Armoured Pipes (Mamaroneck, N.Y.) ................... 15

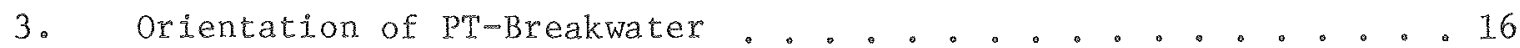

4. Schematic of PT-1 Breakwater Module . . . . . ......20

5. Tire Retainer at End of Pipe ............... 21

6. First Step in Breakwater Assembly: Rolling Tires into Place . . 24

7. Tires are in Position, Ready to be Tied .......... 24

8. Guiding Conveyor-Belt Strip through Tire Casings . . . . . 25

9. Tensioning Belt Before Completing Belt-to-Belt Connection ...25

10. Belts are Overlapped and Bolted Together ..........26

11. Belt is Anchored to Side Wall of One Tire..........26

12. Assembly of PT-1 (foreground) and PT-2 Modules ....... 27

13. Breakwater and Mooring System Components . . . . . . . . 27

14. PT-1 Module Ready for Lift into Wave Tank . . . ..... 28

15. Forces on Pipe-Tire Unit ............... 30

16. Large Wave Tank at CERC with Breakwater and MS-1 Mooring System . 38

17. View Towards Wave Generator (Large Wave Tank, CERC) ......39

18. View Towards Beach (Rock Revetment) ............40

19. Inserting PT-1 Breakwater ................4 40

20. Turbulence Associated with Wave Damping . ...........41

21. Attachment of Seaward Mooring Line (MS-1) ..........41

22. Strain-Gauge-Cantilever Force Gauge . . . . . . . . . 42

23. Tire Mooring Damper (6 tires used in MS-1) 。. . . . . 46

24. Load-Elongation Curves for Mooring-Line Inseres . . . 。 . 47 
25. Stress-Strain Diagram for Belt Connection ..........48

26. Mooring Bridle Used in Field Installation ...........49

27. Definition Sketch for PT-Breakwater ............. 54

28. Wave and Force Record for Long Waves $(\mathrm{d}=4.7 \mathrm{~m}, \mathrm{~T}=8.0 \mathrm{sec}) \ldots . .61$

29. Wave and Force Record for Short Waves $(d=4.7 \mathrm{~m}, \mathrm{~T}=3.2 \mathrm{sec}) \ldots . .62$

30. Wave and Force Record for steep Waves $(d=4.7 \mathrm{~m}, \mathrm{~T}=5.5 \mathrm{sec}) \ldots . .63$

31. Wave and Force Record for Shallow-Water Waves $(\mathrm{d}=2.0 \mathrm{~m}, \mathrm{~T}=5.5 \mathrm{sec}) .64$

32. Foxce-Gauge Calibration Record and Curve ........... 65

33. Definition Sketch for Force Analysis .............66

34. Wave-Transmission Data for PT-1 Breakwater $(\mathrm{d}=4.7 \mathrm{~m}) \ldots \ldots 71$

35. Wave-Transmission Data for PT-1 Breakwater $(\mathrm{d}=2.0 \mathrm{~m}) \ldots \ldots 72$

36. Wave-Transmission Design Curves for PT-1 Breakwater ......73

37. Wave-Transmission Data for PT-2 Breakwater $(\mathrm{d}=4.7 \mathrm{~m})$. .... 75

38. Wave-Transmission Data for PT-2 Breakwater $(\mathrm{d}=2.0 \mathrm{~m}) \ldots \ldots$

39. Wave-Transmission Design Curves for PT-2 Breakwater . . . . 77

40. Comparison of $\mathrm{PT}-1$ and $\mathrm{PT}-2$ Wave Attenuation $(\mathrm{d}=4.7 \mathrm{~m}) \ldots 78$

41. Comparison of Goodyear and PT-2 Wave Attenuation $(\mathrm{d}=4.7 \mathrm{~m}) \ldots 81$

42. Comparison of Goodyear and $\mathrm{PT}-2$ Wave Attenuation $(\mathrm{d}=2.0 \mathrm{~m}) \ldots . .82$

43. Influence of $\mathrm{D} / \mathrm{d}$ on Goodyear Wave Attenuation . . . . . . 83

44. Wave-Transmission Design Curves for Goodyear and PT-Breakwater. . 84

45. PT-1 Peak-Nooring-Force Data (MS-1, $\mathrm{d}=2.0 \mathrm{~m}) \ldots \ldots 8$

46. PT-1 Peak-Mooring-Force Data $(M S-1, \mathrm{~d}=4.7 \mathrm{~m}) \ldots . \ldots 89$

47. Effect of Mooring-System Compliance on $\mathrm{F}$ (MS-1 and $\mathrm{MS}-2$,

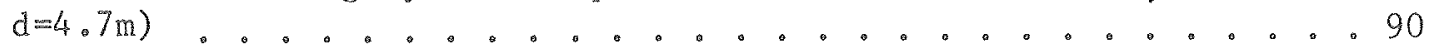

48. PT-1 Peak-Mooring-Force Data (MS-3, $\mathrm{d}=4.7 \mathrm{~m}) \ldots . \ldots 1$

49. PT-2 Peak-Mooring-Force Data $(M-3, d=4.7 m) \ldots . . . . .93$

50. PT-2 Peak-Mooring-Force Data (MS-3, d=2.0m) .........94

51. Goodyear Peak-Mooring-Force Data (ref. 3, d=2.0m) .......96 
Page

52. Goodyear Peak-Mooring-Force Data (ref. 3, d=4.0m) ......997

B-1 Correlation of $\mathrm{F}$ and $\mathrm{F}_{2}(\mathrm{MS}-1, \mathrm{~d}=2.0 \mathrm{~m}) \ldots \ldots \ldots$

B-2 Correlation of $F$ and $F_{2}(M S-1, d=4.7 m) \ldots \ldots . \ldots 14$

$\mathrm{B}-3$ Correlation of $\mathrm{F}$ and $\mathrm{F}_{2}(\mathrm{MS}-2, \mathrm{~d}=4.7 \mathrm{~m}) \ldots \ldots 115$

B-4 Correlation of $F$ and $F_{2}(M S-3, d=4.7 m) \ldots \ldots 116$

B-5 Correlation of $\mathrm{F}$ and $\mathrm{F}_{\mathrm{S}}(\mathrm{MS}-1, \mathrm{~d}=2.0 \mathrm{~m}) \ldots \ldots \ldots$

B-6 Correlation of $\mathrm{F}$ and $\mathrm{F}_{\mathrm{S}}(\mathrm{MS}-1, \mathrm{~d}=4.7 \mathrm{~m}) \ldots \ldots 118$

B-7 Correlation of $\mathbb{F}$ and $F_{S}(M S-2, d=4,7 m) \ldots \ldots . \ldots 119$

B-8 Correlation of $F$ and $F_{S}(M S-3, d=4,7 m) \ldots \ldots . \ldots$

C-1 PT-1 Wave Transmission Data for MS-1 ........... 122

C-2 PT-1 Wave Transmission Data for MS-1 (discrete H/L) . . 。. 123

C-3 PT-1 Wave Transmission Data for MS-2 ........... 124

C-4 PT-1 Wave Transmission Data for MS-2 (discrete H/L) . . . . 125

C-5 PT-1 Wave Transmission Data for MS-3 . . . . . . . . 126

C-6 PT-1 Wave Transmission Data for MS-3 (discrete H/L) . . . . 127

C-7 PT -1 Wave Transmission Data for MS $-3(\mathrm{~d}=2.0 \mathrm{~m}$, discrete H/L $)$. . 128

C-8 PT-2 Wave Transmission Data for MS-3 (discrete H/L) 。 。. . 129

C-9 PT-2 Wave Transmission Data for MS-3 $(\mathrm{d}=2.0 \mathrm{~m}$, discrete $\mathrm{H} / \mathrm{L})$. . 130 


\section{List of Tables}

Number

1

2

3

4

$A-1$

$A-2$

$A=3$

$A-4$

$A-5$

$A-6$

A- 7
Title

Page

Cost Estimates of PT-Breakwater Components . . . 35

Mooring-System Compliance ............ 45

Summary of Test Conditions ........... 52

Summary of Peak-Mooring-Force Data . . . . . 87

PT-1 Breakwater with $\mathrm{MS}^{-1}(\mathrm{~d}=4.7 \mathrm{~m}) \cdots, \ldots \circ 105$

PT-1 Breakwater with MS-1 $(\mathrm{d}=2.0 \mathrm{~m}) \cdot \ldots . . .06$

PT- 1 Breakwater with $M S-2(d=4.7 \mathrm{~m}) \cdot . \cdot . \cdot 107$

PT-1 Breakwater with MS-3 $(\mathrm{d}=4.7 \mathrm{~m}) \cdots . . . . .108$

PT-2 Breakwater with MS-3 (d=4.7m) ...... 109

$\mathrm{PT}-2$ Breakwater with $\mathrm{MS}-3(\mathrm{~d}=2.0 \mathrm{~m}) \cdots \cdot . \cdot 110$

PT-DB Breakwater with MS-3 (d=4.7m) ...... 111 


\section{Preface}

This report presents the results of a series of prototype scale tests of a floating breakwater that incorporates massive cylindrical members (steel or concrete pipes, telephone poles, etc.) in a matrix of scrap truck or authomobile tires. The breakwater was developed by the senior author while on the faculty of the State University of New York at Buffalo (SUNY) and is referred to as the Pipe-Tire Breakwater (PT-Breakwater). Tests were conducted in the large wave tank at the U.S. Army Coastal Engineering Research Center (CERC), under the joint direction of Dr. Volkex W. Harms, (SUNY and Lawrence Berkeley Laboratory, University of California) and Dr. Robert M. Sorensen (Chief Coastal Processes and Structures Branch, (CERC). Breakwater modules were preassembled at SUNY in Buffalo, New York, and then transported to CERC by truck, where final assembly on location was again performed by SUNY personnel. Wave-tank tests were conducted jointly by CERC and SUNY personne1.

James McTamany of CERC's Coastal Structures Branch capably conducted a series of wave-tank experiments and also performed mooring system load-deflection tests. The able assistance of SUNY technicalspecialist John Sarvey and students Tom Bender, Patrick Hughey and PauI Speranza is gratefully acknowledged. Difficult crane operations and frequent wave-generator stroke changes were performed cheerfully and capably by operations support personnel at CER. .

This research was sponsored in part by the New York Sea Grant Institute under a grant from the Office of Sea Grant, National Oceanic and Atmospheric Administration (NOAA), U.S. Department of Commerce, through the State University of New York at Buffalo. It was also supported by the U.S. Department of Energy under contract W-7405-ENG-48 to the Marine Sciences Group, Lawrence Berkeley Laboratory, University of California。 


\section{SYMBOLS AND DEFINITIONS}

B

$\mathrm{C}_{\mathrm{t}}$

d

D

$\mathrm{F}$

g

G

$\mathrm{H}$

$\mathrm{H}_{\mathrm{t}}$

L

T

$B / D$

$\mathrm{D} / \mathrm{d}$

$\mathrm{H} / \mathrm{L}$

$L / B$

width or beam of breakwater (dimension in direction of wave motion)

wave-height transmission ratio, $\mathrm{C}_{t}=\mathrm{H}_{t} / \mathrm{H}$

water depth

tire diameter

peak mooring force on seaward mooring line (per unit length of breakwater)

gravitational acceleration

center-to-center distance between pipes of PT-Breakwater

incident wave height

transmitted wave height

wave length

wave period

breakwater aspect ratio

relative draft

wave steepness

relative wave length 
Greek Symbols

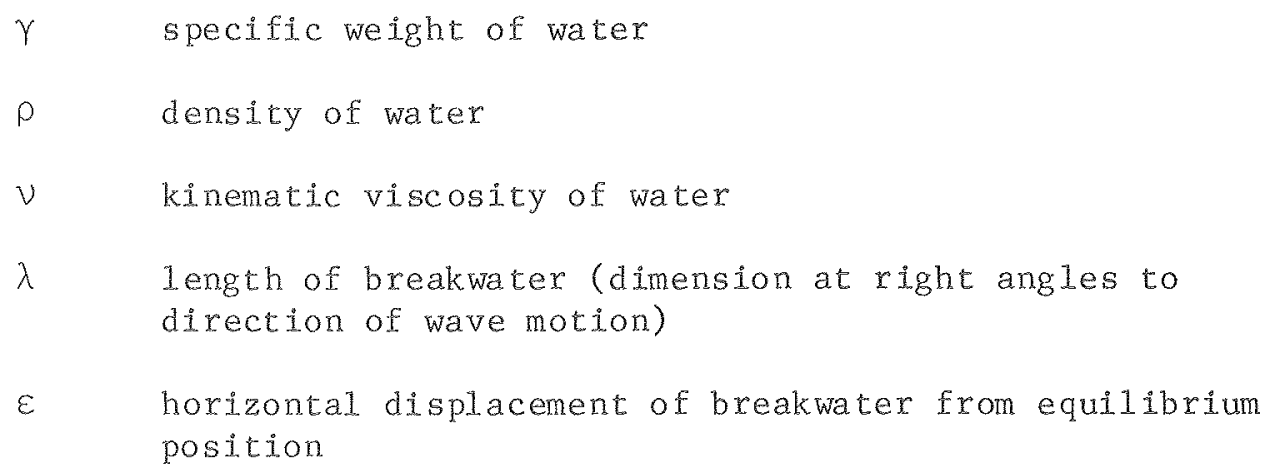




\section{INTRODUCTION}

The idea of constructing floating breakwaters almost entirely from scrap pneumatic-tire casings was conceived almost two decades ago by R.L. Stitt and resulted in a patent for the Wave-Maze floating tire breakwater (Stitt, 1963; Kamel and Davidson, 1968). More recently, this concept has been adapted in the development of the so-called Goodyear floating tire breakwater (Kowalski, 1974; Candle, 1976). Both breakwaters are flexible in all directions since no rigid structural members are utilized. The Goodyear module differs from the Wave-Maze with regards to size (automobile tires as opposed to truck tires), geometric arrangement of tires (single-layer upright versus triple layer "sandwich") and binding materials and techniques (typically conveyorbelt loops as opposed to bolted tiremtire connections). A number of breakwaters of both types have been installed, with various levels of success, on the Great Lakes, the east and west coasts of the United States, and overseas.

Although the installation of floating breakwaters is frequently favored over that of botcom-resting structures for a number of environmentally $y^{\text {ow }}$ lated reasons (e.g. impact on water circulation, fish migrations, laxge water depth, etc.), the principal reason for considering floating breakwaters made of tires is their relatively low cost. For small marinas (say less than 100 boat slips) they are frequently the only wave-protection system that is economically feasible, with costs typically ranging from \$10-\$100 per horizontal square metex of breakwatex. At the same time, it must be recognized that floating tire breakwaters provide less wave protection, are less rugged and have lower 
extreme-event survival capabilities than conventional bottom-resting structures such as rubble-mound and sheet-pile breakwaters. Experience gained from field installations and prototype-scale laboratory tests suggests that the Goodyear and Wave-Maze floating tire breakwaters should be limited to semi-protected sites, or short-fetch applications (say $10 \mathrm{~km}$ or less), with significant wave heights below 4 feet, perhaps even 3 feet. At locations with more severe wave climates (large wave height and period), several Iimitations have been encountered with regards to:

(1) Structural Integrity

Wave-induced loads increase approximately with the square of the wave height. Under severe wave action the following problems have been encountered: modules connected to the seaward mooring lines separate because of excessive loads, anchors fail or "walk" because of large mooring forces, flotation material is lost from individual tires because of excessive stretching and twisting, and tire connection and binding materials reach their fallure limit.

\section{(2) Breakwater Size}

The dimension of the breakwater in the direction of wave propagation (width or beam) must generally be at least as large as the locally predominant wave length (design wave). This implies that a very large breakwater will be required at sites with long-period. waves, which not only increases breakwater costs but also may not be feasible because of space-limitation. 
(3) Buoyancy

Portions of the breakwater may begin to sink if individual tires lose their flotation material (e.g., due to stretching and twisting under high loads), or if the structure gains too much weight with time (due to suspended sediments in the tire casings, or excessive maxine growth).

In an attempt to improve upon the characteristics discussed above, another floating breakwater concept that utilizes pneumatic tire casings as major construction material has recently been developed by the senior authox at the State University of New York at Buffalo (Harms and Bender, 1978, Harms, 1979). It is referred to as the Pipe-Tire Breakwater (PTBreakwater)* and is basically a hybrid structure, with massive rigid cylindrical members (steel or concrete pipes, for example) embedded in a flexible matrix of scrap tires. Experiments pexformed with several small-scale PT-Breakwater models (Harms, 1979), and one full-scale breakwater (unpublished), demonstrated that this structure provides significantly more wave protection than Goodyear or Wave-Maze breakwaters of equal size. These early laboratory tests also suggested that a full-scale PT-Breakwater would have superior extreme-event survival capabilities, while preliminary calculations indicated that costs remained sufficienty low for this wave-protection system to be economically attractive.

In view of the contribution that the PT-Breakwater could potentially make in the area of low-cost wave protection, it was decided to

\footnotetext{
*In the earlier literature, precursors to the PT-Breakwater were
} referred to as the Wave-Guard Breakwater. 
obtain engineering design-data for this breakwater by performing prototype-scale experiments over a range of wave conditions encountered in practice. This was accomplished through a joint test program between the State University of New York at Buffalo and the U.S. Army Coastal Engineering Research Center (CERC). Full-scale tests were conducted in the large wave tank at CERC and are the subject of this report. Investigations were aimed at defining the wave-transmission and mooring force characteristics of PT-Breakwaters; it was also intended that structural-failure modes be analyzed, should it be possible to induce these within the range of wave conditions that could be generated in the tank。

A general impression of a floating PT-Breakwater is provided by Figures 1 and 2. This field installation at Mamaroneck, New York is based upon the PT-1 module discussed in the report: it is constructed of truck tires, with steel pipes serving as structural members and flotation chambers. The orientation of pipes with respect to the incident wave train is shown in Fig. 3 . 


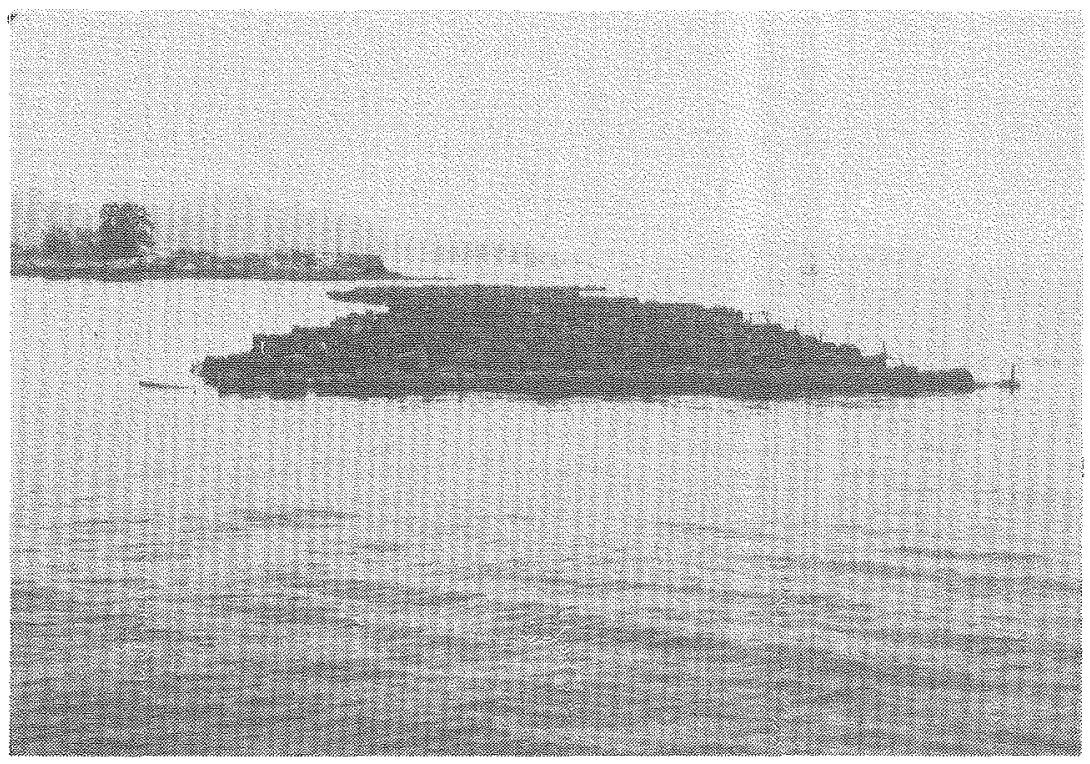

Fig. 1

Pipe-Tire Breakwater Field Installation at Mamaroneck, New York (misalignment due to transitional mooring)

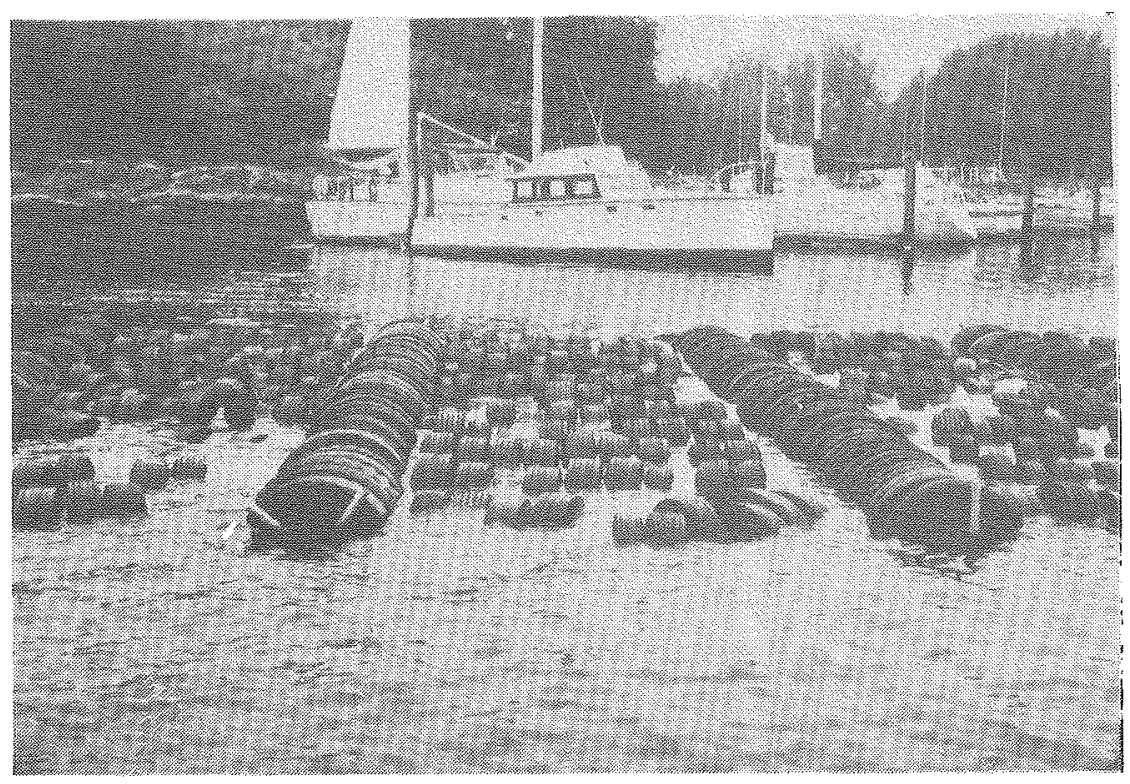

XBB $\quad 806 \cdots 7349 \mathrm{~A}$

Fig. 2

Typical PT-Breakwater Module with Tire-Armoured Pipes (Mamaroneck, N.Y.) 


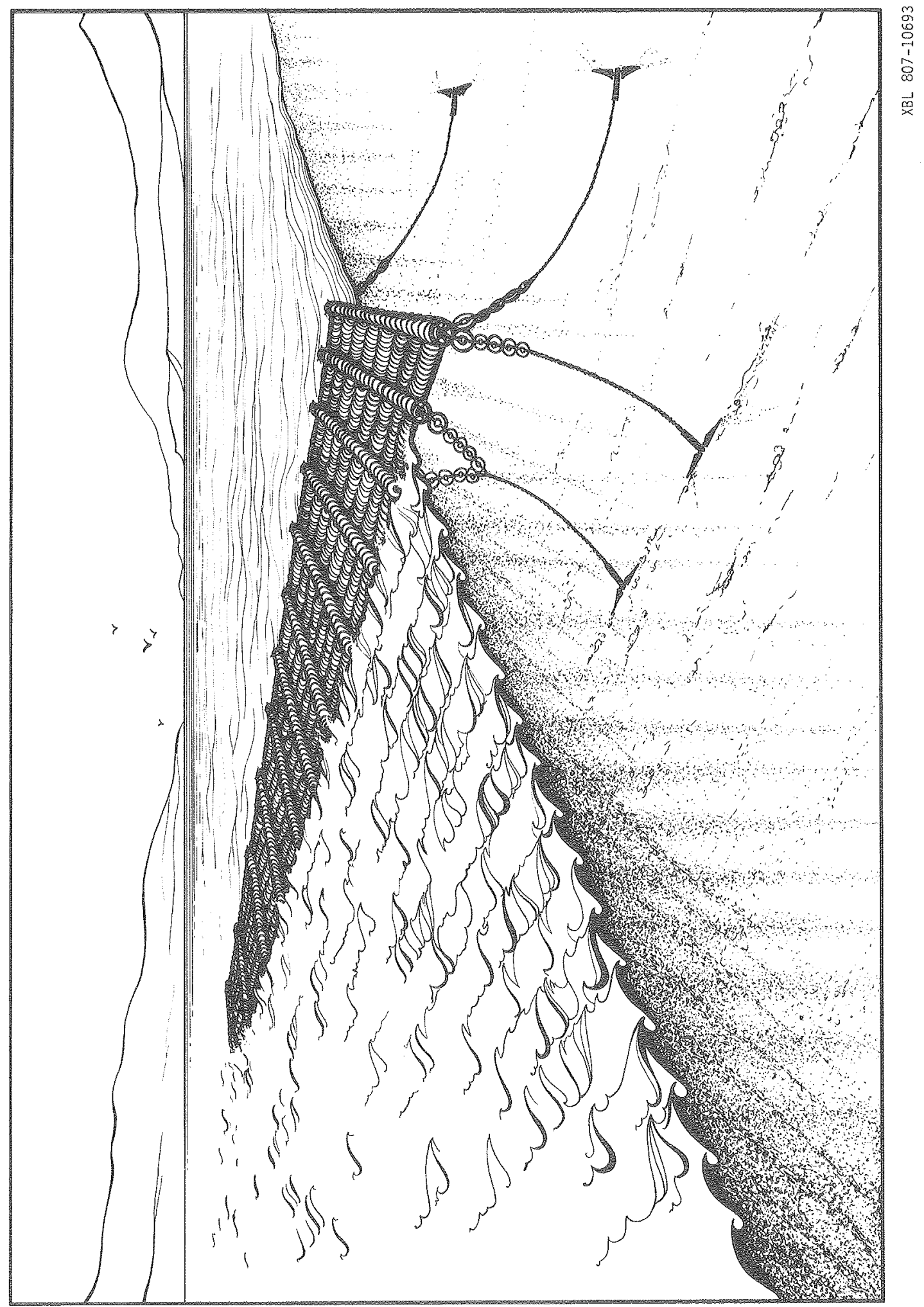

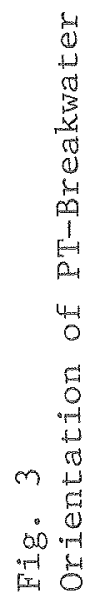


II. THE PIPE-TIRE BREAKWATER

The PT-Breakwatex is basically a mat of flexibly-intercomected scrap tires, floating near the surface, into which massive cylindrical members are woven to provide stiffness in the direction of wave motion and serve as buoyancy chambers. Major structural features of the PTBreakwater are (a)densely-spaced tires, (b)tire-amoured longitudinal stiffeners (frequently steel pipes) and (c) flexible connections and binding materials (no steel-to-rubber connections). The orientation of pipes with respect to the incident wave train is shown in the artists impression of Fig. 3, with major structural features of the breakwater given in the module schematic, Fig. 4, and the definition sketch Fig. 27. 
1. Breakwater Modules and Components

Two versions of the PT-Breakwater were tested in the large wave tank at CERC; they are shown in Fig. 12 and are designated as the PT-1 and $\mathrm{PT}-2$ modules. The PT-1 module, the more massive of the two since it is composed of truck tires and steel pipes, is shown in the foreground. The PT-2 module is constructed from car tires and used telephone poles. From the detailed drawing of the PT-1 module, Fig. 4, several important structural features of the breakwater emerge:

(1) A series of parallel conveyor-belt loops takes all lateral loads (at right angles to the direction of wave motion), supports all tires that are not "riding" on the pipe, and couples one module to the next。

(2) Wave-induced hydrodynamic loads are ultimately transferced from tire-strings to the tire-armoured steel pipe. This takes place in stages: wave action displaces tire-strings and belt-loops in the direction of wave motion (along the pipe), this causes the pipetires to slide along the pipe and be compressed as they transfer their load to the tire-retainer at the end of the pipe (Figs. 4 and 5).

(3) The pipe itself effectively "floats" in a dense matrix of flexibly connected tires.

The tire-retainer used in the PT-1 module is shown in Figs. 4 and 5. In the case of the PT-2 module, the retainer was a tire casing that was held in place by a $1.9 \mathrm{~cm}(3 / 4$ inch) threaded steel rod extending through the telephone pole and casing. 
Standard marine-steel-pile pipes were utilized as buoyancy chambers and stiffeners in the PT-1 module: they were $12.2 \mathrm{~m}$ ( $40 \mathrm{ft}$ ) in length, and $41 \mathrm{~cm}$ (16 inch) in diameter, with a wall thickness of $0.71 \mathrm{~cm}(0.281$ inch). Scrap telephone poles were used for the PT-2 module: $12.2 \mathrm{~m}$ (40 ft) in length, with a diameter of $33 \mathrm{~cm}$ (13 inches) at the butt end and $23 \mathrm{~cm}$ (9 inches) at the tip.

Truck tires ranging in size from $9.00-18$ to $10.00-20$, with average diameter of $102 \mathrm{~cm}$ (40 inches), were used for PT-1. Car tires with rim sizes ranging from $32-38 \mathrm{~cm}$ ( $13-15$ inches) were employed for PT-2: the average diameter was about $65 \mathrm{~cm}$ (26 inches).

A 3-ply conveyor-belt strip, $14 \mathrm{~cm}$ ( 5.5 inch) wide and $1.3 \mathrm{~cm}(0.5$ inch) thick, served as binding material; this had a rated breaking strength of $7900 \mathrm{~kg}$ (17000 1bs).A 5-hole bolted connection (Figs. 13 and 23) was used to tie the belt into continuous loops. 

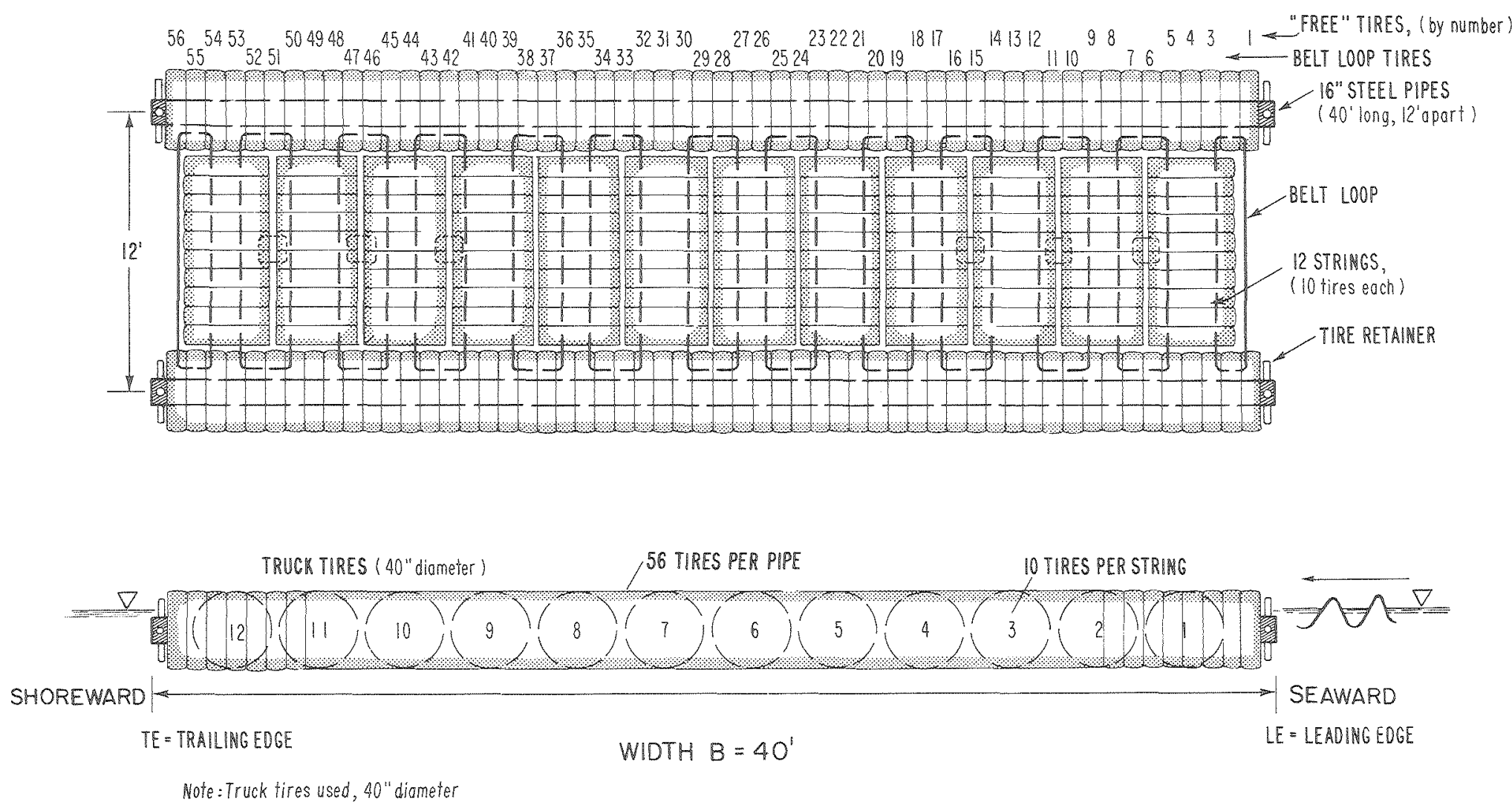

Fig. 4

Schematic of PT-I Breakwater Module 


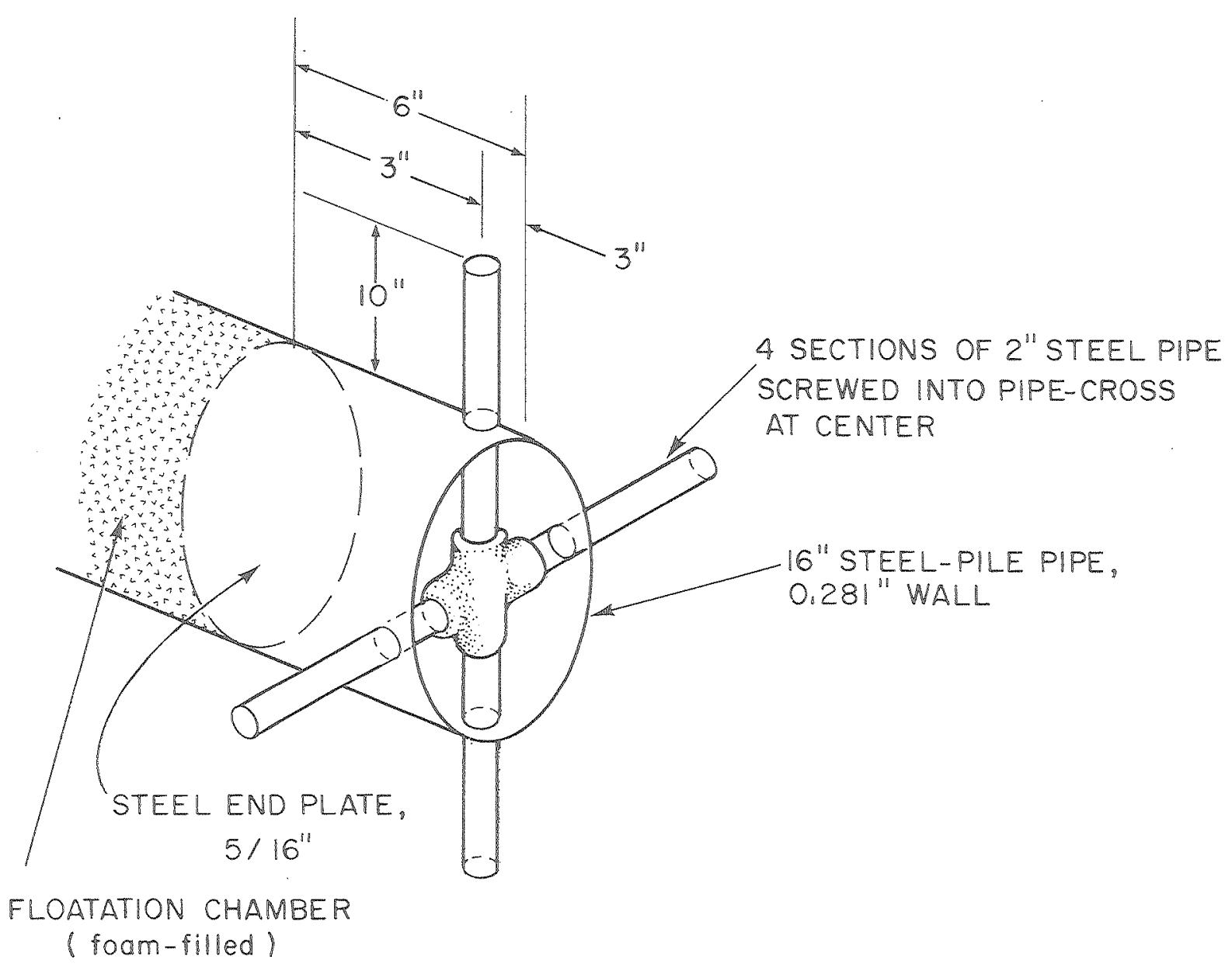




\section{Construction Procedures}

In this section, the procedures followed in the construction of the PT-1 modules wil1 be described. The procedures used for the PT-2 breakwater are very similar and are therefore not covered. With regards to Field installations and on-site construction, it should be ensured that a crane with sufficient lifting capacity be provided: the 2-pipe PT-1 module weighs approximately 11 metric tons, and the PT-2 module about 4 metric tons.

Assembly of the breakwater starts by simply arranging the tires according to the pattern shown in Fig. 4, but leaving out those tires labelled "free tires", i.e., all tires not somehow connected to a belt. This phase is depicted in Fig. 6 where the last tire is just being rolled into place, and Fig. 7 where the conveyor-belt strips are being prepared by cutting to length and punching the 5-hole bolt pattern with a gasket or leather punch (a1so shown in Fig。12).

Having assembled the tires, the belts are next guided through the tire casing according to the pattern shown in Fig. 4. This is just being accomplished in Figs. 8 and 9. The belt-to-belt connection is now completed by overlapping the belt-ends and inserting the 5 bolts required for each connection; this is being done in Fig. 10. A single bolt is used to fix each belt-loop to the side wall of one "belt-loop tire" (see Figs. 11 and 4); this prevents the belt from rotating under wave action.

After all belt-loops have been bolted together and anchored, the remaining "free" tires are rolled into place. The unit is now ready for 
the pipe to be inserted. One fork lift raises the pipe and positions it for entry into the long tunnel created by 56 aligned tires, while a second fork lift, or similar device, pushes and aligns the pipe as required. This having been accomplished, the module appears as shown in the foreground of Fig. 12. The tire-retainer shown in Fig. 5 (or the one depicted in Fig. 13) is now installed at each end of the pipe, and the PT-1 module is ready to be lifted into the water, Fig. 14. 


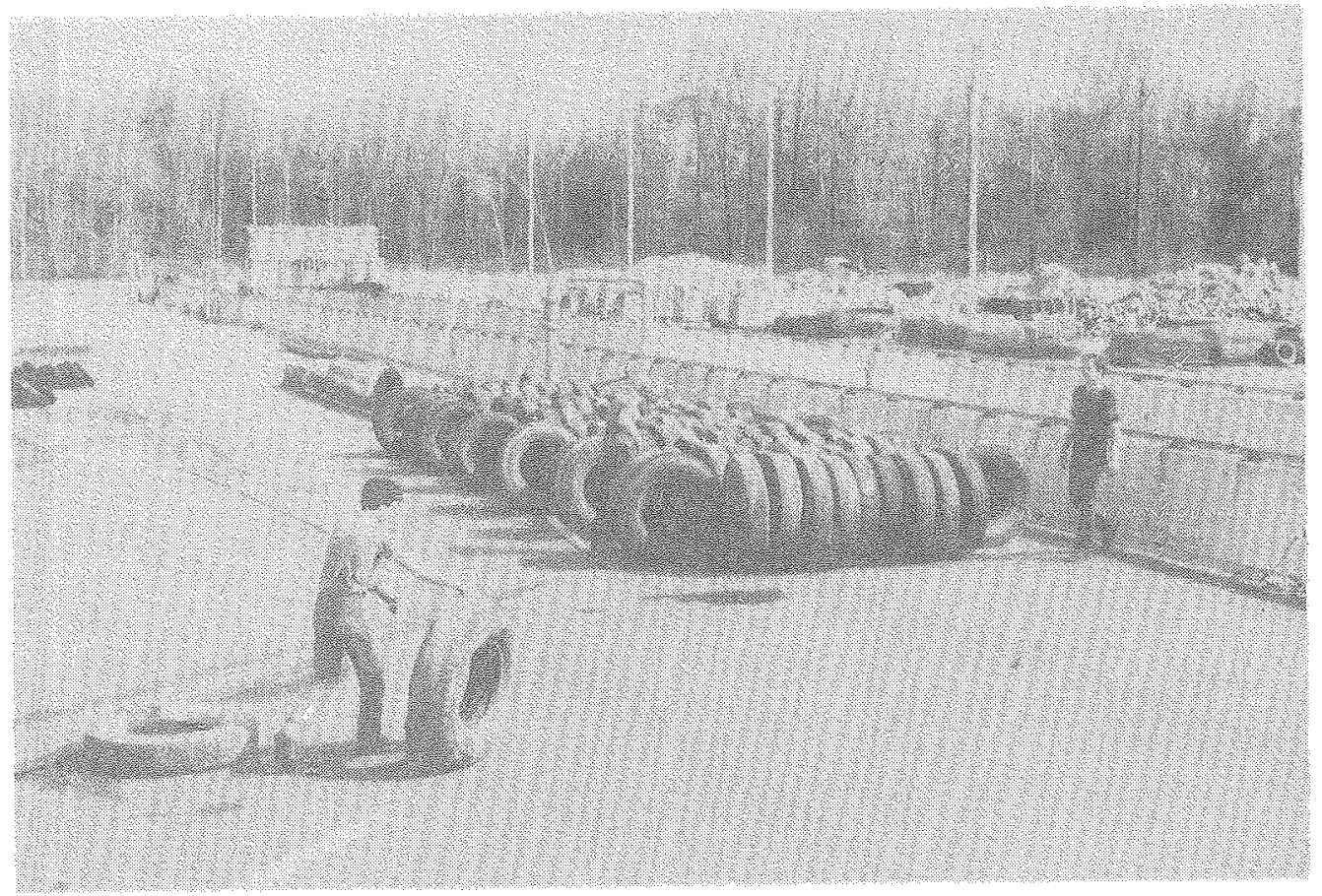

Fig. 6

First Step in Breakwater Assemb1y:

Rolling Tires into Place

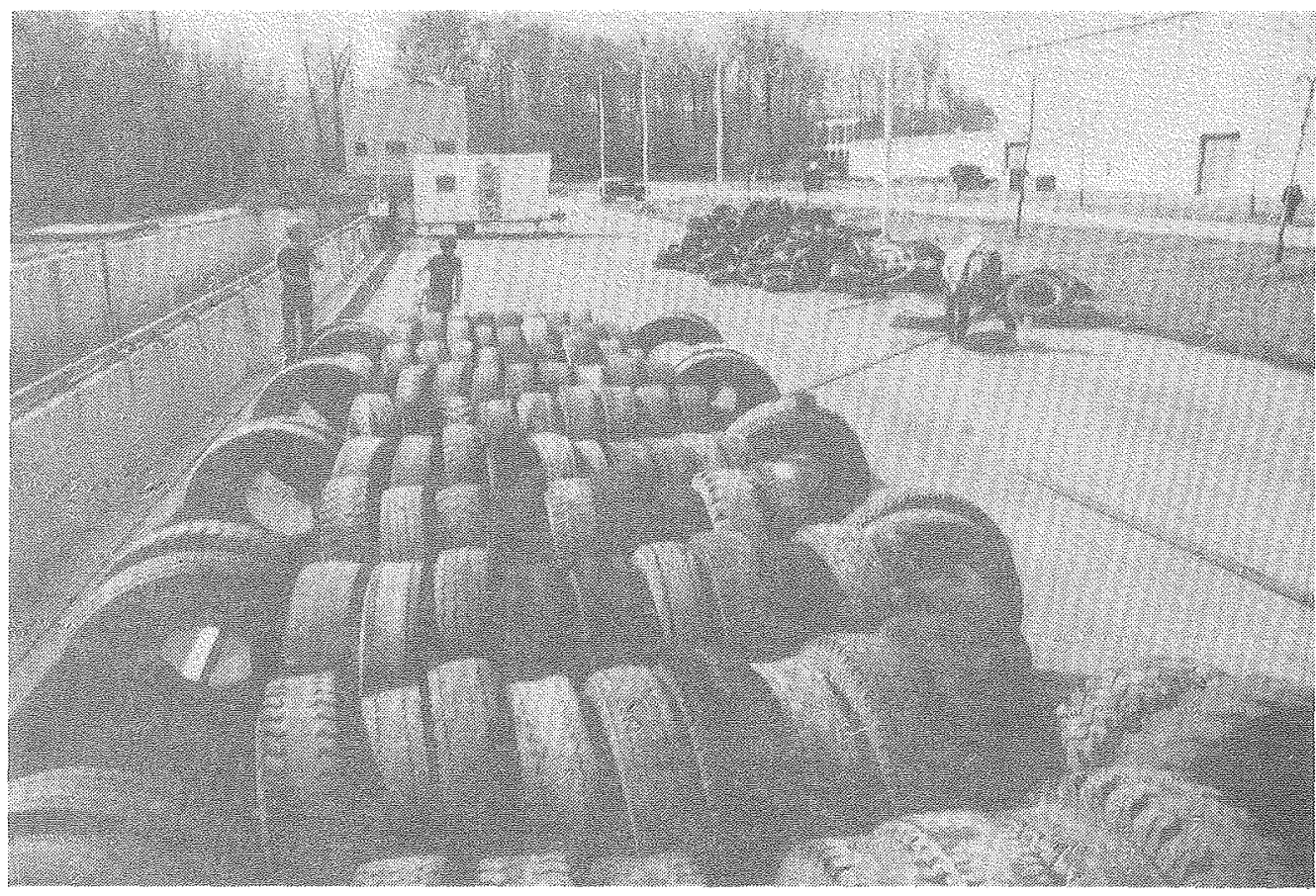

XBB $8011-13640$

Fig. 7

Tires are in Position, Ready to be Tied 


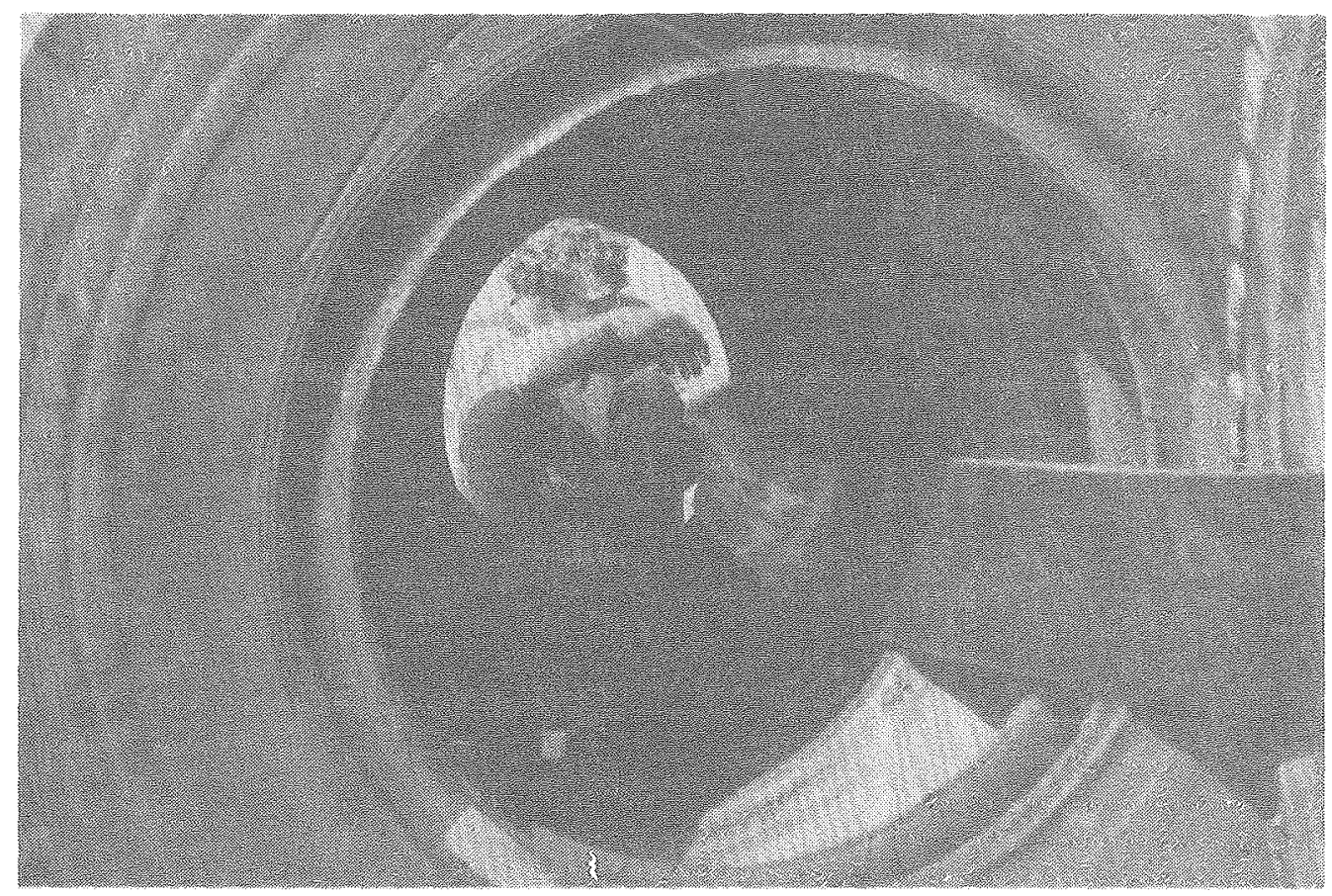

Fig. 8

Guiding Conveyor Belt Strip Through

Tire Casings

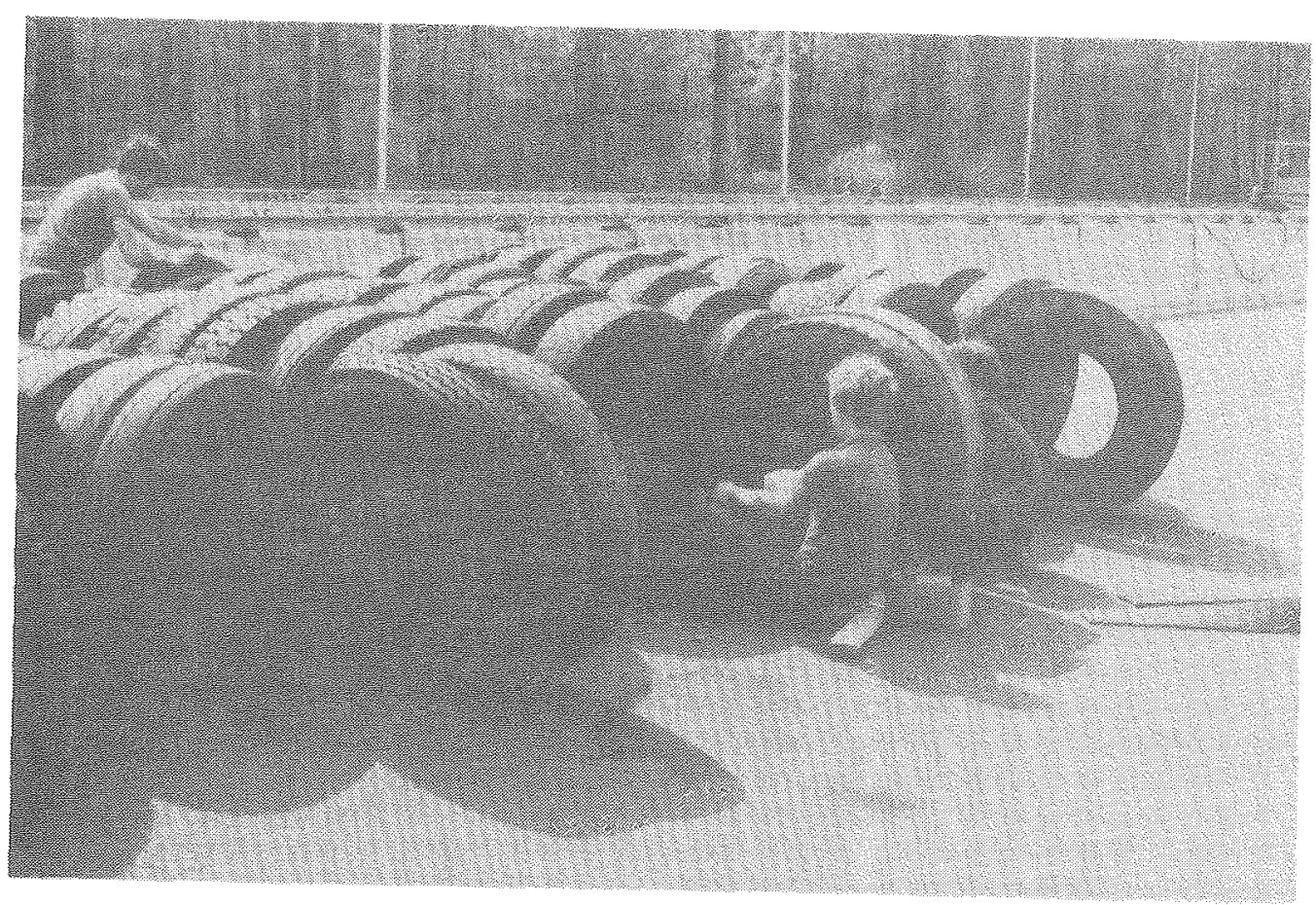

Fig。 9

XBB $8011-13639$

Tensioning Belt Before Completing Belt-to-Belt Connection 


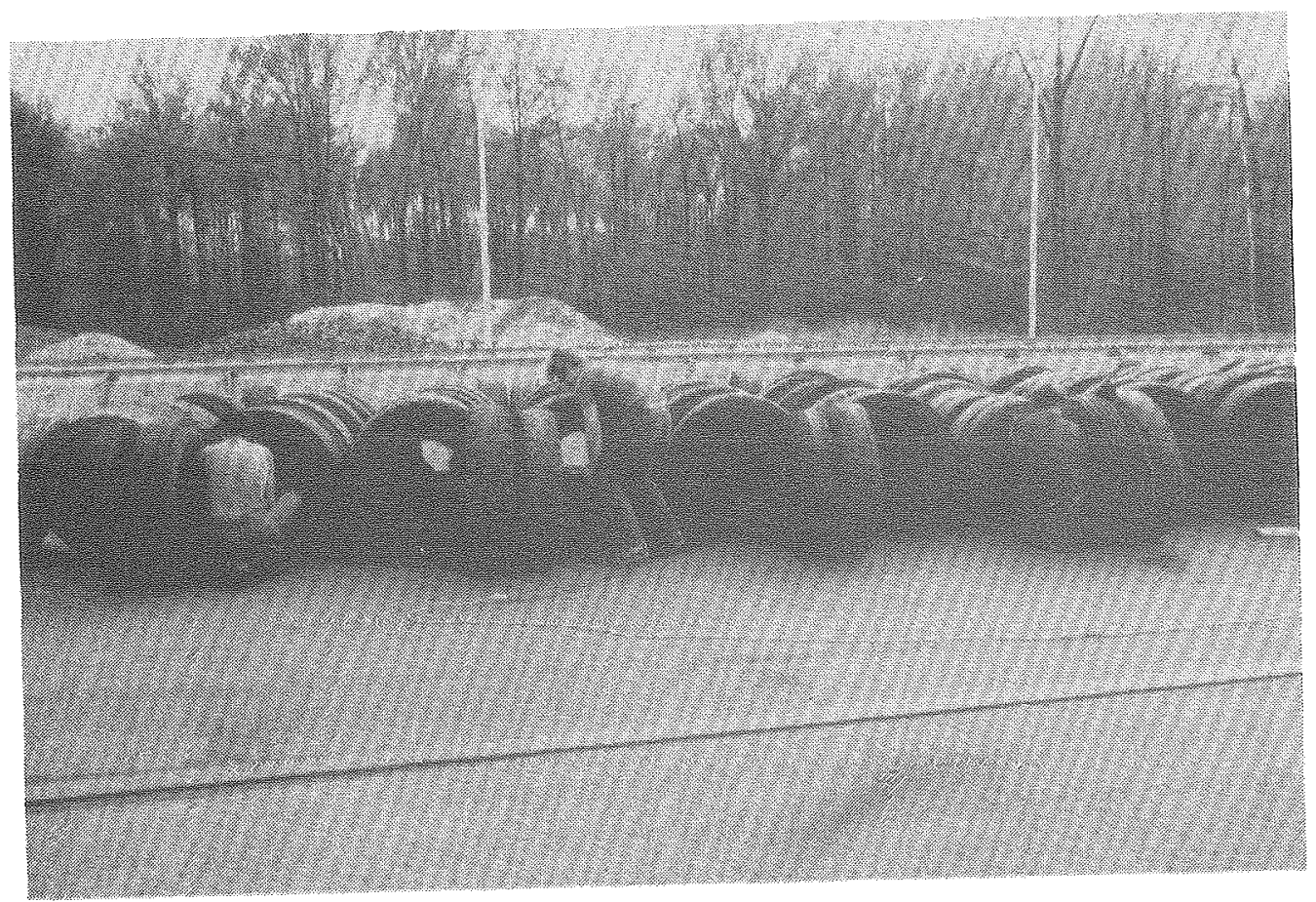

Fig. 10

Belts are Overlapped and Bolted Together

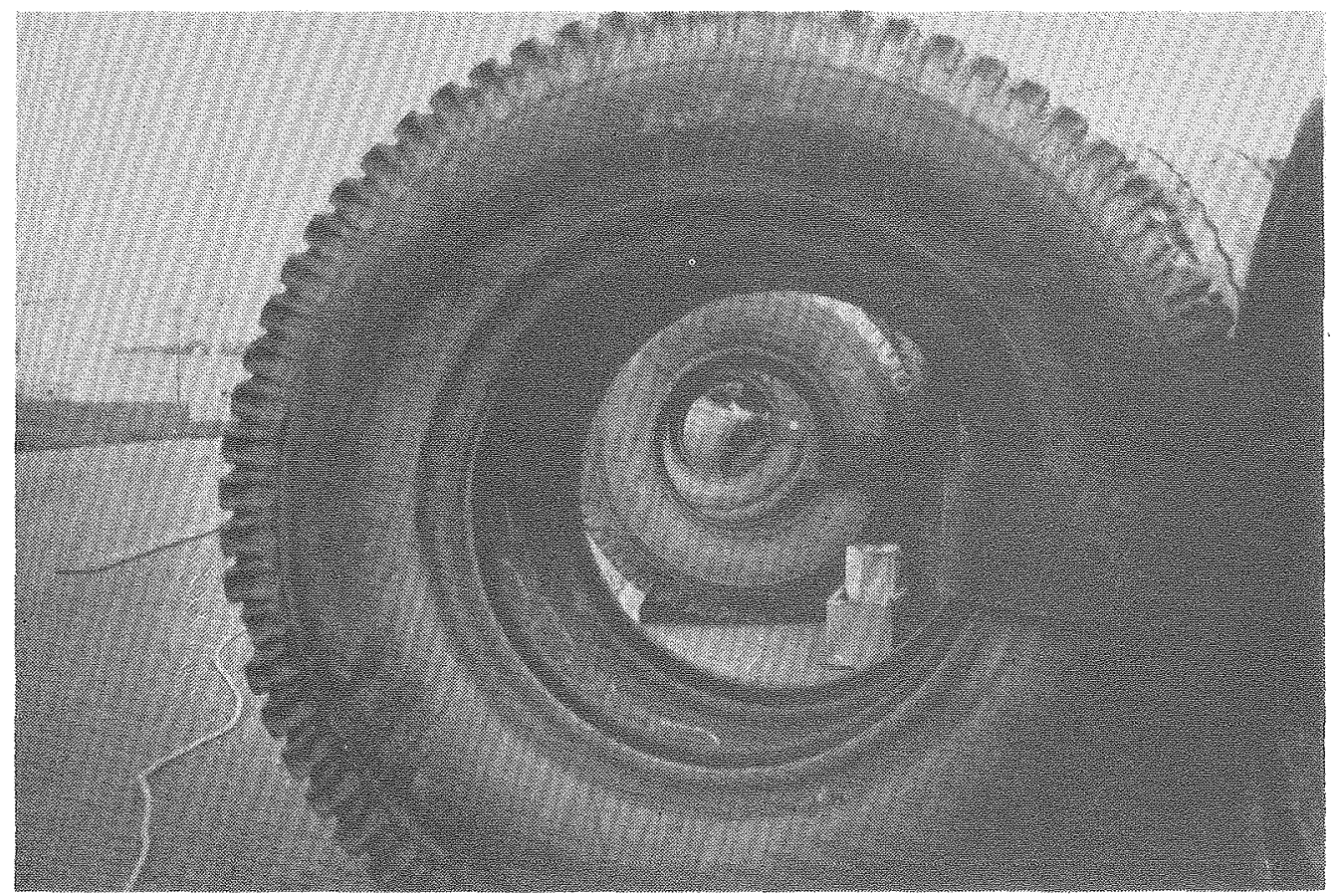

XBB $8011-13638$

Fig. 11

Belt is Anchored to Side Hall of One Tire 


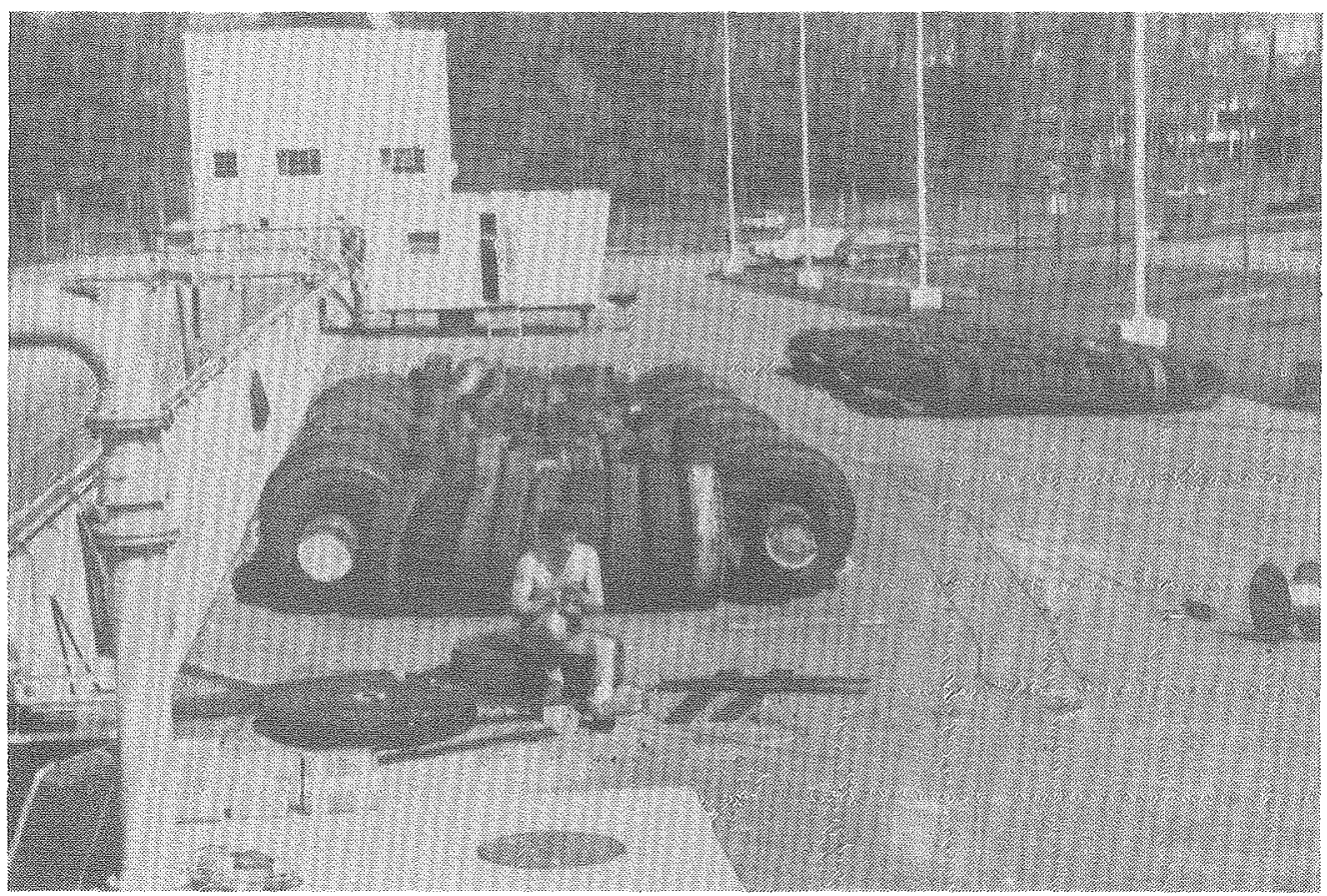

Fig: 12

Assembly of PT-1 (foreground)

and $\mathrm{PT}-2$ Modules

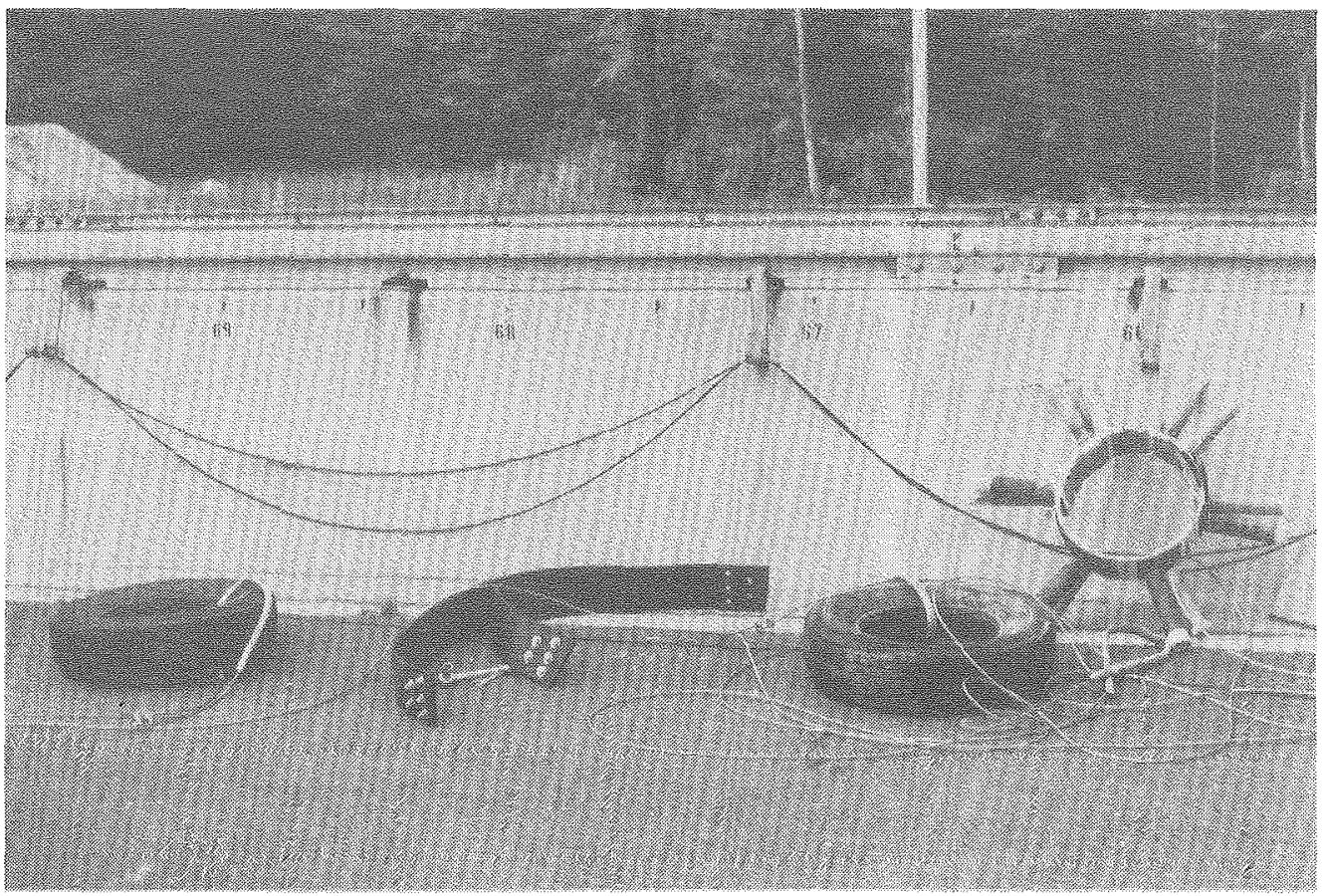

Fig. 13

Breakwater and Mooring System Components 


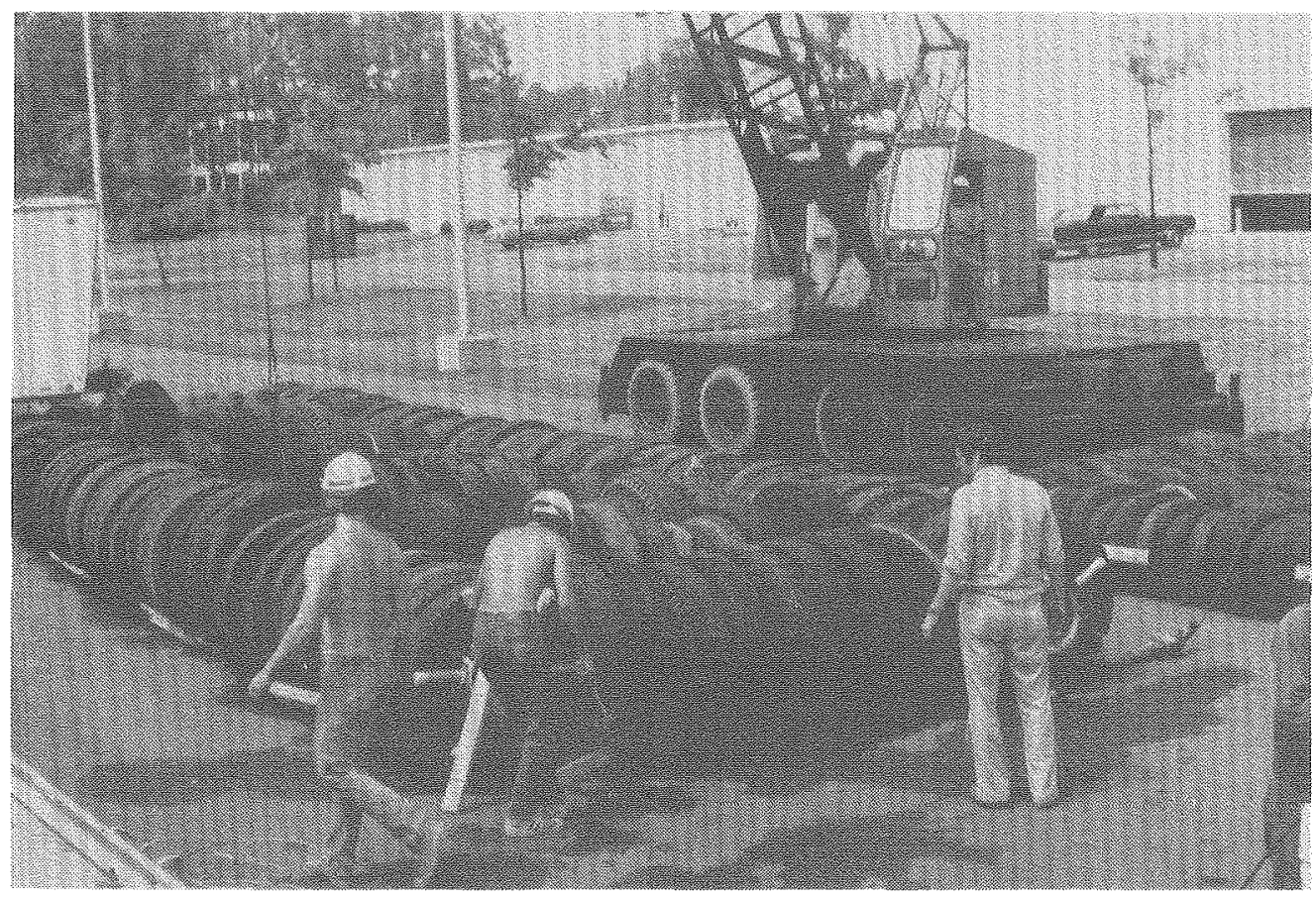

XBB $8011-13634$

Fig. 14

PT-1 Module Ready for Lift into Wave Tank 


\section{Breakwater Buoyancy}

a. Pipe Buoyancy Test. A simple buoyancy test was performed by resting steel I-beams on top of one of the tire-armoured pipes of the PT-1 module until total submergence was attained, (i.e., crown of tires just at the water surface, Case B in Fig. 15.) Starting from the static, noload equilibrium position of the breakwater (i.e., crown of pipe at water level and interior of the tire vented to atmosphere, case A), two steel I-beams each weighing $98 \mathrm{~kg} / \mathrm{m}$ and $10.7 \mathrm{~m}$ in 1 ength were placed onto the tire-armoured pipe. These provided precisely the loading required for total submergence of the pipe-tire unit. In each case, equilibrium demands that

$$
F+n\left(W_{t a}+W_{t W}\right)+F_{e}=F_{p}+n F_{a}
$$

where

$$
\begin{aligned}
& F=\text { added external load } \\
& F_{e}=\text { extraneous loads (from mooring system, etc.) } \\
& F_{a}=\text { buoyancy force per tire due to entrapped air } \\
& F_{p}=\text { net buoyant force due to pipe (lift minus weight) } \\
& W_{t w}=\text { weight of tire segment submerged in water } \\
& W_{t a}=\text { weight of tire segment in air } \\
& n=\text { number of tires on pipe }
\end{aligned}
$$

In our case, the pipe is $12.2 \mathrm{~m}$ in length $(41 \mathrm{~cm}$ outside diameter and a weight of $70.2 \mathrm{~kg} / \mathrm{m}$ in air), provides a net lift of $59.5 \mathrm{~kg} / \mathrm{m}$ when totally submerged, and supports 49 truck tires. Truck tires have a specific gravity of approximately 1.2 with a weight of $W_{t}=41 \mathrm{~kg}$ in air 


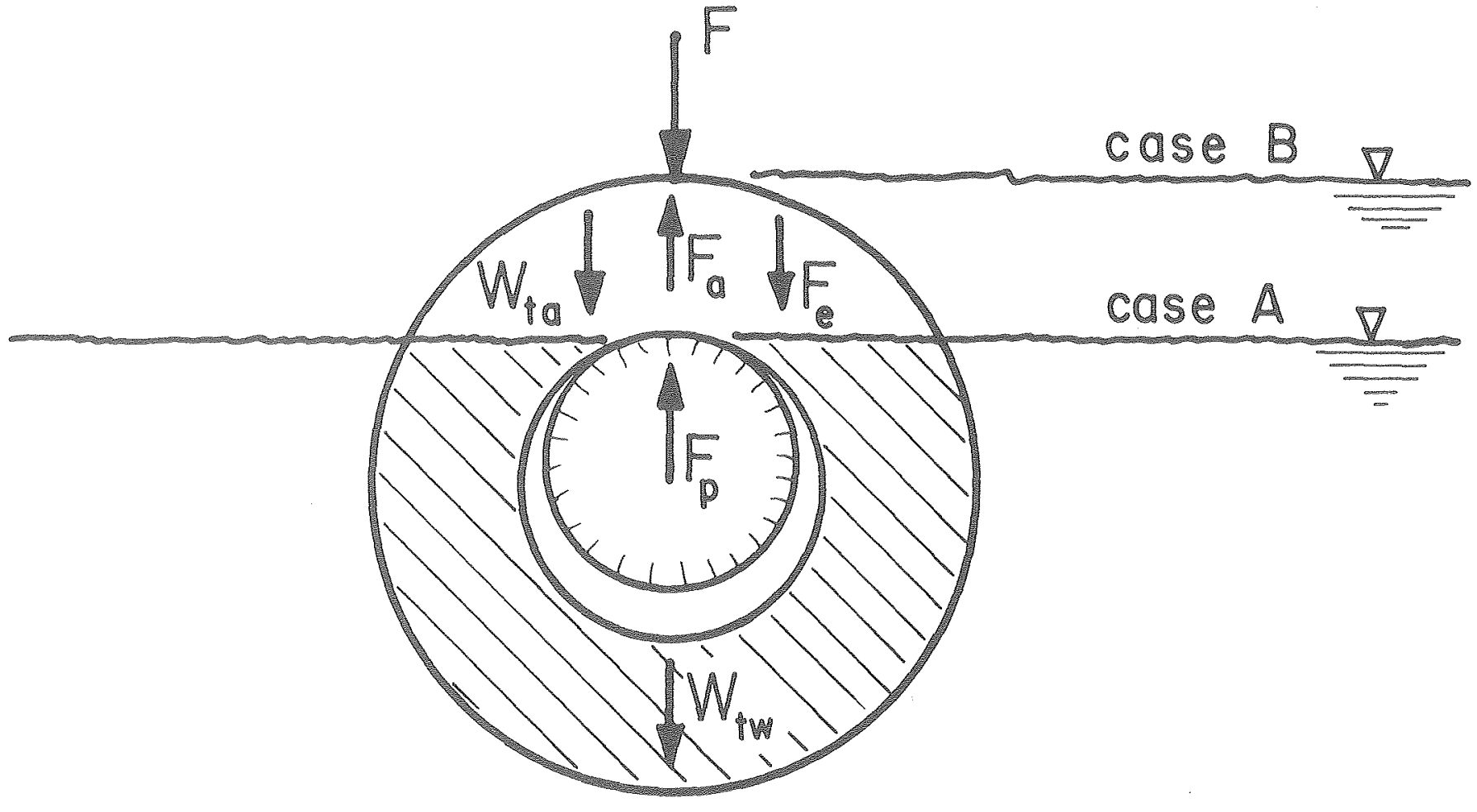

Fig. 15

Forces on Pipe-Tire Unit 
for the sizes predominantly used, i.e., 10.00-20 and 9.00-18 truck tires. Submerged in water this weight is reduced to approximately $1 / 6$ of $W_{t}$, or $6.8 \mathrm{~kg}(15 \mathrm{lb})$ if all air is expelled. Applying these values to case $A$ (which corresponds to $F=F_{a}=0$ and approximately $3 / 4$ of tire material submerged) and using Equation 1, it follows that the extraneous load is a small lift force of $26 \mathrm{~kg}$, i.e. $F_{e}=-26 \mathrm{~kg}$. When the external load $F$ is applied (case $B$ ) the buoyancy force resulting from air entrapped in each tire may be calculated from Equation 1 to be:

$$
\begin{aligned}
& 10.7(196)+49(0+6.8)+(-26)=12.2(59.5)+49 F_{a} \\
& F_{a}=34.2 \mathrm{~kg} / \text { tire }
\end{aligned}
$$

On an average, this implies that 34 liters $\left(1.2 \mathrm{ft}^{3}\right)$ of air are trapped in the crown of each tire. It is not known at what rate this trapped air would escape under static conditions; during wave action the tire-crown would be alternately vented and replenished with air. In determining the flotation requirements for the complete structure, the weight of suspended sediments that may accumulate in the tire casings and the influence of marine growth should be considered.

b. Equilibrium of Breakwater. The load-carrying capacity of the breakwatex must be carefully considered, particularly in areas where the weight of the breakwater is likely to increase substantially with time due to deposition of suspended sediments within the tire casings, biofouling, etc. In extreme cases, all of the tires may have to be foamed to provide adequate reserve buoyancy, whereas at other sites the lift provided by the steel-pipe flotation chambers alone is sufficient. Equation 1 may be used to estimate the reserve buoyancy provided by a. 
"clean" single-pipe PT-1 module if some terms are redefined:

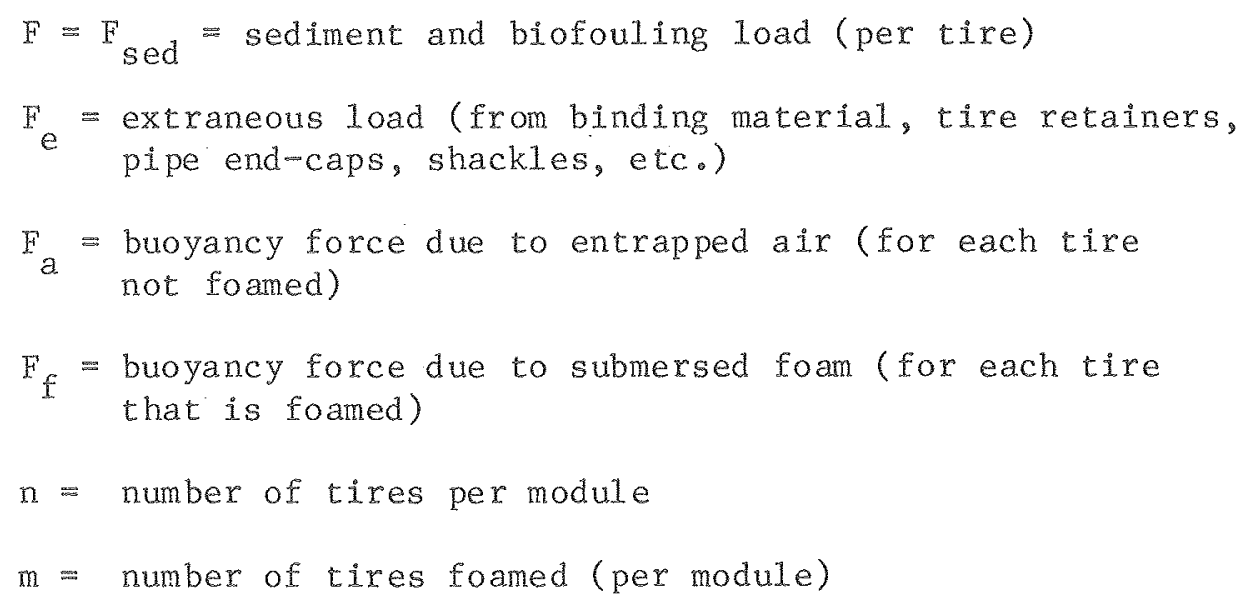

This leads to

$$
\begin{aligned}
& n F_{\text {sed }}+n W_{t w}+F_{e}=F_{p}+(n-m) F_{a}+m F_{f} \\
& F_{s e d}=\left(F_{a}-W_{t w}\right)+(1 / n)\left(F_{p}-F_{e}\right)+(m / n)\left(F_{f}-F_{a}\right)
\end{aligned}
$$

Using the following approximate values and estimates for the PT-1 module:

$$
\begin{aligned}
& F_{e}=220 \mathrm{~kg} \\
& F_{p}=(60 \mathrm{~kg} / \mathrm{m})(12 \mathrm{~m})=720 \mathrm{~kg} \\
& W_{t w}=7 \mathrm{~kg} \\
& F_{a}=17 \mathrm{~kg} \text { (50\% of value from buoyancy test) } \\
& F_{f}=34 \mathrm{~kg} \text { (crown fully foamed, } 34 \text { liters) } \\
& \mathrm{n}=176 \text { tires }
\end{aligned}
$$

one obtains

$$
\begin{array}{ll}
F_{\text {sed }}=(17-7)+(1 / 176)(720-280)+(\mathrm{m} / \mathrm{n})(34-17) \\
\mathrm{F}_{\text {sed }}=13+17(\mathrm{~m} / \mathrm{n}) & \mathrm{kg} / \text { tire }
\end{array}
$$


Example 1:

If none of the tires are foamed, $m=0$ and $m / n=0$ in the equation above, so that $F_{\text {sed }}=13 \mathrm{~kg} / \mathrm{t}$ ire. Therefore a weight increase of approximately 13 $\mathrm{kg}$ per tire can be accommodated before the breakwater starts to submerge。

Example 2:

If all of the tires are foamed, $m=n$ and $m / n=1$ above, so that $F_{\text {sed }}=30$ $\mathrm{kg} /$ tire. In this case, each tire can carry approximately $30 \mathrm{~kg}$ of additional load, for a total reserve buoyancy of about $5300 \mathrm{~kg}$ per singlepipe module. 


\section{Cost Estimates}

A list of major construction components for the PT-1 module, and their respective costs as of mid-1980, are given in Table 2 . It is noteworthy that the steel pipe accounts for nearly $60 \%$ of the total cost. Substantial savings are consequently possible if used pipe can be purchased, as was done at the Mamaroneck site where used dredge pipe was obtained at a fraction of the cost indicated in Table 2. As a precautionary measure, it has been assumed that the steel pipe is filled with foam before the end-caps are welded into place. The total componentcost amounts to $\$ 19.60$ per square meter of breakwater $\left(1.80 \$ / \mathrm{ft}^{2}\right)$.

Assembly and launching procedures should be carefully considered and planned in advance so as to take full advantage of cost-saving site conditions. Since the anchoring system can be very costly, alternatives should be carefully investigated, e.g., the use of anchor piles may be less costly than concrete clump anchors or "steel" embedment anchors depending upon availability of pile-driving equipment and geotechnical conditions. 
Table 1

Cost Estimates of PT-Breakwatex Components

Module Dimensions: $\quad 3.7 \mathrm{~m} \times 12.2 \mathrm{~m}(B=12.2 \mathrm{~m})$

Materials : Truck tires $(9.00-18$ and 10.00-20)

Steel pipe ( $4 \mathrm{~cm}$ dia. steel-pile pipe)

Conveyor-belt material $(3-\mathrm{ply}, 14 \mathrm{~cm} \times 1.3 \mathrm{~cm})$

Nylon bolts, washers, nuts ( $13 \mathrm{~mm}$ )

\begin{tabular}{|c|c|c|c|c|}
\hline Item & Quantity & $\begin{array}{l}\text { Unit Cost } \\
\text { (US } \$ \text { ) }\end{array}$ & $\begin{array}{l}\text { Tota1 } \\
\text { (US\$) }\end{array}$ & $\begin{array}{c}\text { Cost per } \\
\text { Square Meter } \\
\text { (us } \$ \text { ) }\end{array}$ \\
\hline Steel Pipe & $12.2 \mathrm{~m}$ & 43.00 & 524.60 & 11.60 \\
\hline $\begin{array}{l}\text { Polyurethane Foam } \\
\text { (Pipe plus } 20 \% \text { of tires) }\end{array}$ & $2.4 \mathrm{~m}^{3}$ & 75.00 & 180.00 & 4.00 \\
\hline $\begin{array}{l}\text { Tying Material } \\
\text { (conveyor belt) }\end{array}$ & $94 \mathrm{~m}$ & 1.15 & 108.10 & 2.40 \\
\hline $\begin{array}{l}\text { Tires } \\
\text { (transportation cost) }\end{array}$ & 176 & 0.25 & 44.00 & 1.00 \\
\hline $\begin{array}{l}\text { Nylon Bolt, Nut } \\
\text { Washer }\end{array}$ & 80 & 0.35 & 28.00 & 0.60 \\
\hline $\begin{array}{l}\text { Cost of Breakwatex } \\
\text { excluding mooring system }\end{array}$ & & & & $\begin{array}{l}19.60 \$ / \mathrm{m}^{2} \\
\left(1.80 \$ / \mathrm{ft}^{2}\right)\end{array}$ \\
\hline
\end{tabular}

and assembly) 
III. EXPERIMENTAL SETUP AND PROCEDURES

1. Test Facility and Instrumentation.

a. Wave Tank. Experiments were performed in CERC's large wave tank which is 194 meters in length, 4.6 meters wide and 6.1 meters deep (635 feet $\times 15$ feet $\times 20$ feet). The tank was operated at two water depths, 2.0 and 4.7 meters ( 6.6 and 15.4 feet), using regular waves ranging in period from 2.6 to 8.1 seconds and wave heights from 0.15 to 1.78 meters ( 0.5 to 5.8 feet). A schematic of the wave tank with piston-type wave generator at one end and a relatively ineffective rock-revetment waveenergy dissipator at the other, is shown in Fig. 16. The breakwater at high and low water is show in Figs, 17-21.

b. Wave Gauge. Two Marsh McBirney voltage-gradient water level gauges (Model 100) were used to measure incident and transmitted waves. They were calibrated twice each day over a range of 2.0 meters by manually lowering and raising the wave staff. The output was recorded on a sixchannel Brush oscillographic recorder.

c. Force Gauge. Loads on the seaward mooring line were measured by a single force gauge located above the tank near the wave generator. The force gauge consisted of a cantilevered steel plate with strain gauges mounted near its base, as shown in Fig. 22. The strain gauges formed two arms of a full Wheatstone bridge that was driven at carrier frequencies. The sensitivity of the force gauge could be varied over a broad range, not only electronically but also mechanically by varying the mooring-cable attachment point on the cantilever (Fig. 22). The force gauge was generally calibrated before and after each test (one wave- 
generator stroke setting) by applying a series of loads to the cantilever using a mechanical load-tightener ("come-along") and a 5000-pound dial force gauge. The electrical output was displayed on a 6-channel Brush oscillographic recorder; typical calibration curves are shown in Fig. 32。 

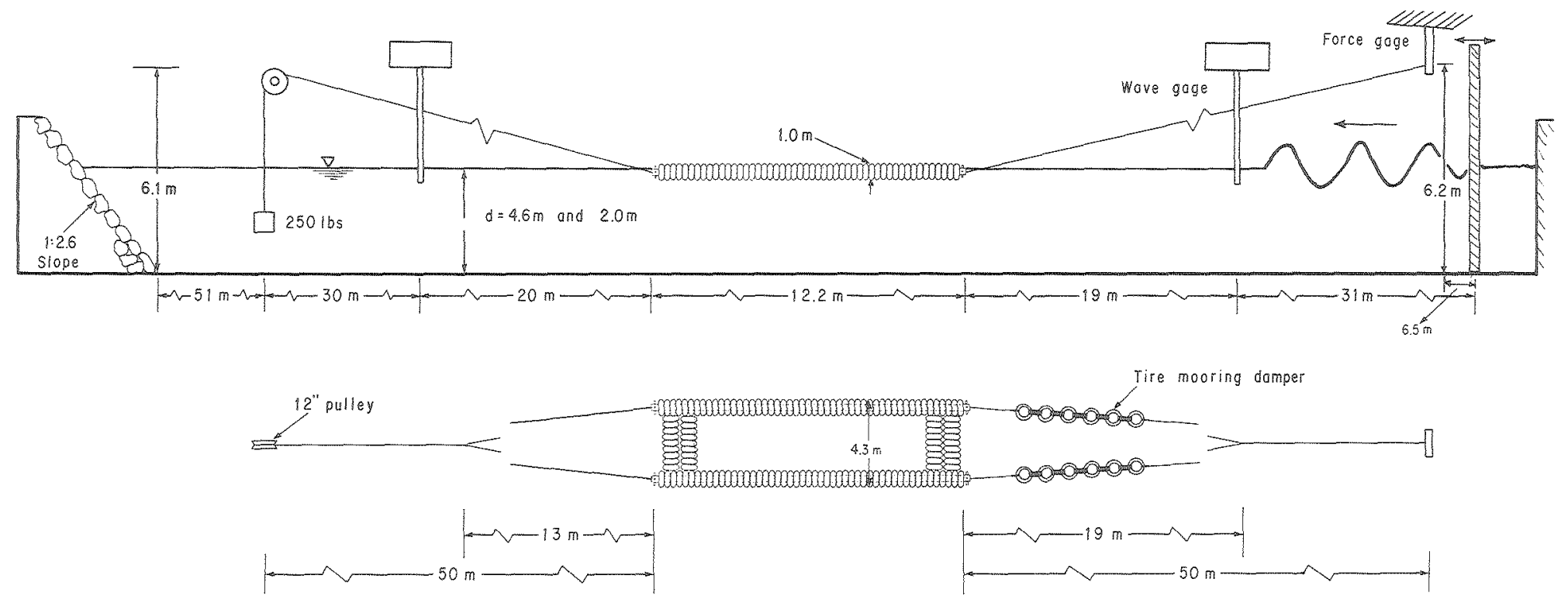

X8L $805-9663$

Fig, 16

Large Wave Tank at CERC with Breakwater and MS-I Mooring System 


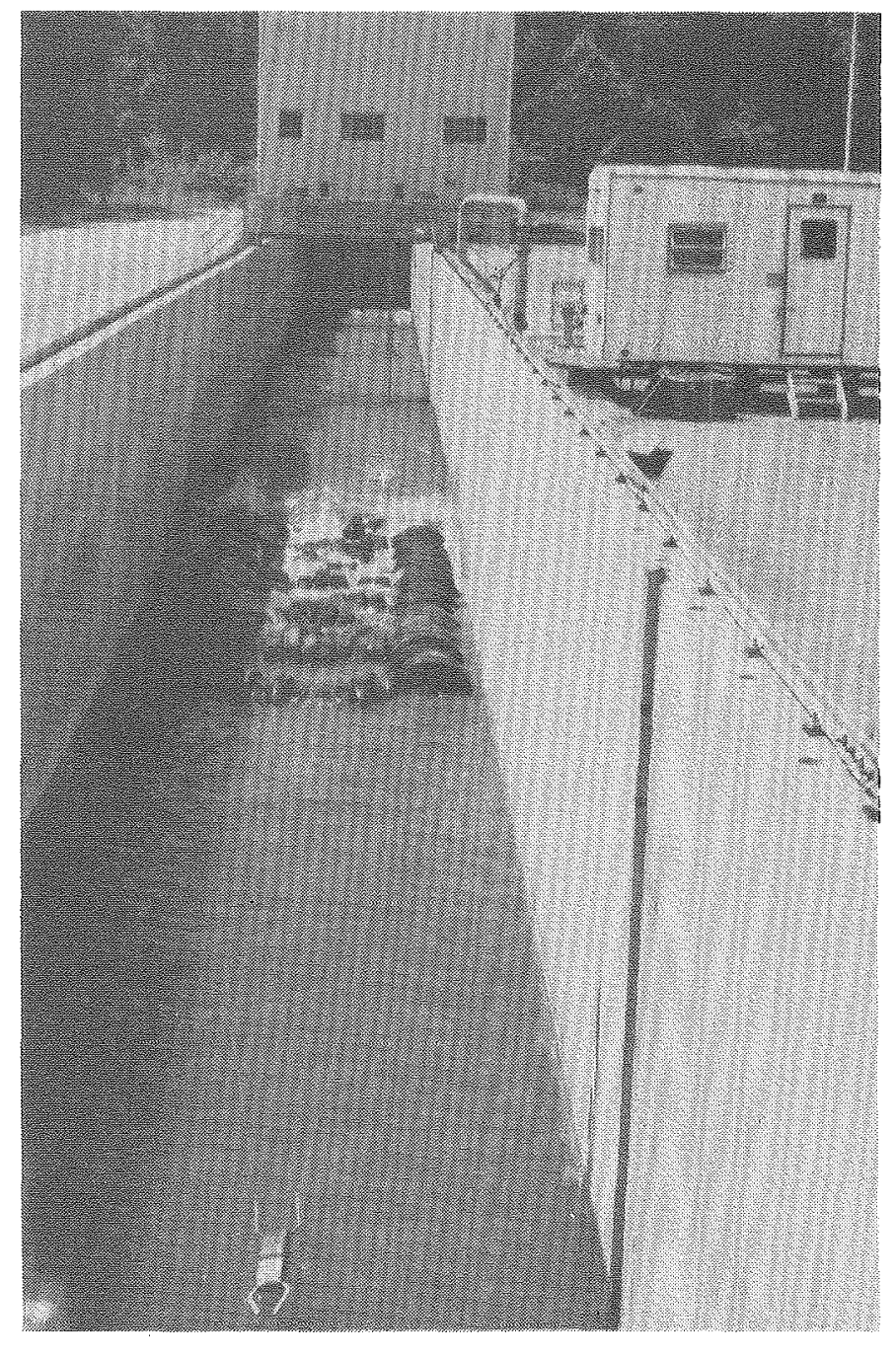

XBB $8011-13633$

Fig. 17 View Towards Wave Generator (Large Wave Tank, CERC) 


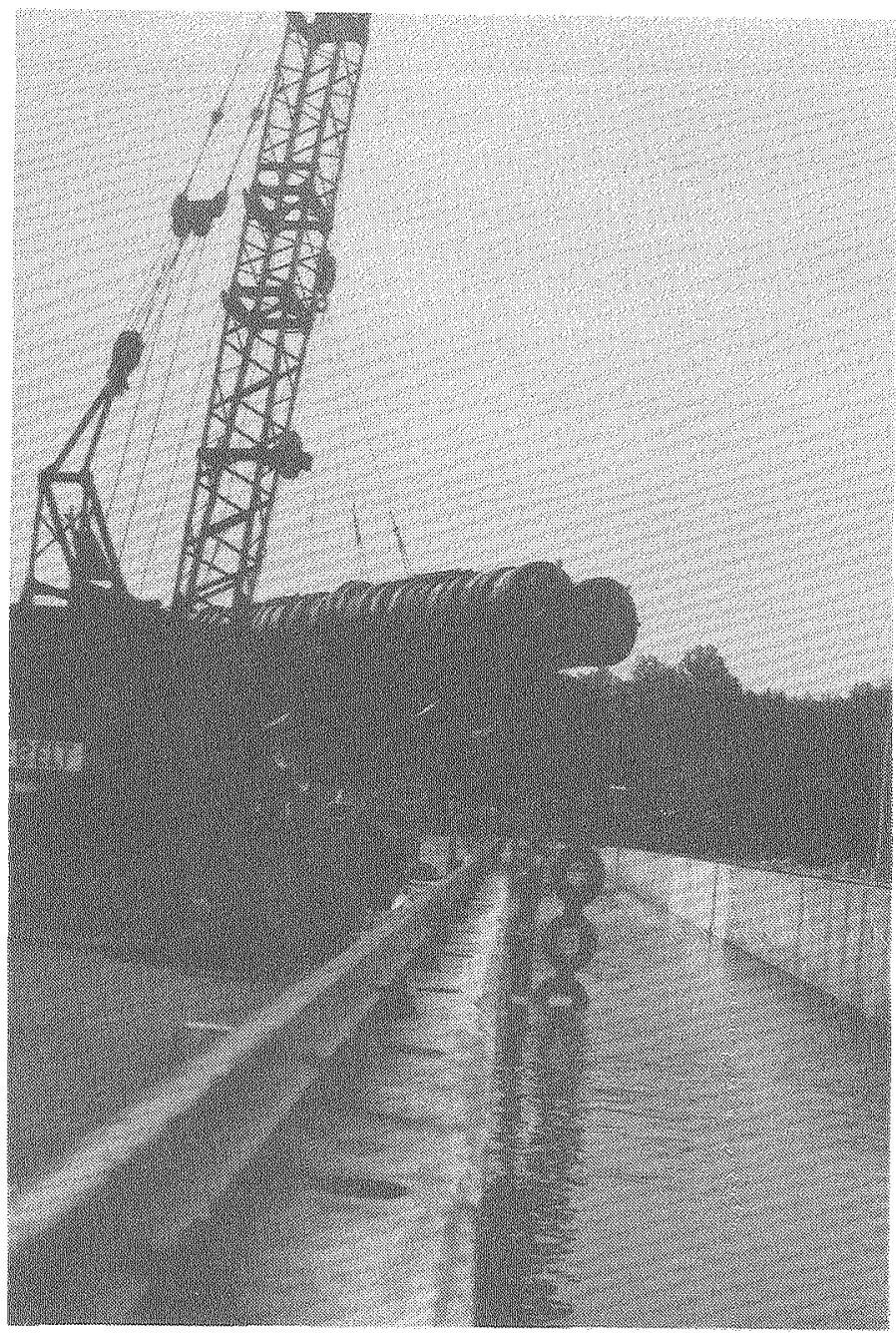

Fig. 19 Inserting PI-1 Breakwater

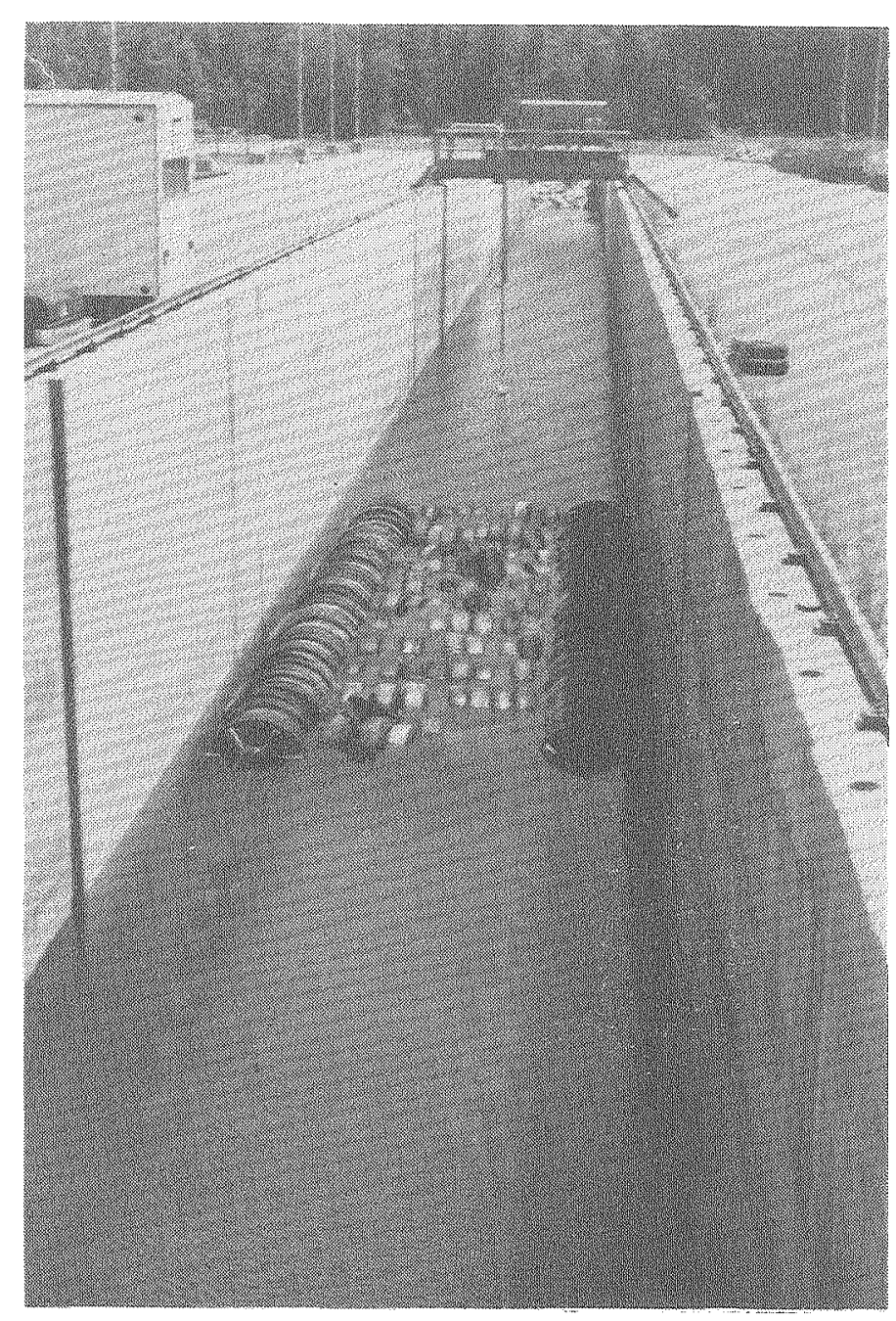

XBB 8011-13635

Fig. 18 View Towards Beach (Rock Revetment) 


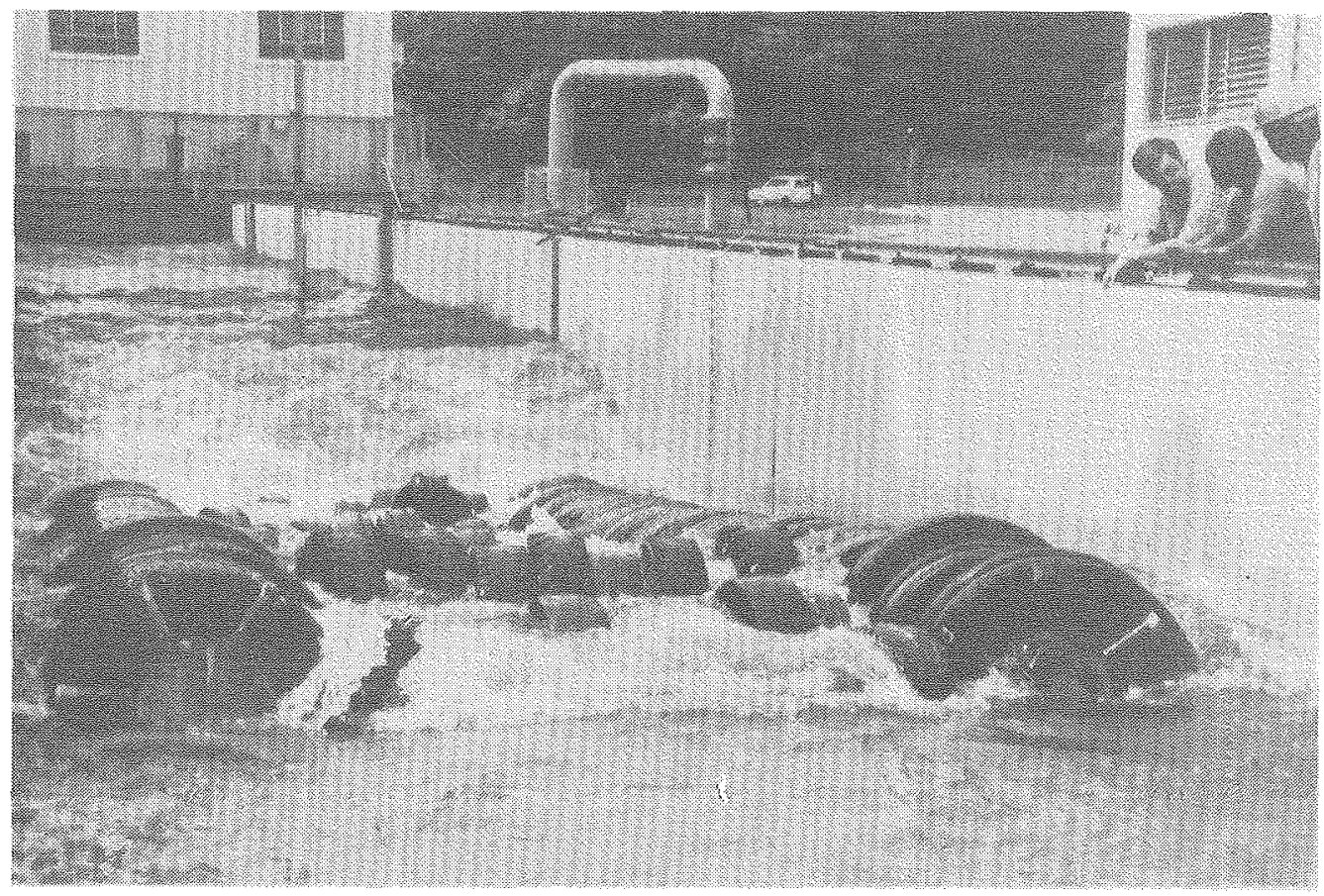

Fig. 20 Turbulence Associated with Wave Damping

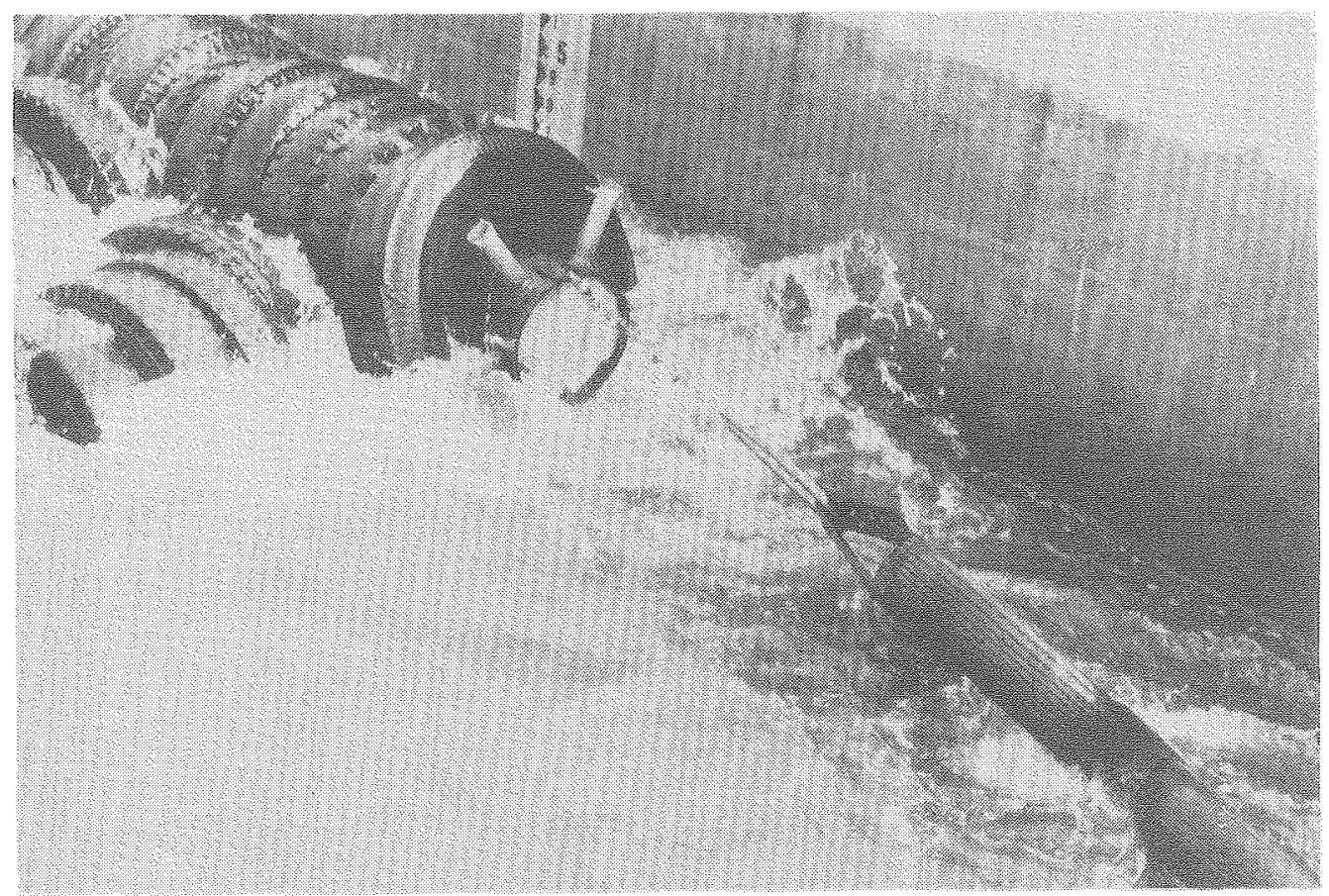

XBB $8011-13636$

Fig. 21 Attachment of Seaward Mooring Line (MS-1 Mooring System) 


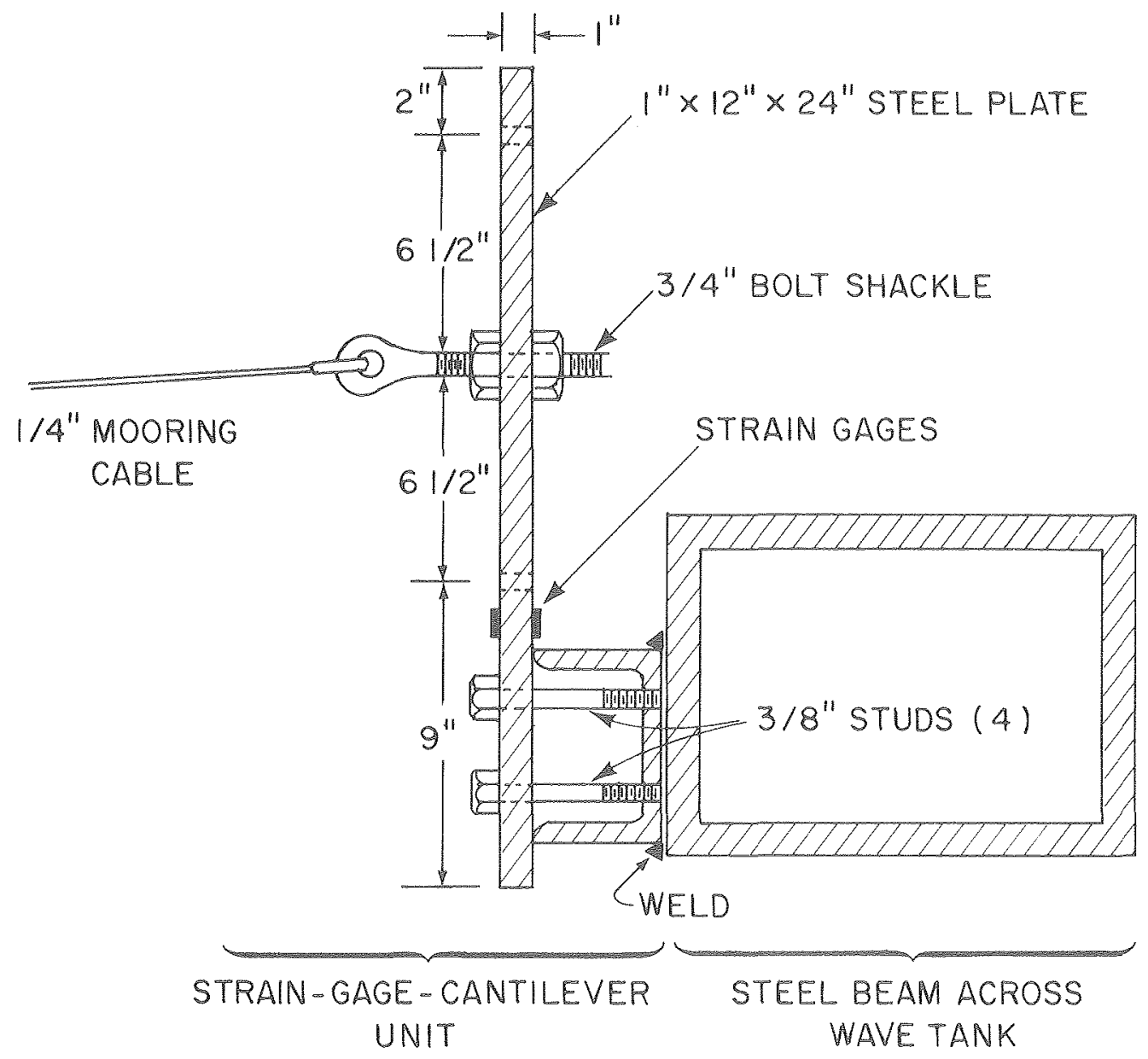

XBL $804-600$

Fig. 22 Strain-Gage-Cantilever Force Gage 
2. Mooring System.

The basic mooring-1ine arrangement used throughout the test program is shown in Fig. 16. The mooring lines were $6 \mathrm{~mm}$ ( $1 / 4$ inches) diameter wire rope, except for two removable segments 6 meters in length that are labelled "tire mooring damper" in Fig. 16, and are also shown in detail in Fig. 23. These sections were installed in order to determine whether a pliant mooring-line insert such as the 6-tire mooring damper could reduce peak mooring forces significanty. Should a relatively "soft" mooring system be desireable, it was felt that the installation of a tire mooring-damper would be a practical way of achieving this. The shoreward mooring bridle was always attached directly to the steel pipes, no mooring-line inserts were used on this side of the breakwater. On the seaward side the mooring bridle was most frequently attached to the steel pipe with cables connected to shackles extending through the pipe wall. An exception to this is MS-3, the third mooring-system tested, in which the mooring bridle was attached to the breakwater via conveyor-belt loops through two tires armouring the pipe. In this case the mooring-line forces are first transmitted to those two tires, only to be transmitted to the pipe itself after the tires have shifted some distance along the pipe and encountered the compressive resistance of other tires restrained by the retainer at the end of the pipe (Fig. 5).

The following mooring configurations were tested (major features are listed in Table 2):

(1) Damper/Pipe-Connection (MS-1)

Tire mooring-force dampers were installed and the mooring bridle 
connected directly to the pipes (soft line, hard connection), Figs. 16,21 and 26.

(2) No-Dampex/Pi pe-Connection (MS-2)

The mooring bridle remained attached to the pipes but the mooring force damper was removed and replaced with a conveyor belt loop of equal length. The load-elongation characteristics of the conveyor-belt loop are similar to those of the wire rope used (hard line, hard connection), Fig. 24 .

(3) No-Damper/Tire-Connection (MS-3)

The conveyor-belt loop remained in place but connection to the breakwater was accomplished by guiding the belt around two tires located on each pipe. In the case of the $\mathrm{PT}-1$ module, tire number 9 and 10 were used for this purpose and for PT-2, number 15 and 16 (hard line, soft connection).

A stress-strain diagram for the conveyor belt with a 5-hole bolted connection is shown in Fig. 25. The strain values are influenced by the connection itself i.e., elongation of bolt holes is being measured along with strecching of the belt. The belt failed at a load of $2270 \mathrm{~kg}$ (5000 1bs), not at the 5-hole bolted connection but at the transition, where the belt had to be reduced in width from $14.3 \mathrm{~cm}$ (5 $5 / 8$ inches) to 8.9 $\mathrm{cm}$ (3 1/2 inches) in order to fit into the testing machine.

Force-displacement relationships for $M S-1$ and $M S-2$ were obtained by tensioning the insert using a large dump truck and reading deflection and force (measuring tape and dial force gauge). The results are plot- 
ted in Fig. 24. Corresponding relationships for MS-3 were not determined, but observations indicate that its elastic properties lie between those of $M-2$ and MS-1.

A mooring bridle utilizing both truck and automobile tires is shown in Fig. 26; this unit was not tested at CERC but has been used in field installations.

Table 2. Compliance of Mooring Systems

\begin{tabular}{lccc}
\hline & MS-1 & Mooring System & MS-3 \\
\hline $\begin{array}{l}\text { Type of Mooring-Line } \\
\text { Insert* }\end{array}$ & $\begin{array}{c}\text { Tire } \\
\text { (soft) }\end{array}$ & $\begin{array}{c}\text { Belting } \\
\text { (hard) }\end{array}$ & $\begin{array}{c}\text { Belting } \\
\text { (hard) }\end{array}$ \\
$\begin{array}{c}\text { Type of Breakwater Connection } \\
\text { Mooring Line Stiffness } \\
\text { (ranked) }\end{array}$ & $\begin{array}{c}\text { Pipe } \\
\text { (hard) }\end{array}$ & $\begin{array}{c}\text { Tires on Pipe } \\
\text { (soft) }\end{array}$ \\
\hline
\end{tabular}

*Inserts are $6 \mathrm{~m}$ in length; belting in form of loop (double strength) with elongation characteristics under load approximately equal to that of wire rope used. 


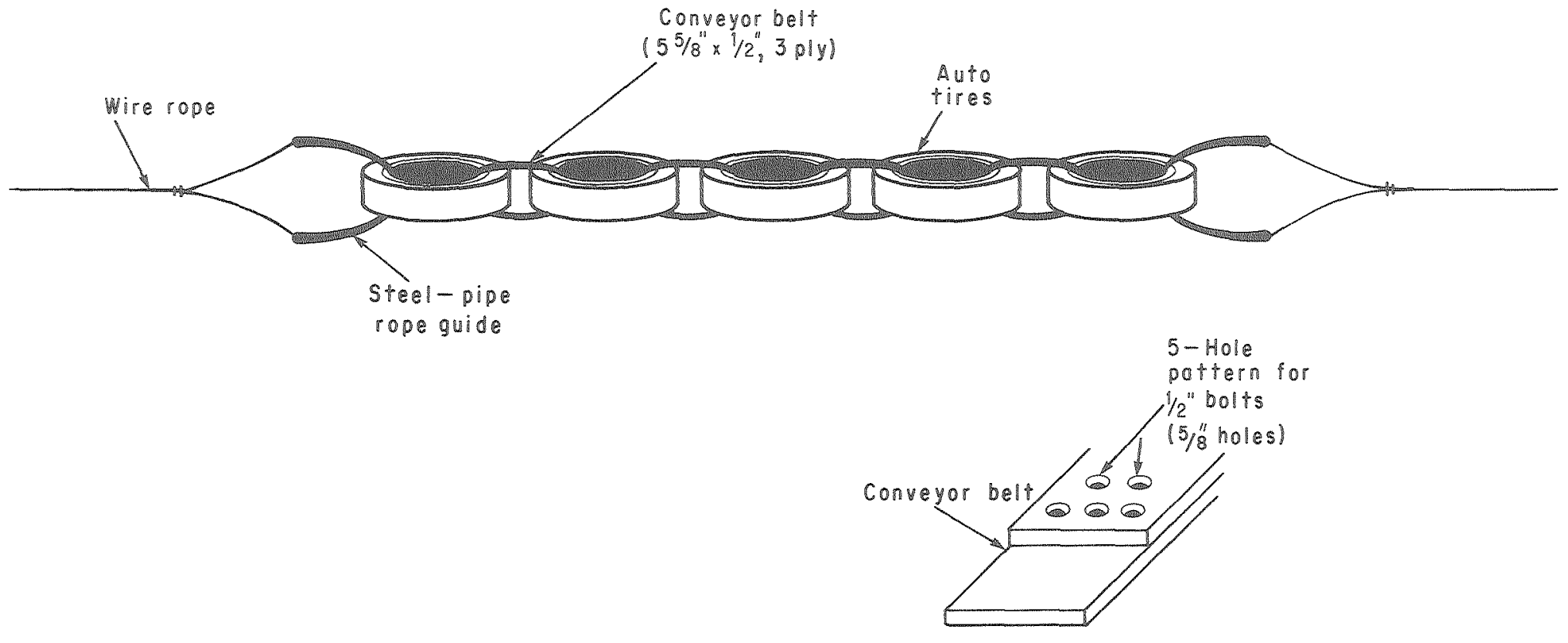

XBL $805-9667$

Fig. 23 Tire Mooring Damper

( 6 tires used in MS-1) 


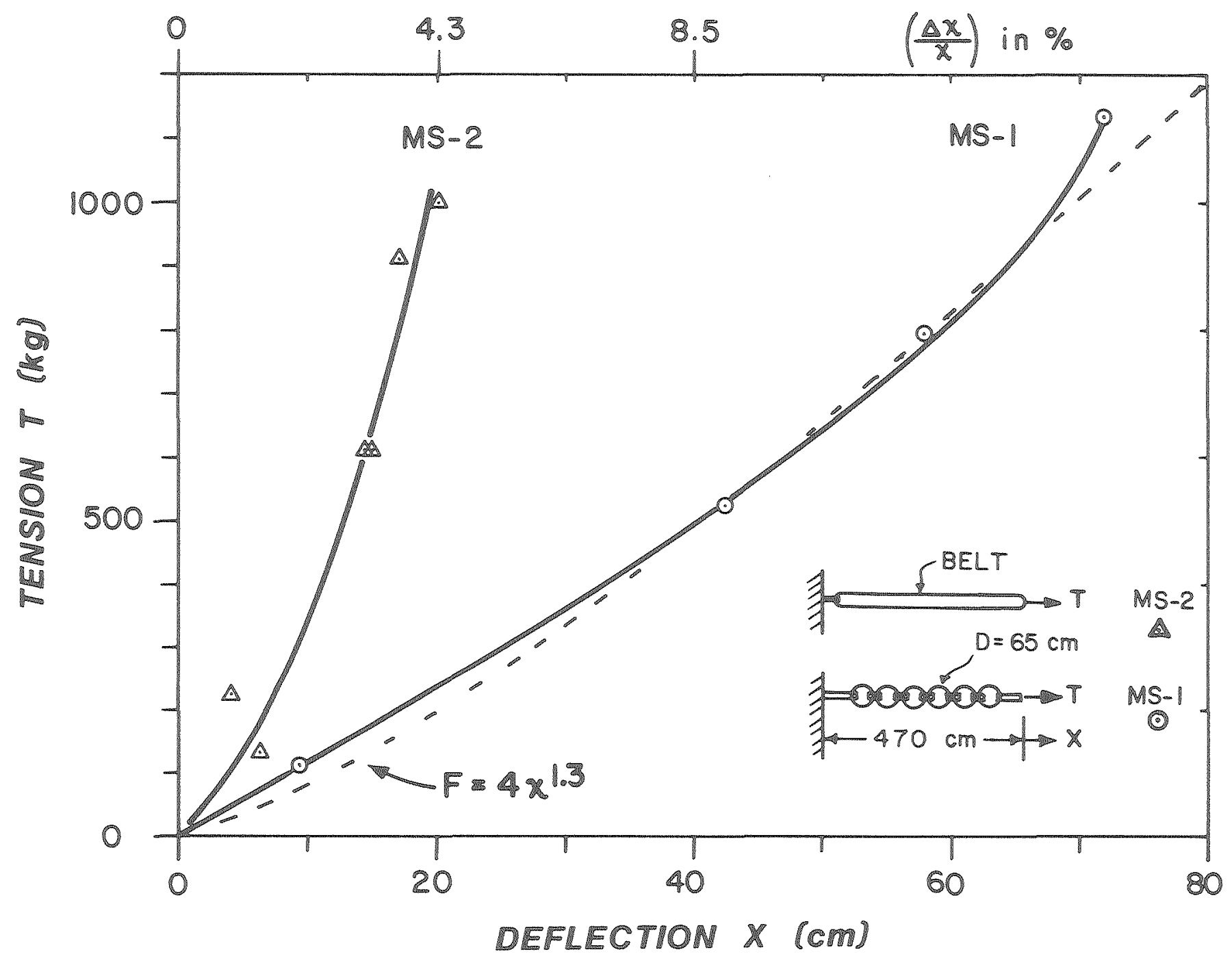

XBL $807-10718$

Fig. 24 Load-Elongation Curves for Mooring-Line Inserts 


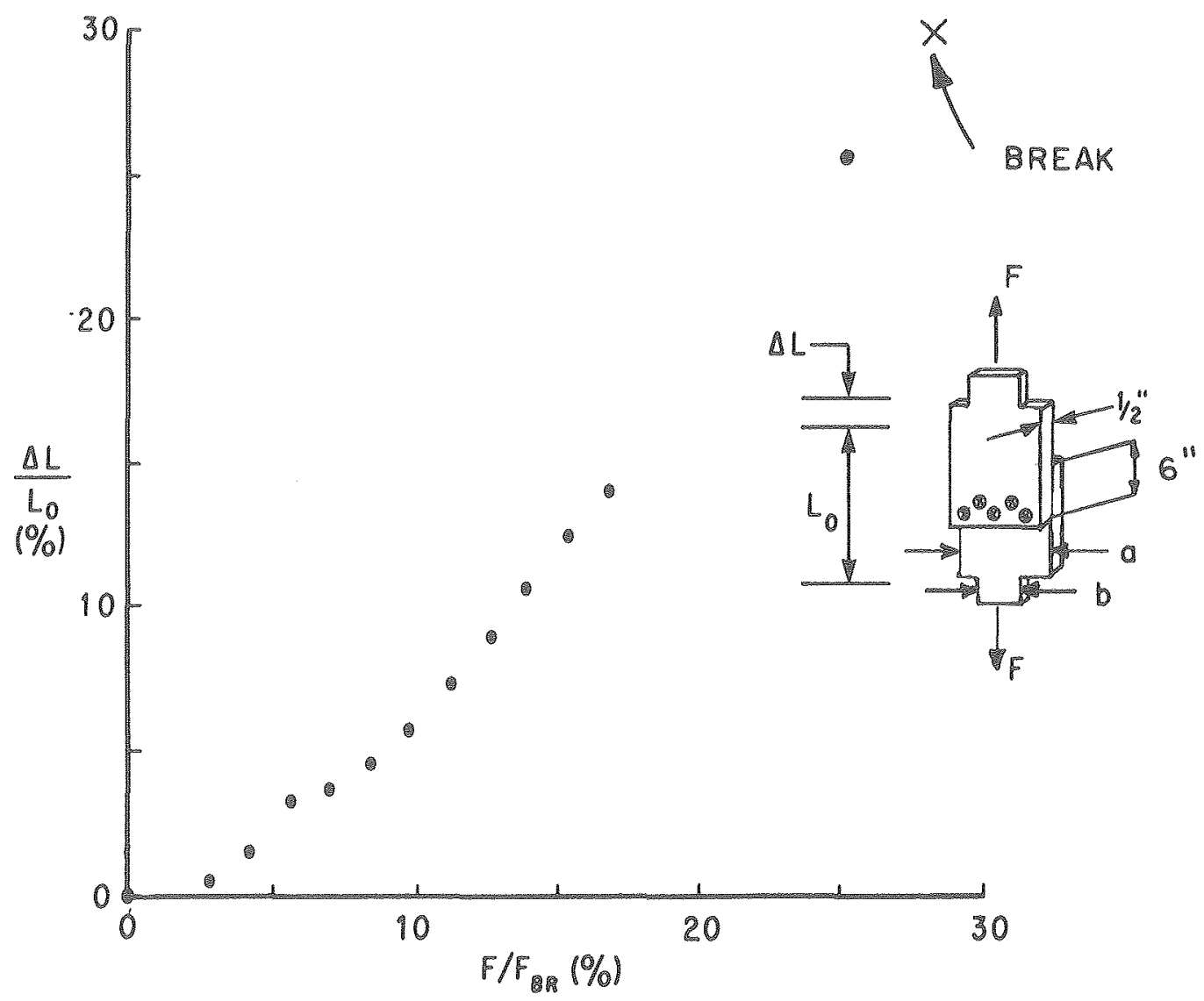

$F=$ applied lood

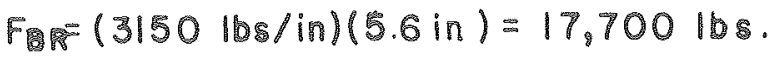

XBL 805-9666

(RATED BREAKING STRENGTH)

$L_{0}=15.1 \mathrm{in}$.

$a=5.6 \mathrm{in}$.

$0=3.8 \mathrm{in}$.

Fig. 25 Stress-Strain Diagram for Belt Connection 


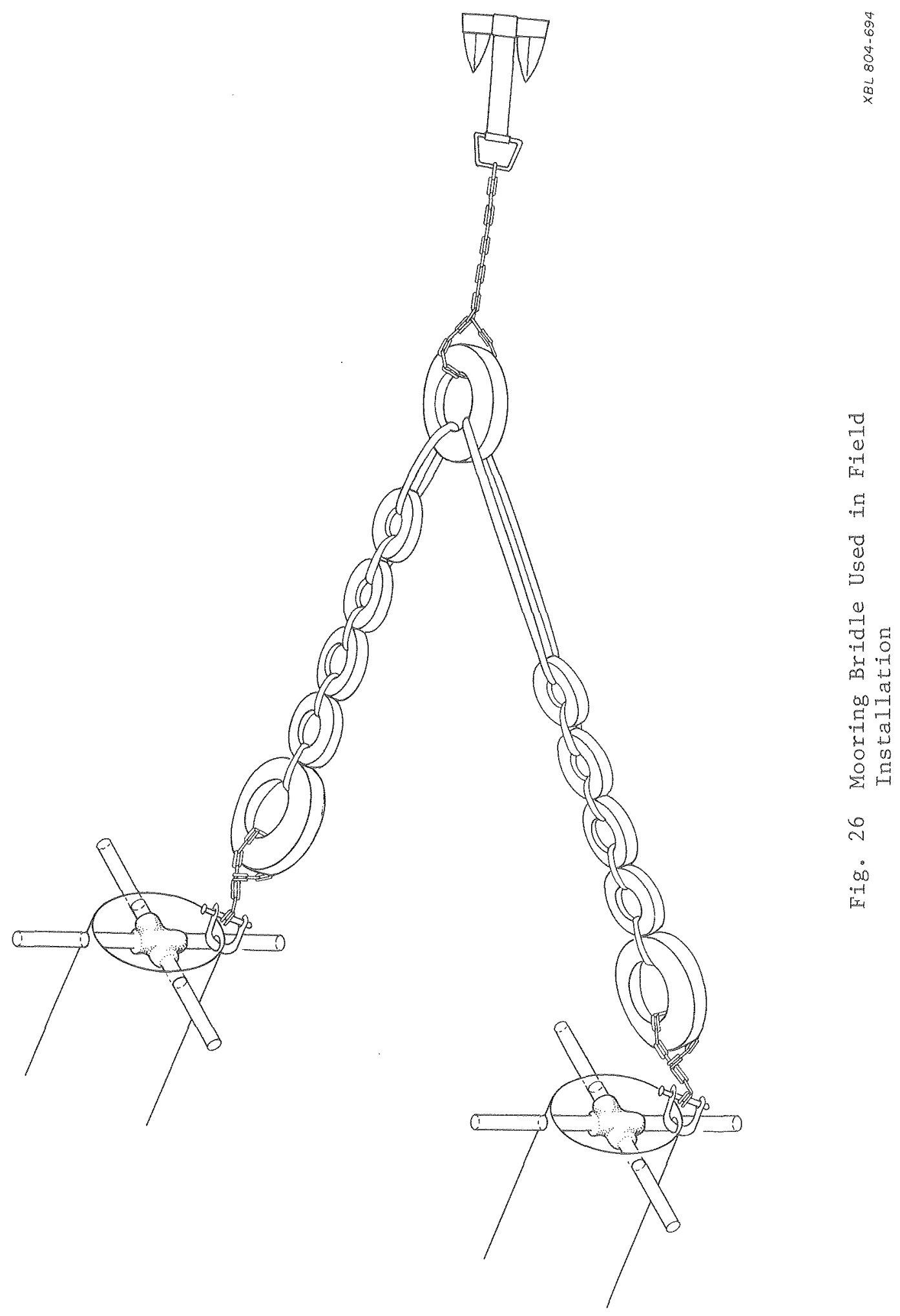


3. Test Procedure and Conditions.

The experimental program was limited to two structures, the PT-1 and PT-2 modules, and two water levels, 2.0 and 4.7 meters $(6.6$ and 15.4 feet). The summary of test conditions given in Table 3 lists one further breakwater designated as PT-DB: this is simply a PT-1 breakwater that has been lengthened in the shoreward direction by attaching the PT-2 module (flexibly, using conveyor-belt 1oops). Data for the PT-DB configuration is 1isted in Appendix A. The PT-1 module was tested with three different mooring systems and was, in general, emphasized in the experimental program: out of a total of 402 runs, 290 were devoted to the PT-1 breakwater. Waves ranged in height from $0.15-1.78 \mathrm{~m}(0.5-5.8$ ft.), with periods from 2.6-8.1 seconds; the wave-generator stroke varied from $0.61-2.13 \mathrm{~m}(2.0-7.0$ feet $)$.

With the breakwater in the tank and attached to the mooring system, test-preparations would generally begin each day by adjusting the water leve1, calibrating the wave gauges and force gauge and checking the stroke setting of the wave generator. The generator would be adjusted to the desired frquency, started, and waves generated for about five minutes; this constitutes a run. After shut-down of the wave generator, a waiting pexiod would follow in order to regain quiescent conditions in the wave tank. This having been attained, waves of another frequency would be generated, and the process repeated until all desired wave periods for that stroke setting had been obtained; this constitutes a test. One test was generally completed per day (sometimes two), and the generator stroke changed in the afternoon so that a new test could be started the following morning. Wave gauges and force gauges were cali- 
brated at the beginning and termination of each day's testing, and sometimes more frequently. 
Table 3. Summary of Test Conditions

\begin{tabular}{|c|c|c|c|c|c|c|c|}
\hline \multicolumn{2}{|c|}{ Break water } & \multirow{2}{*}{$\begin{array}{l}\text { Number } \\
\text { of Runs }\end{array}$} & \multirow{2}{*}{$\begin{array}{c}\text { Wa ter Depth } \\
(\mathrm{m})\end{array}$} & \multirow{2}{*}{$\begin{array}{l}\text { Mooring } \\
\text { System }\end{array}$} & \multirow{2}{*}{$\begin{array}{c}\text { Generator } \\
\text { Stroke } \\
(\mathrm{cm})\end{array}$} & \multirow{2}{*}{$\begin{array}{c}\text { Wa ve Height } \\
(\mathrm{cm})\end{array}$} & \multirow{2}{*}{$\begin{array}{c}\text { Wave Period } \\
(\mathrm{sec})\end{array}$} \\
\hline Type & $\begin{array}{c}\text { Be ann } \\
(\mathrm{m})\end{array}$ & & & & & & \\
\hline $\mathrm{PT}-1$ & .2 & 101 & 2.0 & & 3 & 13 & .1 \\
\hline $\mathrm{PT}-1$ & 12.1 & 92 & 4. & & & 42 & .0 \\
\hline $\mathrm{PT}-1$ & 12.2 & 62 & 4.7 & & & $32-132$ & $2.6-8.1$ \\
\hline $\mathrm{PT}-1$ & 12.2 & 37 & 4.7 & & 22 & $30-130$ & $2.6-8.1$ \\
\hline $\mathrm{PT}-2$ & 12.2 & 40 & 2.0 & MS & 22 & $18-110$ & $2.6-8.1$ \\
\hline $\mathrm{PT}=2$ & 12.2 & 36 & 4.7 & $M S-3$ & $61-122$ & $30-150$ & $2.6=8.1$ \\
\hline $\mathrm{PT}-\mathrm{DB}$ & 25.9 & 34 & 2.0 & $\mathrm{MS}-3$ & $61-122$ & $28-132$ & $2.6-8.1$ \\
\hline
\end{tabular}


IV. DATA REDUCTION AND ANALYSIS

1. Dimensional Analysis.

For a particular breakwater and mooring system, the transmitted wave height $\mathrm{H}_{t}$ may be expressed as a function of the following variables:

$H_{t}=f[H, L, B, D, G, \lambda, m, k, \varepsilon, d, \gamma, \nu, g]$

where

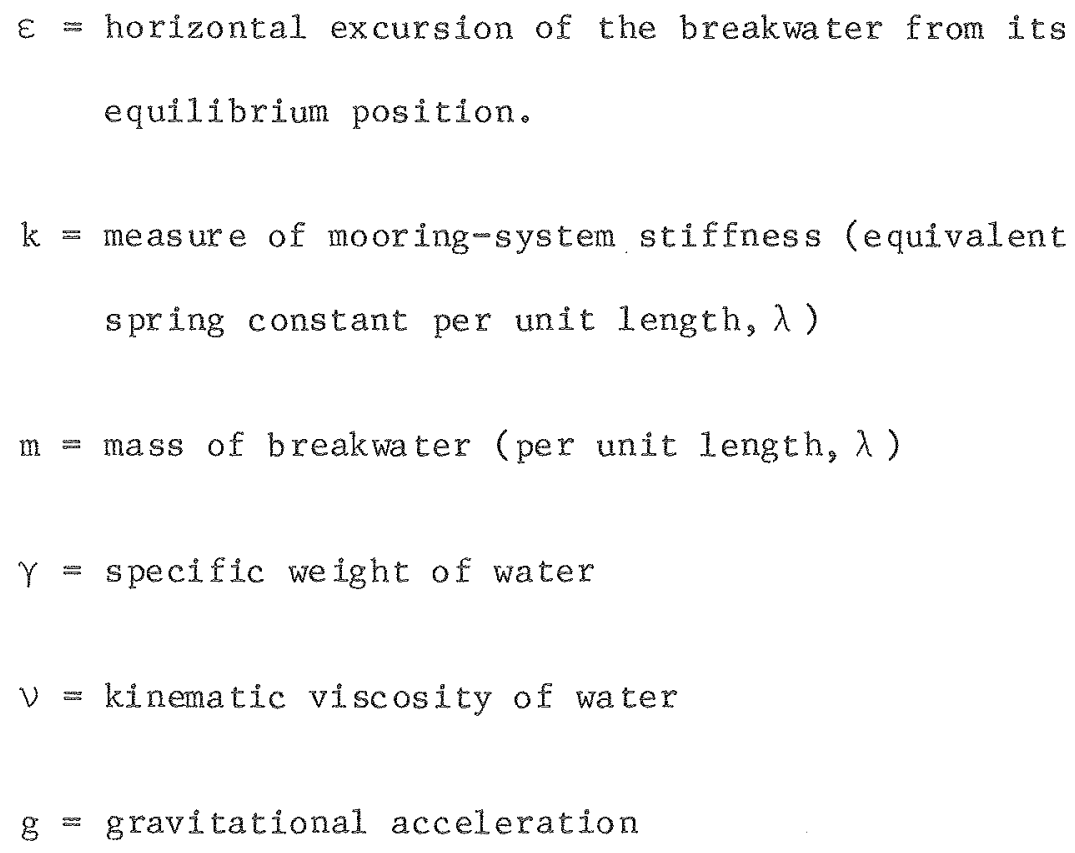

and the remaining terms are defined in the definition sketch, Fig, 27. Since this expression contains 3 dimensionally-independent physical variables (in length, mass, time), we may, according to Buckingham's $\pi$ - Theorem, replace this relationship involving 14 physical variables by one involving 11 nondimensional groups: 


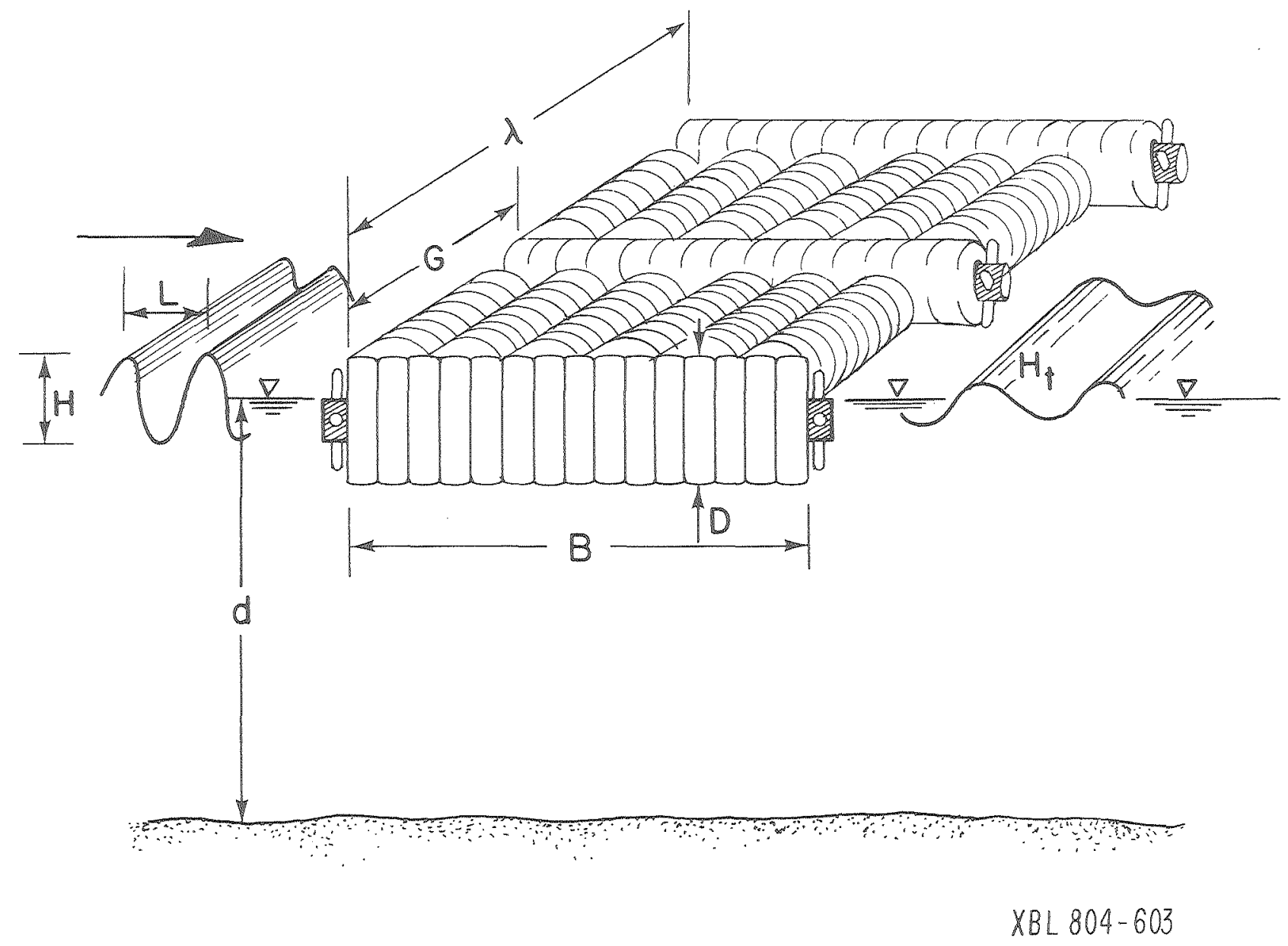

Fig. 27 Definition Sketch for PT-Breakwater 

$\mathrm{H} / \mathrm{H}_{\mathrm{t}}$
wave transmission ratio, $C_{t}$
$B / D, \quad G / D, \lambda / D, k \varepsilon / m g$
structure parameters
$\mathrm{H} / \mathrm{L}$
wave steepness
$L / B, \quad \varepsilon / H$
wave-structure parameters
$\mathrm{D} / \mathrm{d}, \quad \gamma B \mathrm{BD} / \mathrm{mg}$
fluid-structure parameters
$\left(\frac{\mathrm{H}}{\mathrm{L}}\right)\left(\frac{\mathrm{D} \sqrt{\mathrm{gL}}}{\mathrm{V}}\right)$
Reynold's Number

Several of the above parameters will now be deleted, for the stated reasons:

(a) $\lambda / D$

Only quasi-two-dimensional experiments, will be considered, i.e., diffraction effects are absent when the breakwater extends across the full width of the tank.

(b) $\mathrm{k} \varepsilon / \mathrm{mg}$

This is the ratio of mooring-system static restoring force to structure weight, and was not changed.

(c) $\varepsilon / H$ Assumed to be a weak parameter that is of little importance for sma11 values of $\varepsilon / H$, i.e., for 
horizontal motions of the structure that are sma11 compared to the wave height.

(d) $\gamma B D / m g$

This parameter relates the mass of fluid displaced by the breakwater to the mass of the breakwater itself. It would remain constant for geometrically-similar breakwaters constructed from the same materials.

(e) $\left(\frac{H}{L}\right)\left(\frac{D \sqrt{g L}}{V}\right)$

This Reynold's Number is based upon the tire diameter and a velocity that is related to the maximum waveinduced water particle velocity; it will be assumed large enough to ensure Reynold's Number-independence.

Upon eliminating the above dimensionless groups, we obtain

$$
C_{t}=f[L / B, H / L, D / d, B / D]
$$

This is the relationship upon which these tests were based. It was found that the order of the dimensionless groups given above corresponds approximately to the order of importance of these paraneters for the tests performed.

We may similarly consider the mooring force relationship to be

$$
F=f\left[H, H_{t}, L, \quad B, D, G, \lambda, m, \quad k, \varepsilon \quad d, \gamma, V, g\right]
$$


and obtain

$$
F / \gamma H^{2}=f[L / B, H / L, D / d B / D]
$$

by similar reasoning. 


\section{Data-Reduction Procedures.}

Analog signals from the wave gauges and force transducer were recorded on three channels of a six-channel Brush oscillographic recorder. Typical records of the seaward-mooring-line force and the incident and txansmitted waves are reproduced in Figures 28-31.

Wave reflections from the steep, rock-armoured beach at the end of the wave tank (Fig. 16) were an annoyance, particularly for the longer waves generated. The incident and transmitted wave heights were therefore generally obtained from the first 5 to 10 waves in the run, i.e., before wave reflections could influence wave-height measurements substantially. Beach reflections were particularly bothersome when generating waves of low steepness and period larger than approximately five seconds.

From the force-gauge records it can be seen that the seaward mooring load fluctuates with the passage of each wave between a maximum value which varies throughout the run and a minimum value which remains essentially constant. The individual force peaks occur as the breakwater surges shoreward during the passage of each wave crest but is prevented from moving very far in this direction by the force cantilever. The seaward movement of the breakwater, on the other hand, is not similarly opposed since no force cantilever was installed on the leeward side of the breakwater. Instead, only a constant negative restoring force, or preload, of approximately $113 \mathrm{~kg}$ (250 1bs) was exerted on the breakwater via the shoreward mooring line and pulley-weight arrangement shown in Fig. 16. The zero-force reference position recorded at the beginning of each run always corresponds to this static preloaded 
condition of the cantilever force gauge. Negative force values, up to the magnitude of this preload, can consequently be obtained as the breakwater surges seaward; these constitute the stable lower limit of the Force records.

Time-sexies analysis of the force data was not considered worthwile since the experiments were limited to regular waves, and also could not be justified because of the level of effort required. For practical purposes, each force record was therefore characterized by a single force value that is considered most useful for design purposes: the peak force, $F$, occurring during the length of record (excluding wave generator start-and-stop transients, which have no counterpart in nature). Typically, this implies that the first five or ten waves were not included in the analysis, nor were those last waves propagating down the tank after shut-dow of the wave generator. Each run generally consisted of at least 50 waves. In addition to the peak mooring force $F$, an approximation to the drift force $\bar{F}$, was also obtained, as was the significant peak force $F_{s}$. The drift force $\bar{F}$ is the net, time-averaged Force acting on the seaward mooring line; it was determined "by eye" as show in Fig. 33 and is therefore subject to larger errors. The signi-m ficant force $F_{s}$ represents the average of the largest $1 / 3$ of the force peaks, again excluding stop-and-start transients; it was obtained manum ally, directly from the data trace.

If start and stop transiencs axe included in the determination of the peak mooring force, as has been done by other investigators (Giles and Sorensen, 1978), the difference between $F$ and this are frequently small but can be quite large, as shown in Appendix B. In that section 
we also compare the peak mooring force, $F$, to the significant peakforce, $F_{s}$, for a large number of tests.

The cantilever force gauge was calibrated at least once at the beginning and ending of each days testing; if zeromdrifts were observed, even more frequently. Calibration was accomplished manually via a separate cable with mechanical load tightener and 50001 b. dial force gauge in series, and attached close to the cantilever. A typical cali= bration record is shown in Fig. 32. The force values are always referenced to the static no-load condition, i.e., with pulley-preload but no waves. 


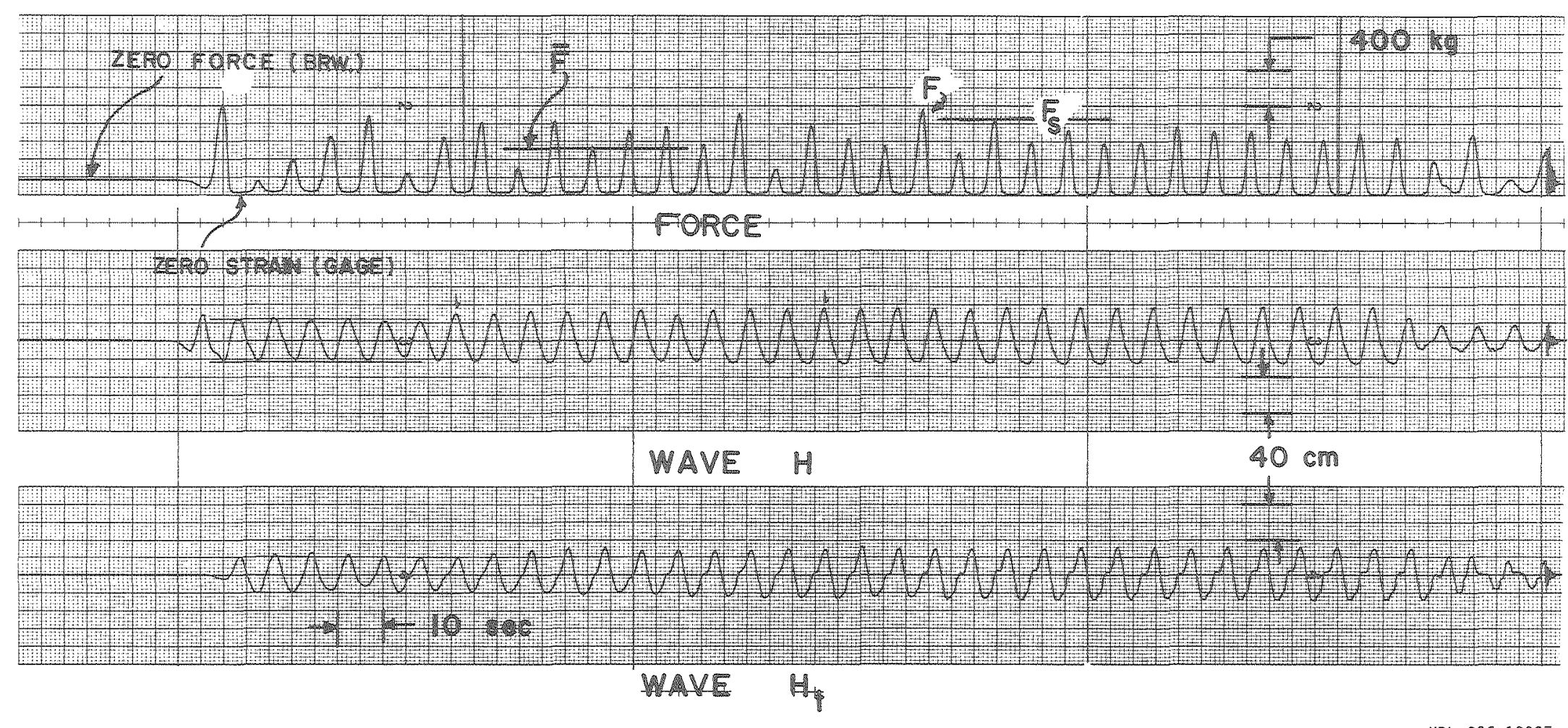

XBL 806-10337

Fig. 28 Wave and.Force Record for Long Waves

$(\mathrm{d}=4.7 \mathrm{~m}, \mathrm{~T}=8.0 \mathrm{sec})$ 


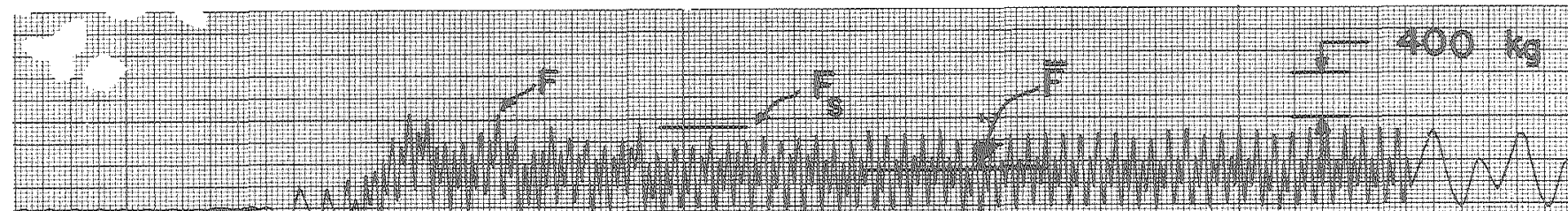

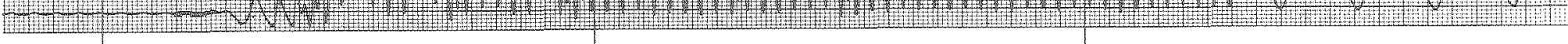
FORCE

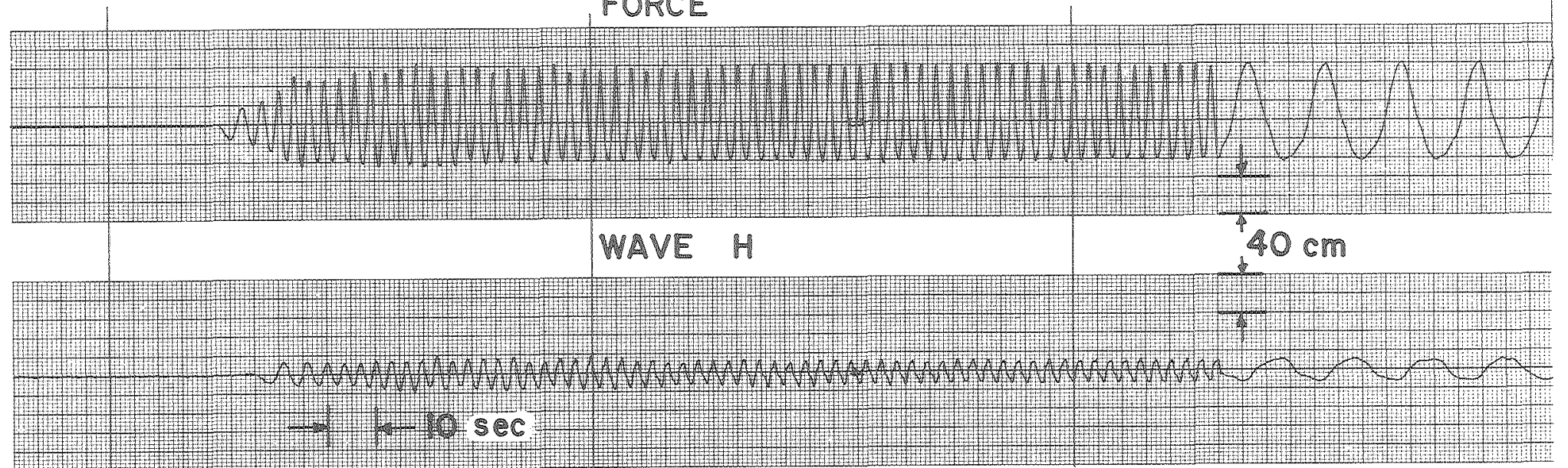
WAVE $H_{\phi}$

XBL $806-10339$

Fig. 29 Wave and Force Record for Short Waves $(\mathrm{d}=4.7 \mathrm{~m}, \mathrm{~T}=3.2 \mathrm{sec})$ 

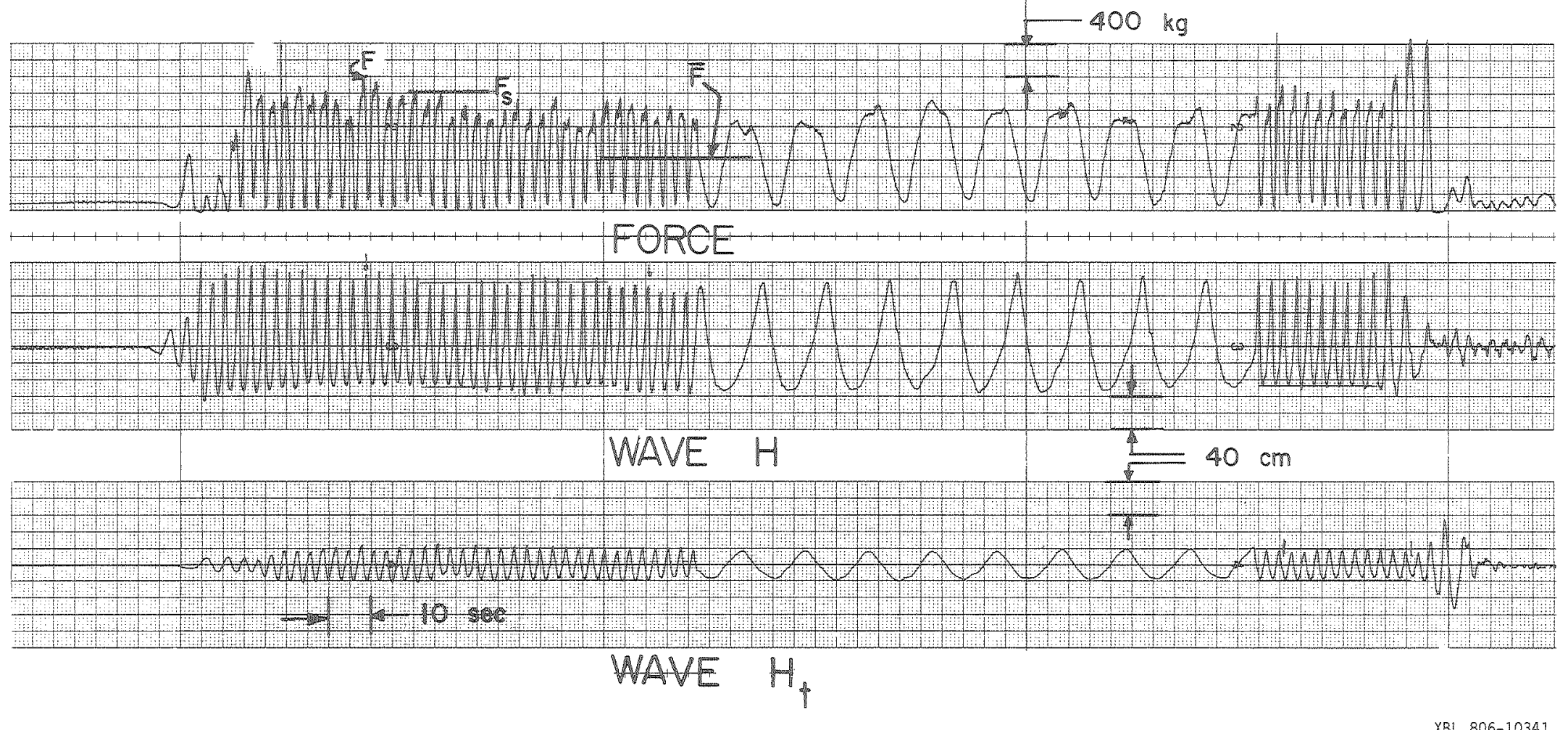

Fig. 30 Wave and Force Record for Steep Waves $(\mathrm{d}=4.7 \mathrm{~m}, \mathrm{~T}=3.0 \mathrm{sec})$ 


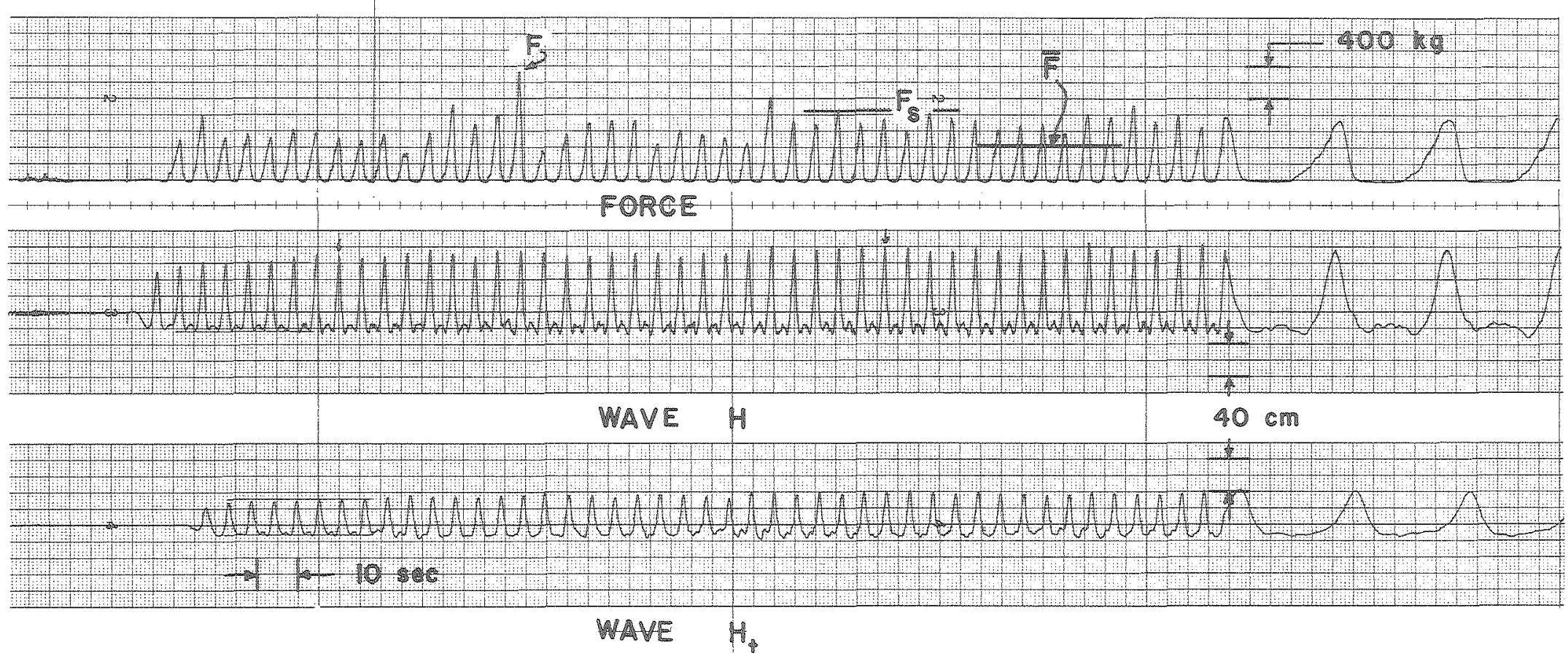

WAVE H

XBL $806-10340$

Fig. 31 Wave and Force Record for Shallow-

Water Waves $(d=2.0 \mathrm{~m}, T=5.5 \mathrm{sec})$ 


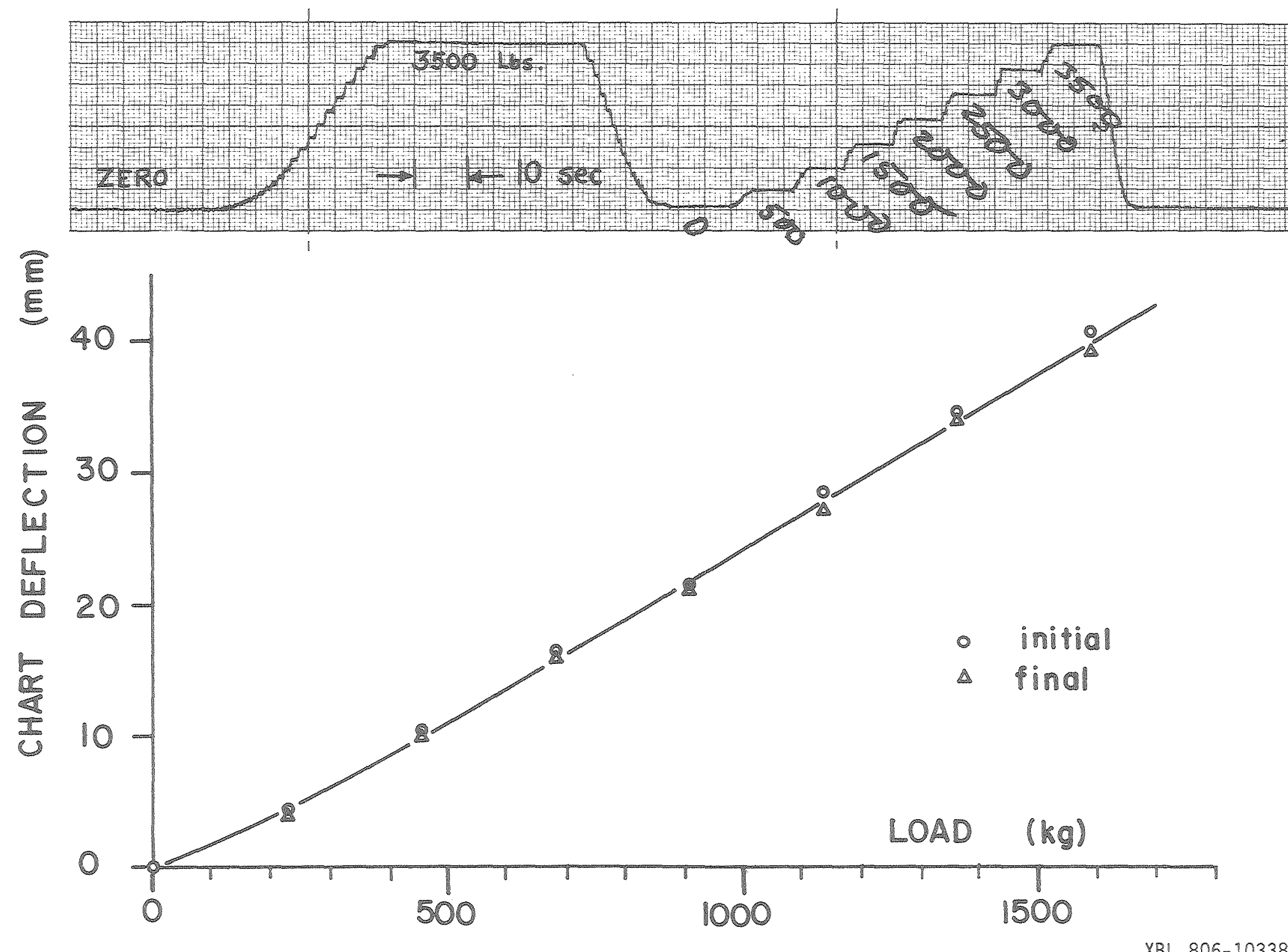

Fig. 32 Force-Gage Calibration Record and Curve 


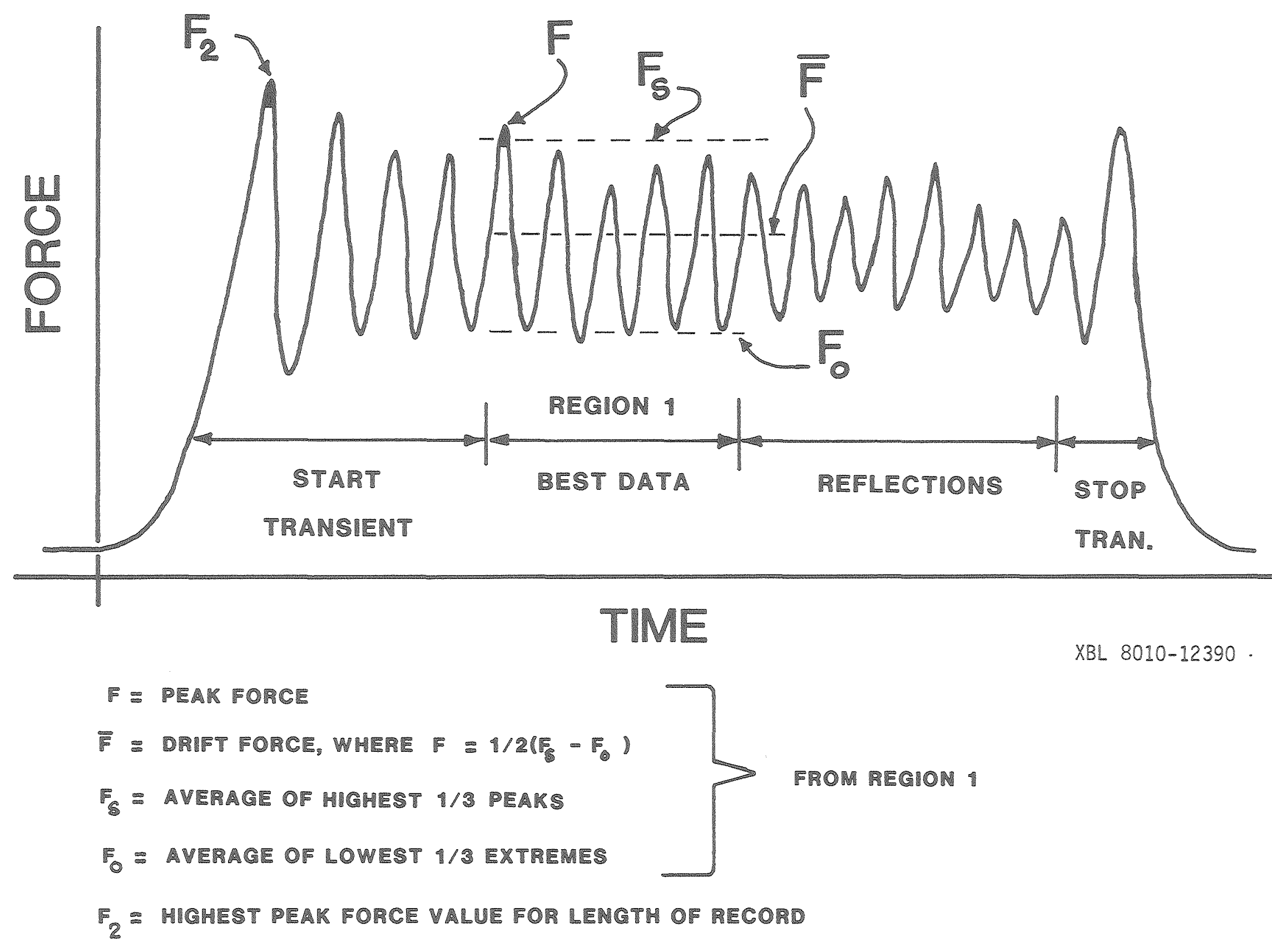

Fig. 33 Definition Sketch for Force Analysis 
V. EXPERIMENTAL RESULTS

1. Wave-Transmission Data.

For each breakwater configuration and water depth, the transmitted wave height depends primarily upon the width of the structure and the incident wave length and height. Dimensional analysis and physical insight were invoked in Section IV to arrive at non-dimensional parameters that would describe the problem more succinctly and clearly than do statements such as the above, and would also guide the experimental effort and analysis of results. This led to a presentation of the data in the form of Fig. 34: the wave-height transmission ratio, $\mathrm{C}_{\mathrm{t}}=\mathrm{Ht} / \mathrm{H}_{\mathrm{s}}$ is presented as a function of relative wave length $L / B^{\text {s }}$ with different symbols designating ranges of wave steepness $\mathrm{H} / \mathrm{L}$. These are considered the primary parameters. Secondaxy parameters are generally listed in the insert of each figure: they specify the water depth (relative depth, $D / d$ ) and breakwater geometry (aspect ratio, B/D, and pipe spacing, $G / D$ ). For design purposes, the transmission characteristics of each breakwater are sumarized in the form of a single wave-height transmission curve. This curve corresponds to a wave steepness of $H / L=0.04$ (a moderate value frequently encountered in practice) and different values of $\mathrm{D} / \mathrm{d}$. Although much data has been obtained at wave steepness other than 0.04 , indicating that the transmission ratio $C_{t}$ generally decreases with increasing wave steepness, the available data is not adequate for defining transmission curves for wave steepness other than 0.04 . Nevertheless, the influence of wave steepness has here been preserved, to a large extent, by grouping the data according to steepness categories; in Appendiss $C$ the value of $H / L$ is actually listed next to each data point. 
Appendix $C$ should be particularly useful for design cases with wave steepness near the extremes encountered in nature, either high or low (say $H / L$ larger than 0.08 or less than 0.02 ), since deviations from the 4\%-design-curve may then become significant. The wave-transmission data in Appendix $C$ has also been segregated with respect to the type of mooring system installed, but it was found that this had no discernible influence on wave-transmission characteristics. It is therefore permissible to combine the data for all mooring systems, as has been done in Fig. 34 。 
a. PT-1 Breakwater. Wave-transmission data for the PT-1 module (truck tires/steel pipe) are shown in Figs. 34 and 35 for two water depths, $D / d$ $=0.22$ and 0.51 . In both cases the transmission ratio $C_{t}$ increases monotonically with relative wave length $L / B$ : the breakwater is very effective in filtering out waves that are shorter than the structure is wide, but becomes increasingly less effective as the wave length increases. It is evident that the breakwater is significantly more effective at the lower depth, particularly for longer waves. The influence of water depth, or relative draft $\mathrm{D} / \mathrm{d}$, becomes particularly apparent in Fig. 36 where the transmission curves axe compared.

The influence of wave steepness is most readily detectable for longer waves (say L/B larger than 2) and, may be important at low water depths: for $L / B=2.9$ and $D / d=0.51$ (Fig. 35), the value of $C_{t}$ decreases dramatically from 0.9 to 0.4 as H/L increases from 0.007 to 0.028 (refer also to Fig. $\mathrm{C}-7$ in Appendix C). The data in Figs. 34 and 35 apply to a single structure, the PT-1 module, with pipe spacing of $G / D=3.3$, aspect ratio of $B / D=12$, and beam $B=12.2 \mathrm{~m}$ ( 40 feet). These conditions may not be altered greatly without also influencing the wave-transmission charactexistics. For example, the design curves of Fig. 36 may not apply to a structure with much larger beam, say $B=24 m$ (80 feet) i.e., or $B / D=24$. Until further data on the importance of $B / D$ has been obtained, it is suggested that the PT-l wave-transmission design curves of Fig. 36 be limited to beam dimensions in the range from 9 to 15 meters (30 to 50 feet). Existing data from small-scale experiments (Harms, 1979) indicates that the transmission curve for $\mathrm{D} / \mathrm{d}=0.22$ does not change significantly as the water depth increases. For deepwater applications with $\mathrm{D} / \mathrm{d}$ less than 0.2 , it is therefore suggested 
that the $\mathrm{D} / \mathrm{d}=0.22$ curve be used for design purposes; at least until further data becomes available. 


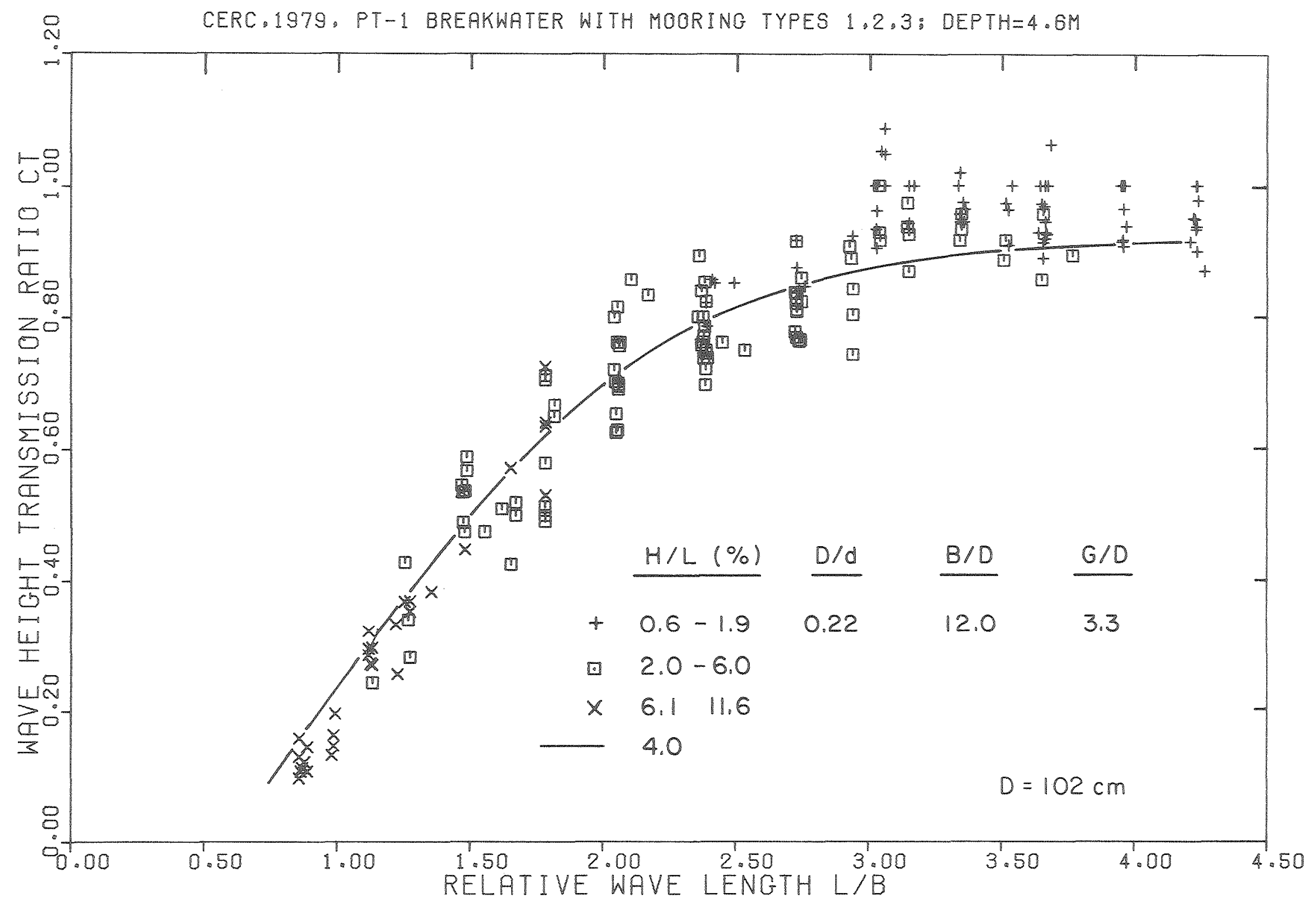

$\times B L 804-7005$

Fig. 34 Wave-Transmission Data for PT-1 Breakwater $(\mathrm{d}=4.7 \mathrm{~m})$ 


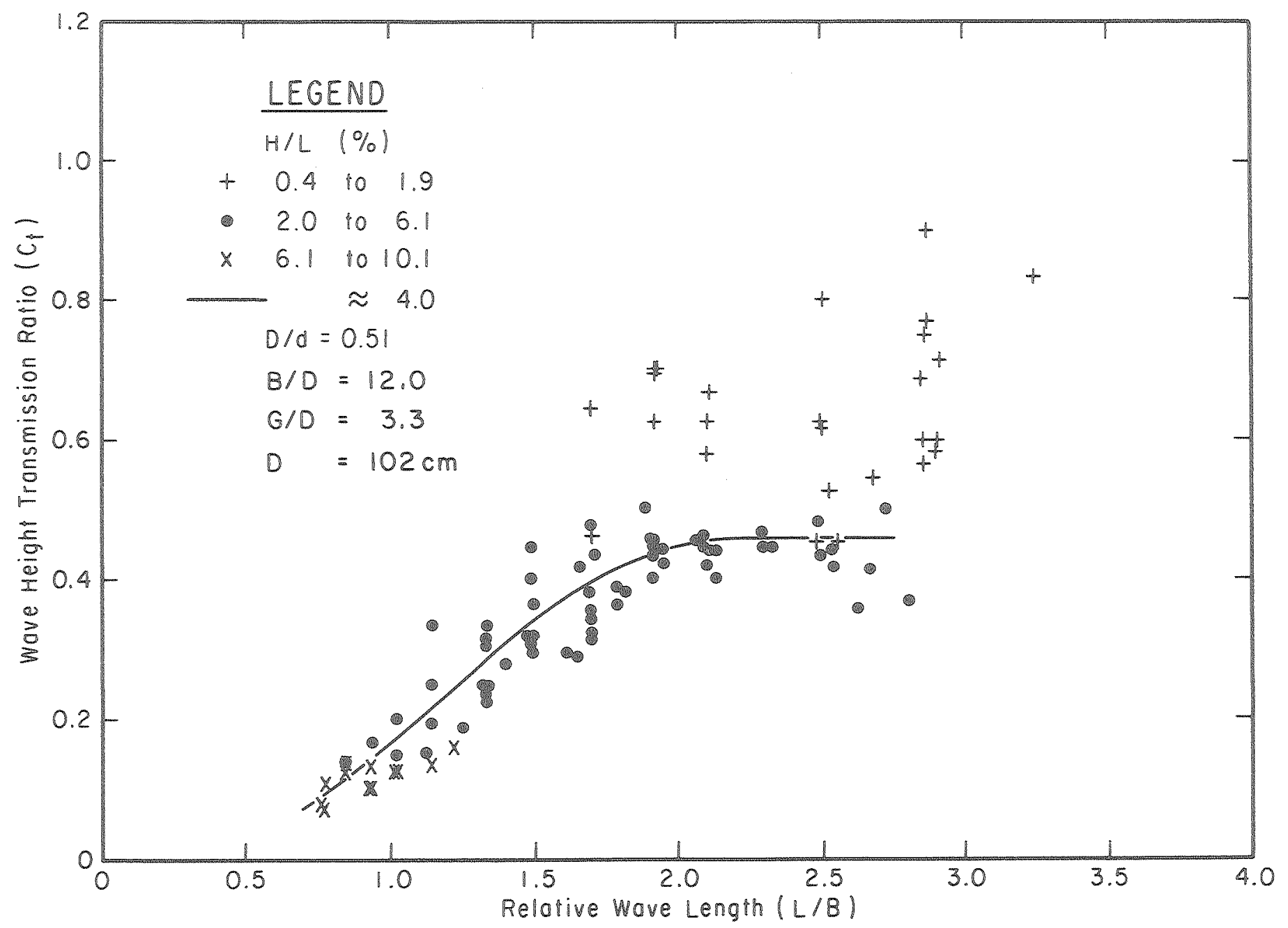

$\times 8 L 804-7004$

Fig. 35 Wave-Transmission Data for PT-1 Breakwater $(d=2.0 \mathrm{~m})$ 


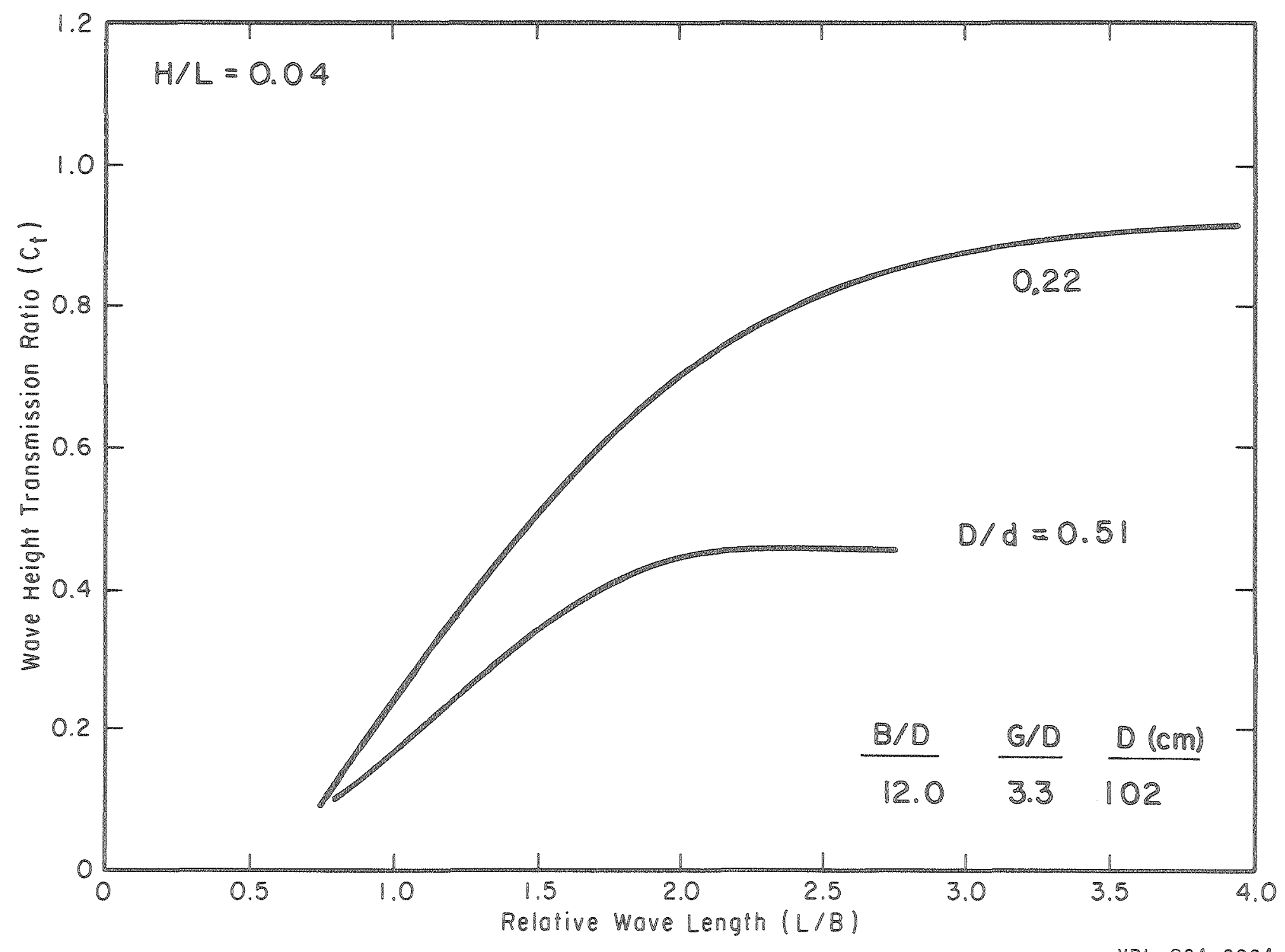

XBL 804-9304

Fig. 36 Wave-Transmission Design Curves for PT-I Breakwater 
b. PT-2 Breakwater. Wave-transmission data for the PT-2 module (automobile tires/telephone pole) are shown in Figs. 37 and 38, with design curves given in Fig. 39. The behavior is very similar to that of the PT-1 module, although a decrease in waveattenuation performance is indicated, at least at the larger water depths considered in Fig. 40 . The influence of wave steepness $H / L$ is again particularly apparent at the lower watex depth $(\mathrm{D} / \mathrm{d}=0.33, \mathrm{Fig} \cdot 38)$ and large values of $\mathrm{L} / \mathrm{B}$. The actual H/L - values associated with each data point are given in Appendices $\mathrm{A}$ and $\mathrm{C}$. 


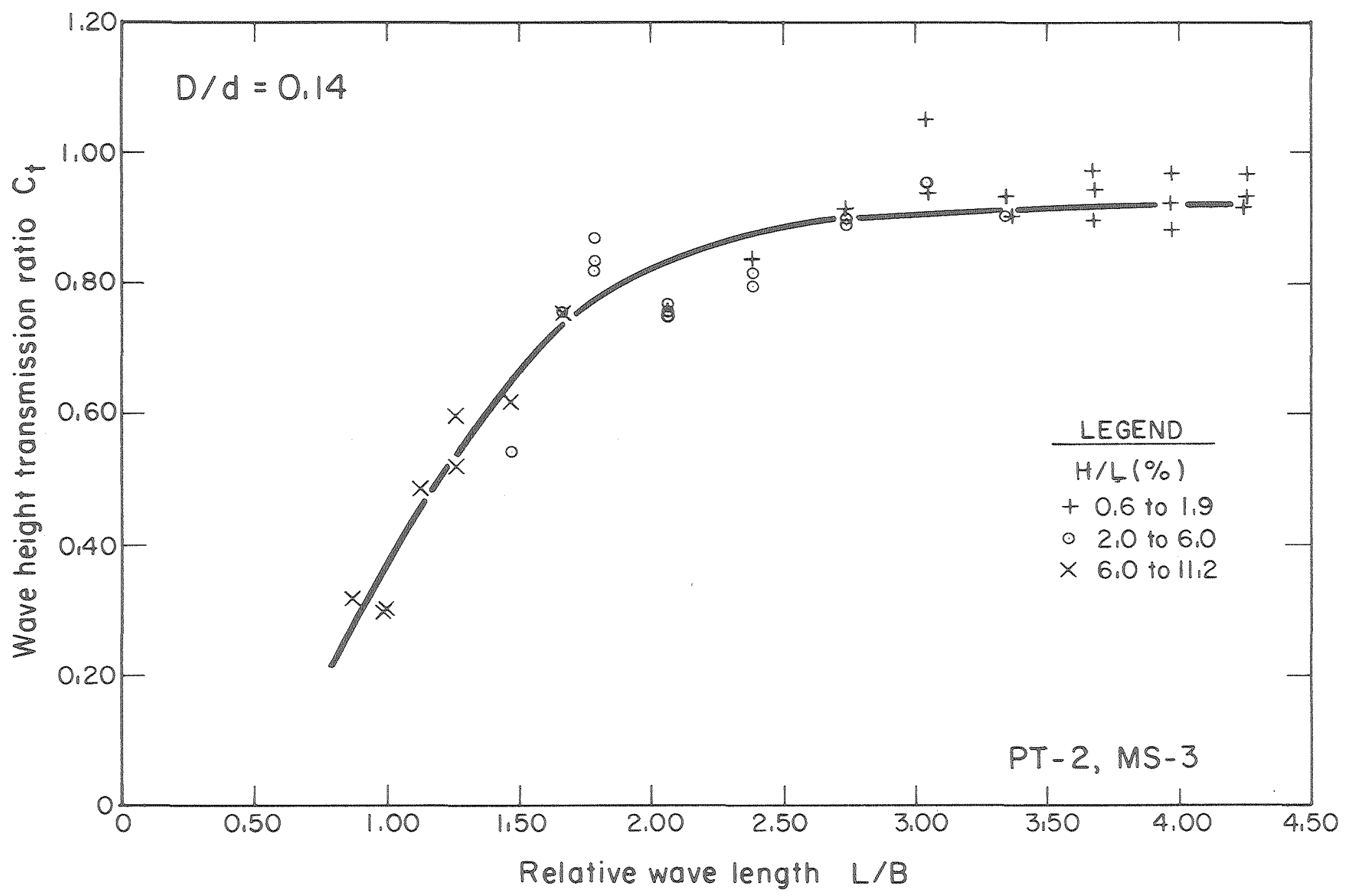

XBL $804-566$

Fig. 37 Wave-Transmission Data for PT-2 Breakwater $(\mathrm{d}=4.7 \mathrm{~m})$ 


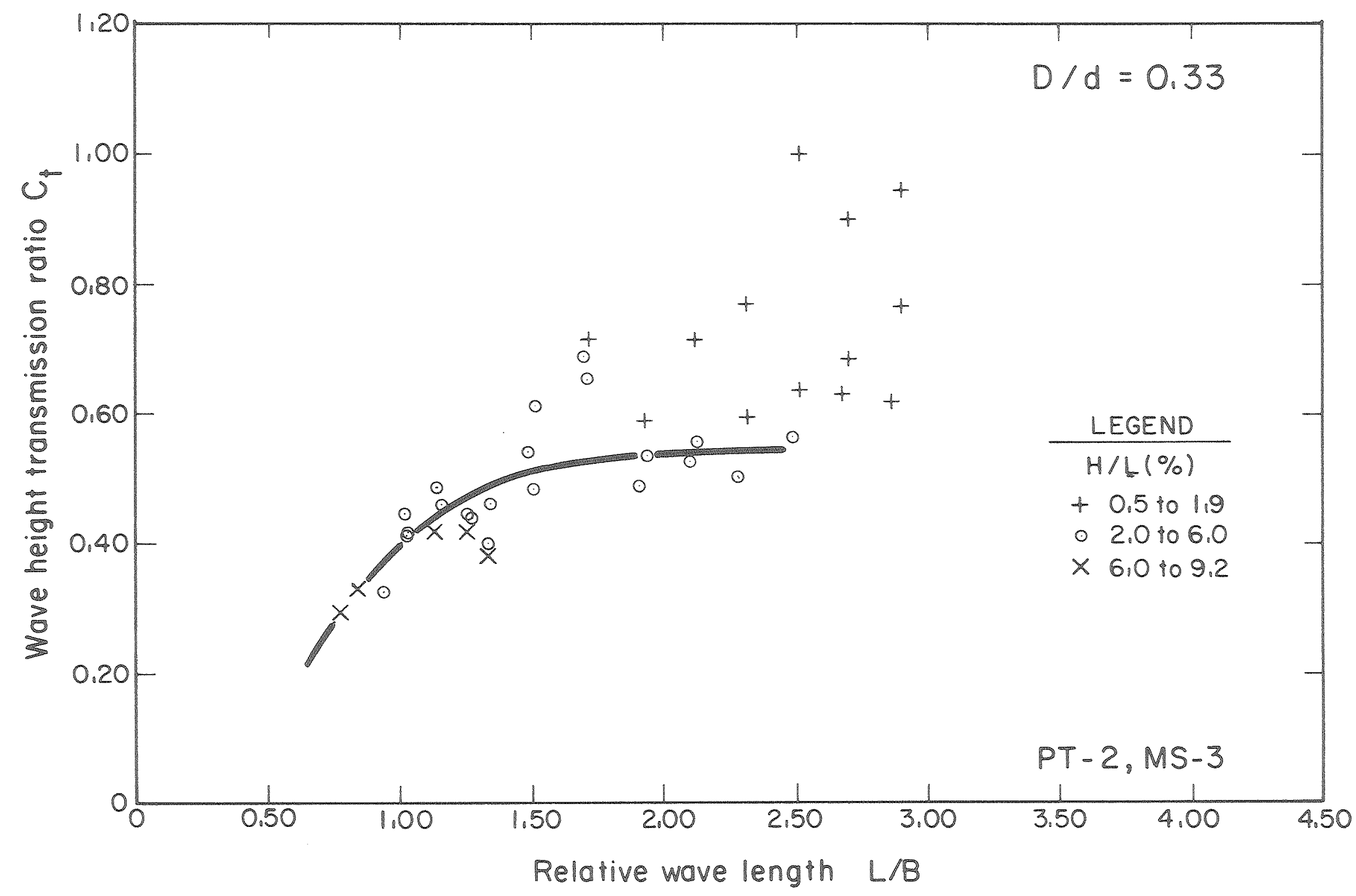

XBL 804-564

Fig. 38 Wave-Transmission Data for PT-2

Breakwater $(\mathrm{d}=2.0 \mathrm{~m})$ 


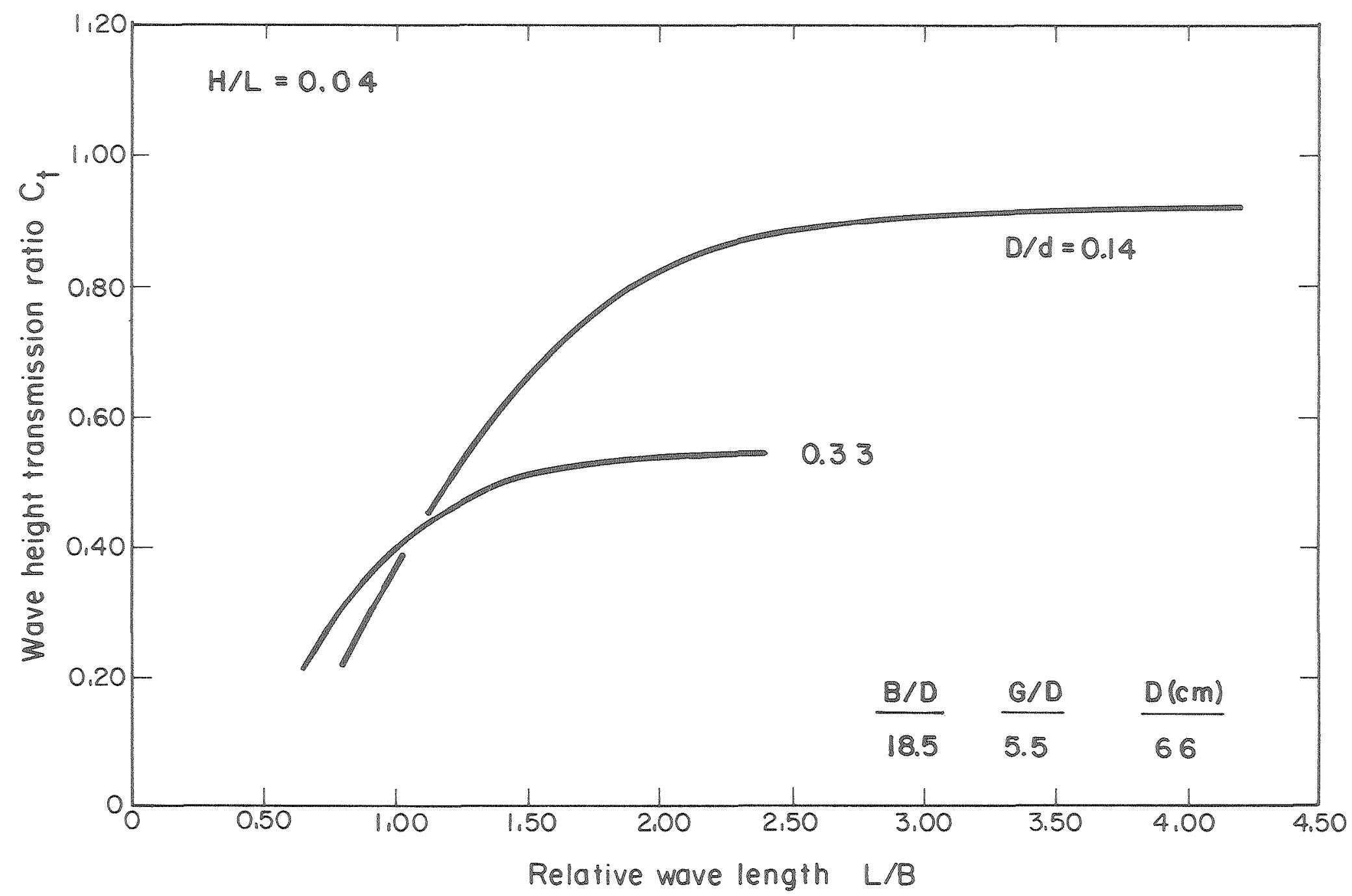

XBL $804-564 A$

Fig. 39 Wave-Transmission Design Curves

for PT-2 Breakwater 


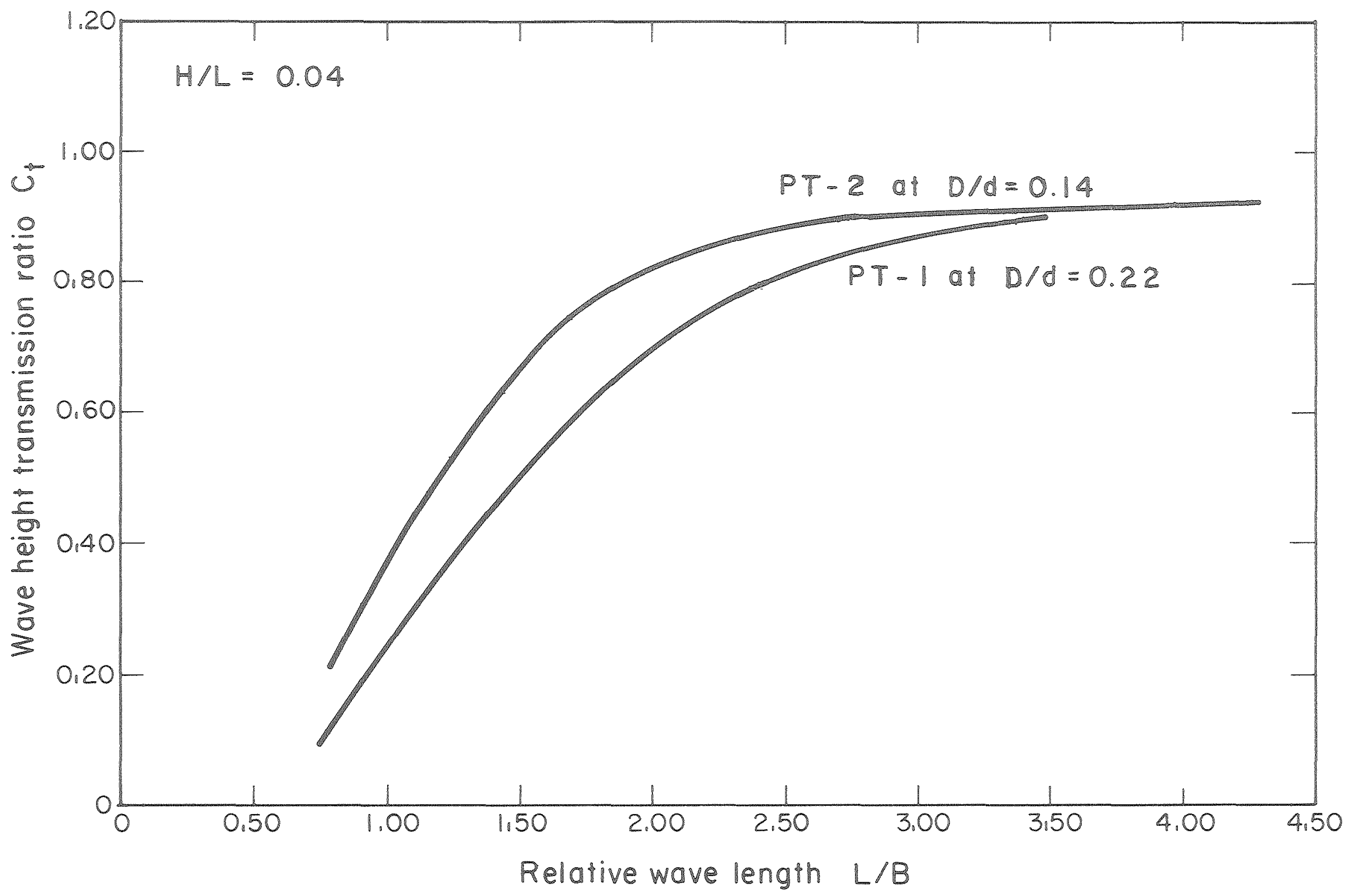

XBL $8010-12391$

Fig. 40 Comparison of $\mathrm{PT}-1$ and PT-2

Wave Attenuation $(\mathrm{d}=4.7 \mathrm{~m})$ 
c. Goodyear Breakwater. Prototype-scale wave-transmission data for the Goodyear floating tire breakwater was obtained by Giles and Sorensen in 1978, also in the large wave tank at CERC. Data for the 6-module-wide Goodyear breakwater has been plotted in Figs. 41 and 42, along with the wave-transmission curve for the PT-2 module. Both of these breakwaters are constructed from automobile tires and have a beam of $12.2 \mathrm{~m}$ ( $40 \mathrm{ft}$ ), which is equivalent to $B / D=18.5$. For the lowerwater-depth case considered in Fig. 42, it is evident that the PT-2 breakwatex is substantially more effective than a Goodyear breakwater of equal size. At the larger depth considered in Fig. 41 the PT-2 breakwater is still superior, but not as much so as at the lower depth.

From extensive smal1-scale experiments by Harms, (1979), the influence of water depth was found not to be of practical importance for the Goodyear breakwater, at least for values of $\mathrm{D} / \mathrm{d}$ less than 0.4 , although $\mathrm{C}_{t}$ clearly decreases as $\mathrm{D} / \mathrm{d}$ increases. How significant the influence of D/d is for the full-scale Goodyear breakwater (Figs. 41 and 42 ) is shown in Fig. 43 where the data for $D / d=0.16$ and 0.33 may be compared while keeping $L / B, H / L$ and $B / D$ constant: the difference in $C_{t}$ is typically less than 0.1 (the $C_{t}$-values near $L / B=2$ are probably spurious)。 Smal1-scale and prototype-scale data are therefore in agreement and the single Goodyear wave-transmission curve of Fig. 44 (Harms, 1979) may be used for most practical applications as long as D/d does not exceed 0.4; near $D / d=0.4$ the design curve will be somewhat more conservative than at lower values of $D / d$.

In Fig. 44 the performance of the PT-1 module is compared to that of a Goodyear breakwater (of equal size). It is apparent that the PT- 
Breakwater provides substantially more wave protection than the Goodyear breakwater. It should be noted that the Goodyear design curve in Fig. 44 is independent of $B / D$, having been tested over a broad range of $B / D$ during experiments at the Canada Centre for Inland Waters (Harms, 1979). A similar series of experiments for the PT-Breakwater were scheduled to commence at CCIW in September, 1980 . 


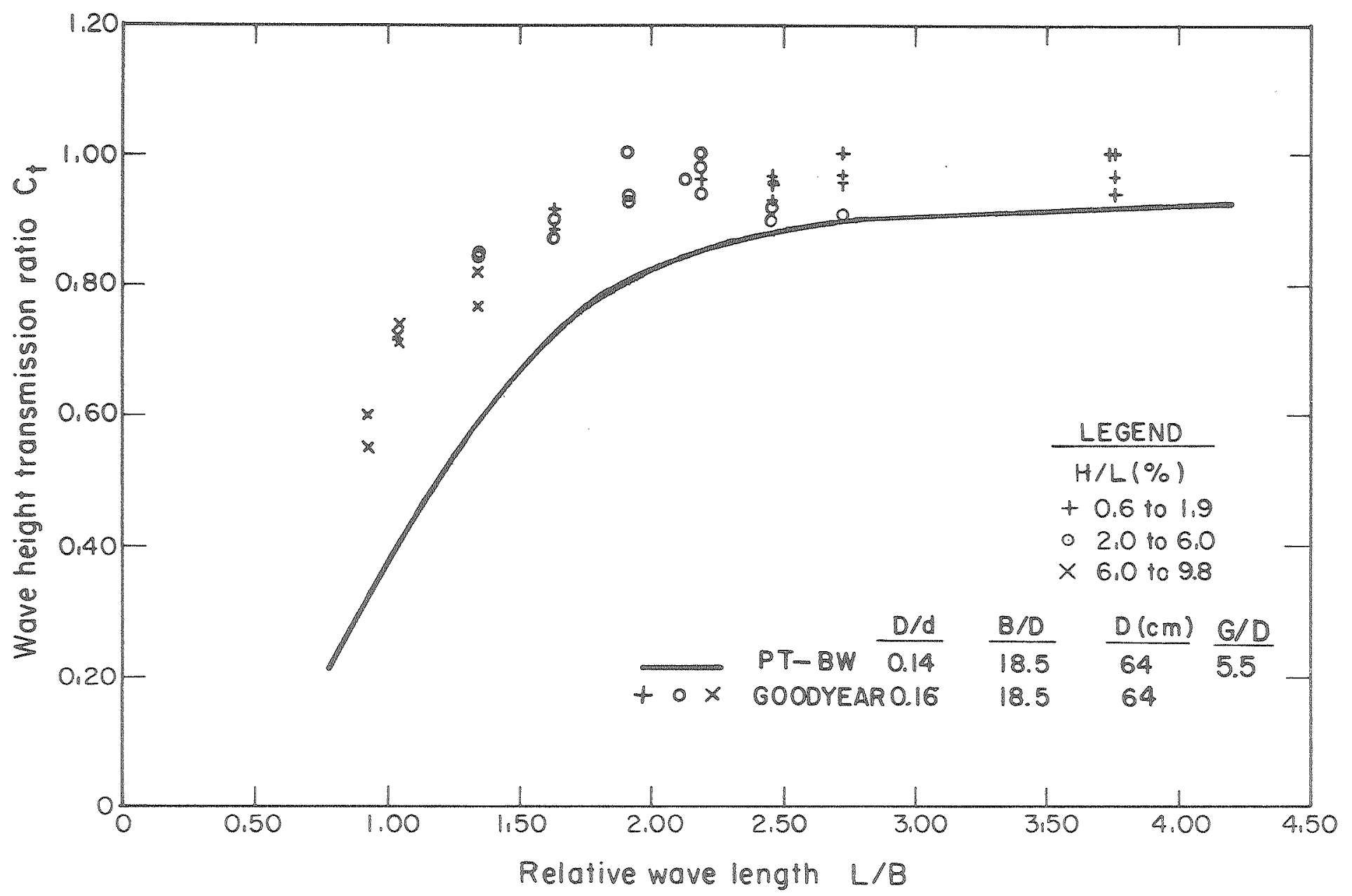

X8L $804-566 \mathrm{~A}$

Fig. 41 Comparison of Goodyear and PT-2

Wave Attenuation $(\mathrm{d}=4.7 \mathrm{~m})$ 


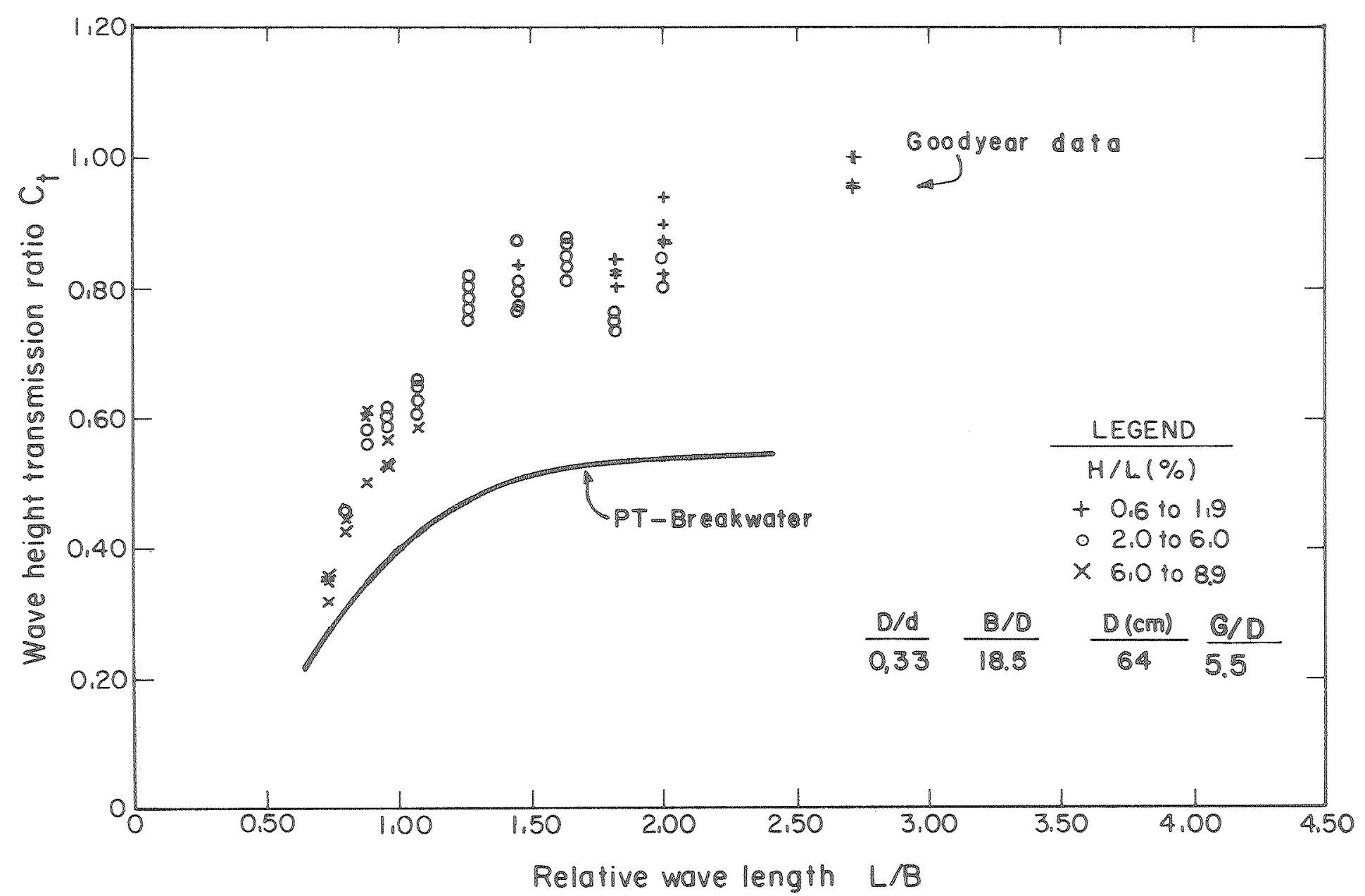

XBL $804-564 B$

Fig. 42 Comparison of Goodyear and PT-2

Wave Attenuation $(\mathrm{d}=2.0 \mathrm{~m})$ 


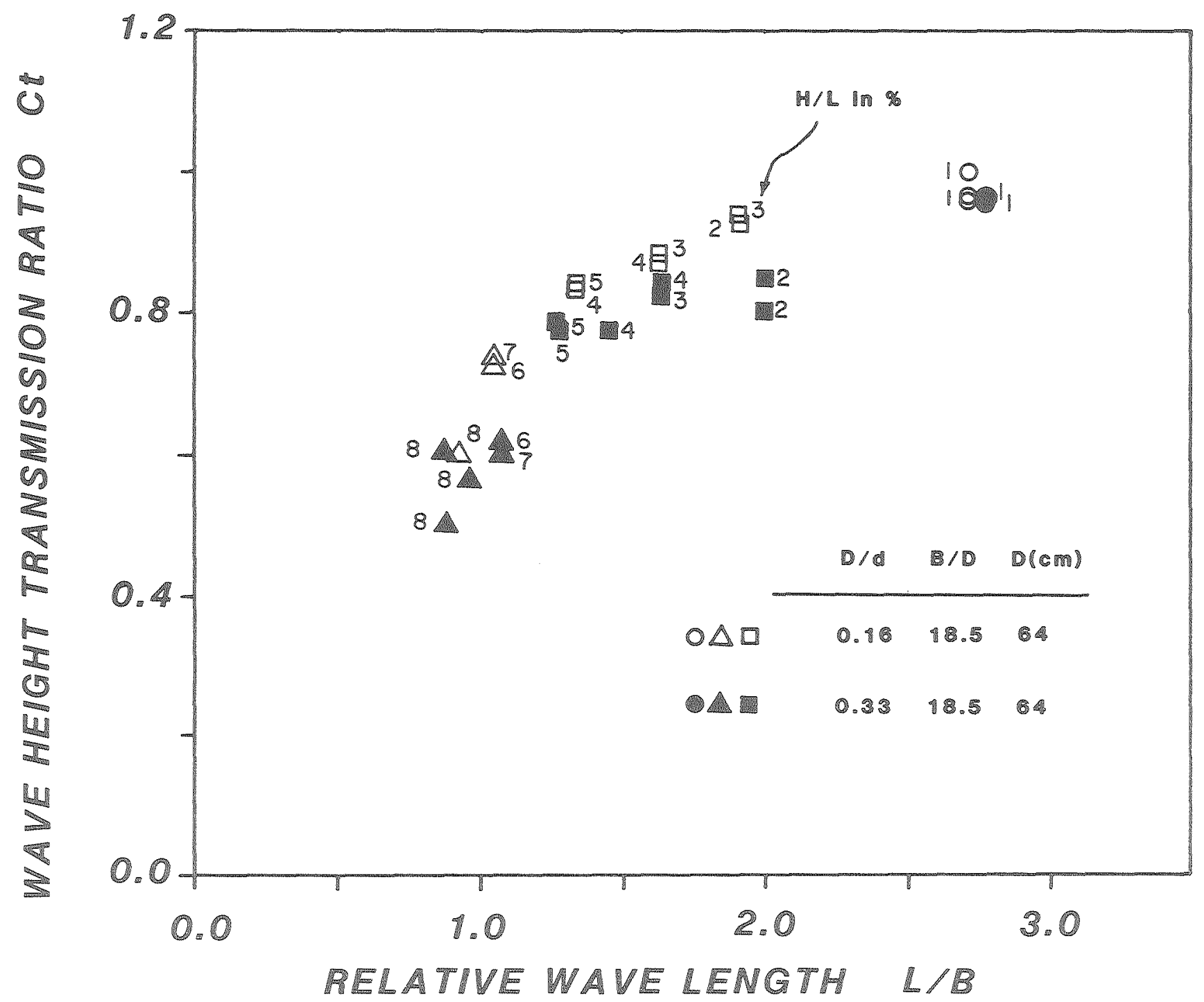

XBL $807-10698$

Fig. 43 Influence of $\mathrm{D} / \mathrm{d}$ on Goodyear Wave Attenuation 


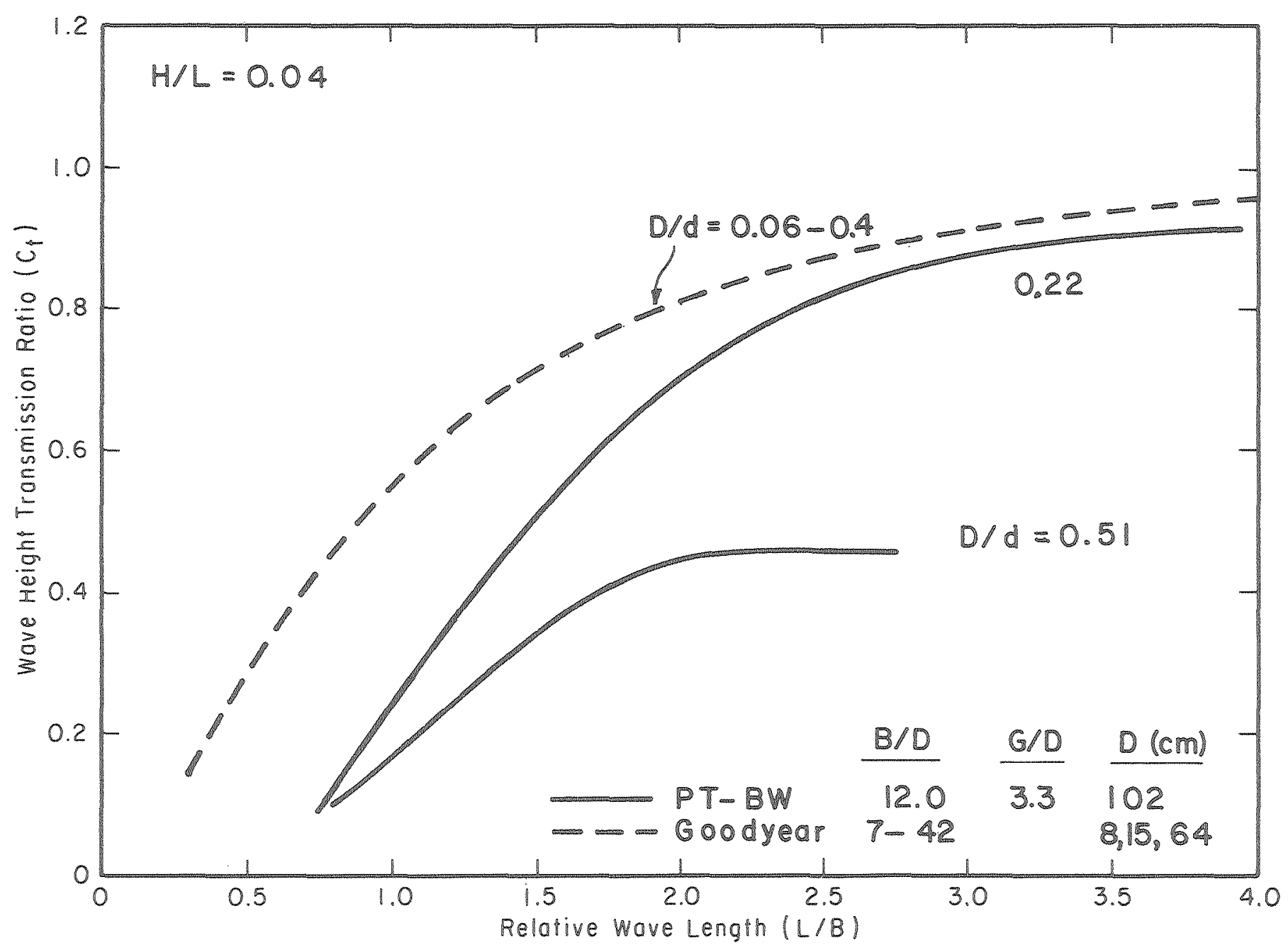

XBL $805-9634$

Fig. 44 Wave-Transmission Design Curves for Goodyear and PI-Breakwater 
2. Mooring Force Data.

a. PT-1 Breakwater This breakwater was tested most extensively in the MS-1 mooring configuration, i.e., with 6-tire mooring-force damper installed. Additional1y, at the larger water depth of $4.7 \mathrm{~m}$ (15 feet), it was also tested with the MS-2 and MS-3 mooring systems. As explained in Section III.2, the MS-2 mooring configuration was the "stiffest" tested and MS-1 the most elastic or "softest", with the elastic properties of MS-3 Iying somewhere between these.

In Figs. 45 and 46 the peak mooring force has been plotted as a function of wave height for the case of MS-1 and two water levels, $\mathrm{D} / \mathrm{d}=$ 0.51 and 0.22 . An exponential relationship between mooring force and wave height can be detected in the data, even though this information is masked at times by the relatively large scatter of data (even at fired L/B) that is common in this type of measurement. The best "by eye" fit has been drawn and indicates that at both water levels $\mathrm{F}$ is proportional to $\mathrm{H}^{3 / 2}$. For a given wave height and length, peak mooring forces are clearly higher at the lower water level. This is reflected in the value of the force coefficient $\mathrm{K}$ Iisted and defined in Table 4. The influence of $\mathrm{L} / \mathrm{B}$ is difficult to quantify from our data: an increase of $\mathrm{F}$ with $\mathrm{L} / \mathrm{B}$ appears to be indicated, particularly at $D / d=0.51$, but additional tests would have to be perfomed to define this relationship.

How the mooxing-system elasticity affects the peak mooring force is shown in Figs, 46-48. In each case the water level is fixed, only the mooxing-line flexibility was changed. A substantial increase in $F$ was noted when the 6-tire mooring-force damper was removed and replaced with a relatively inflexible section of conveyor belt, i.e., switching from 
MS-1 to MS-2. This is apparent from Fig. 47, where the MS-2 data is shown in relationship to the MS-1 curve from Fig. 46: a11 of the data lies above the MS-1 curve, with much of it very far above it. The MS-3 data and curve-through-data are shown in Fig 48. This system results in forces somewhat higher than for the MS-1 system but 1ower than the MS-2 case, the corresponding values of $k$ are given in Table 4. 
Table 4. Sumary of Mooring Force Data*

\begin{tabular}{|c|c|c|c|c|c|c|}
\hline \multirow{5}{*}{$\begin{array}{l}\text { Mooring } \\
\text { System }\end{array}$} & \multicolumn{6}{|c|}{ Force Coefficient $K$} \\
\hline & \multicolumn{2}{|c|}{$\mathrm{PT}-1$} & \multicolumn{2}{|c|}{$\mathrm{gT}-2$} & \multicolumn{2}{|c|}{ Goodyeax } \\
\hline & & $\approx \mathrm{K}$ & \multicolumn{2}{|c|}{$\frac{F}{\gamma R^{2}}=K$} & \multicolumn{2}{|c|}{$\frac{F}{\gamma \mathrm{H}^{2}}=K$} \\
\hline & \multicolumn{2}{|c|}{$D / d$} & \multicolumn{2}{|c|}{$D / d$} & \multicolumn{2}{|c|}{$D / d$} \\
\hline & 0.22 & 0.51 & 0.14 & 0.33 & 0.16 & 0.33 \\
\hline$M S-1$ & 0.28 & 0.46 & $(0.20)$ & $(0.33)$ & - & - \\
\hline$M S-2$ & 0.50 & - & - & - & - & - \\
\hline$M S-3$ & 0.37 & - & 0.27 & 0.44 & - & - \\
\hline Goodyeax & - & - & - & $=$ & 0.14 & 0.11 \\
\hline
\end{tabular}

*For design purposes it is suggested that $F$ be Increased by $100 \mathrm{~kg} / \mathrm{m}$ 。

( ) Estimated values. 


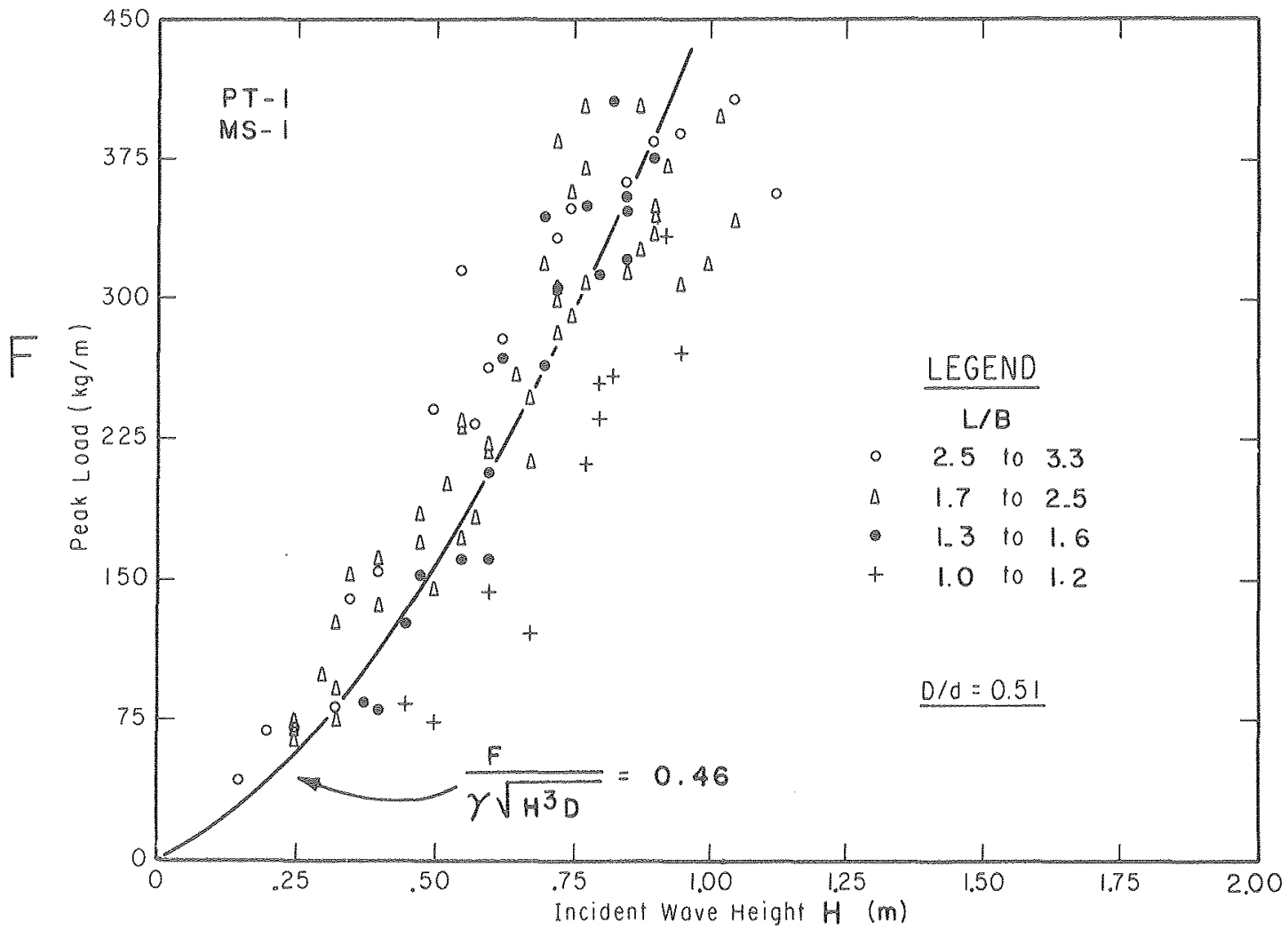

XBL 804-9301A

Fig. 45 PT-1 Peak-Mooring-Force Data $(\mathrm{MS}-1, \mathrm{~d}=2.0 \mathrm{~m})$ 


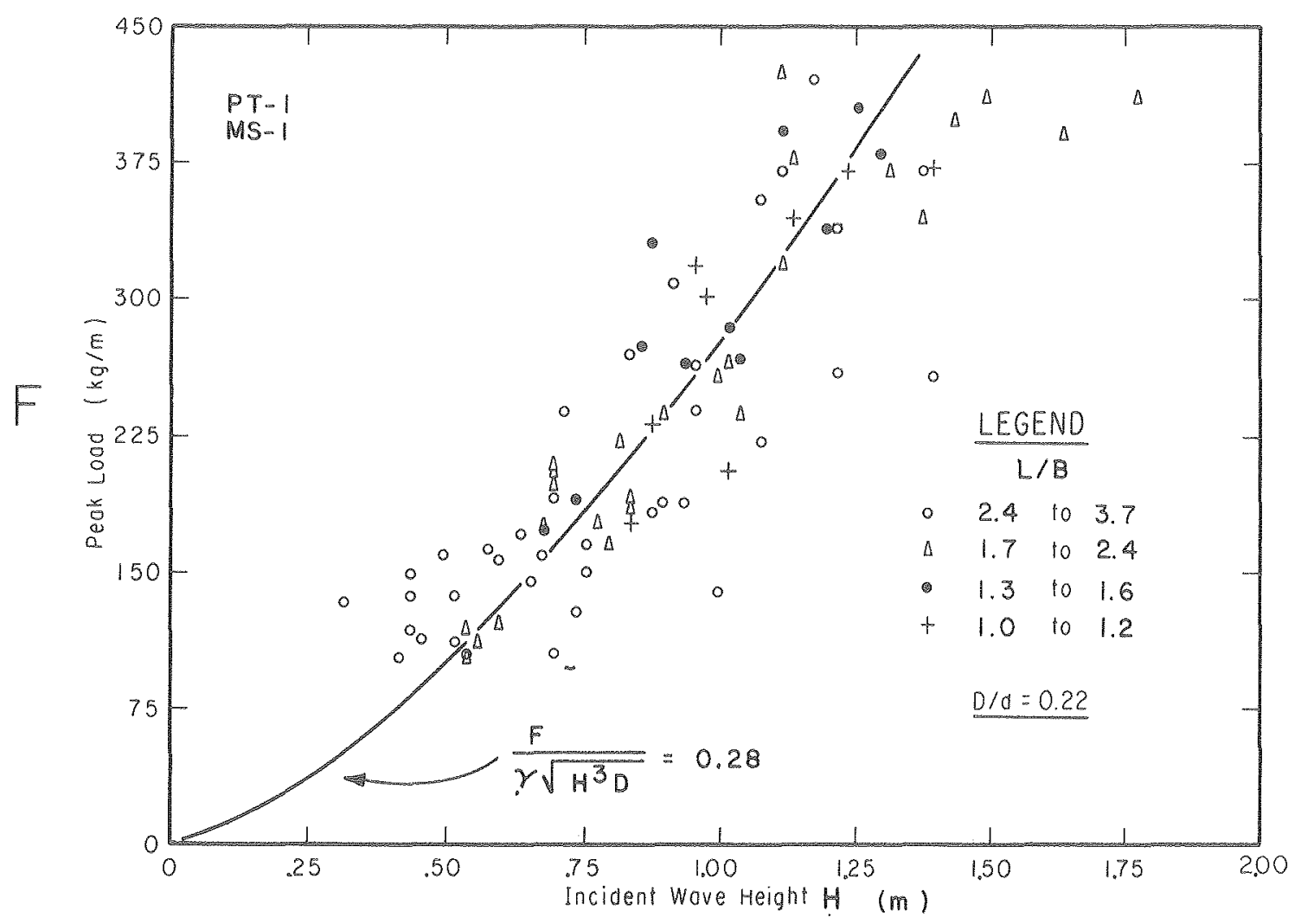

$X B L \quad 804-9300 A$

Fig. 46 PT-1 Peak-Mooring-Force Data $(\mathrm{MS}-1, \mathrm{~d}=4.7 \mathrm{~m})$ 


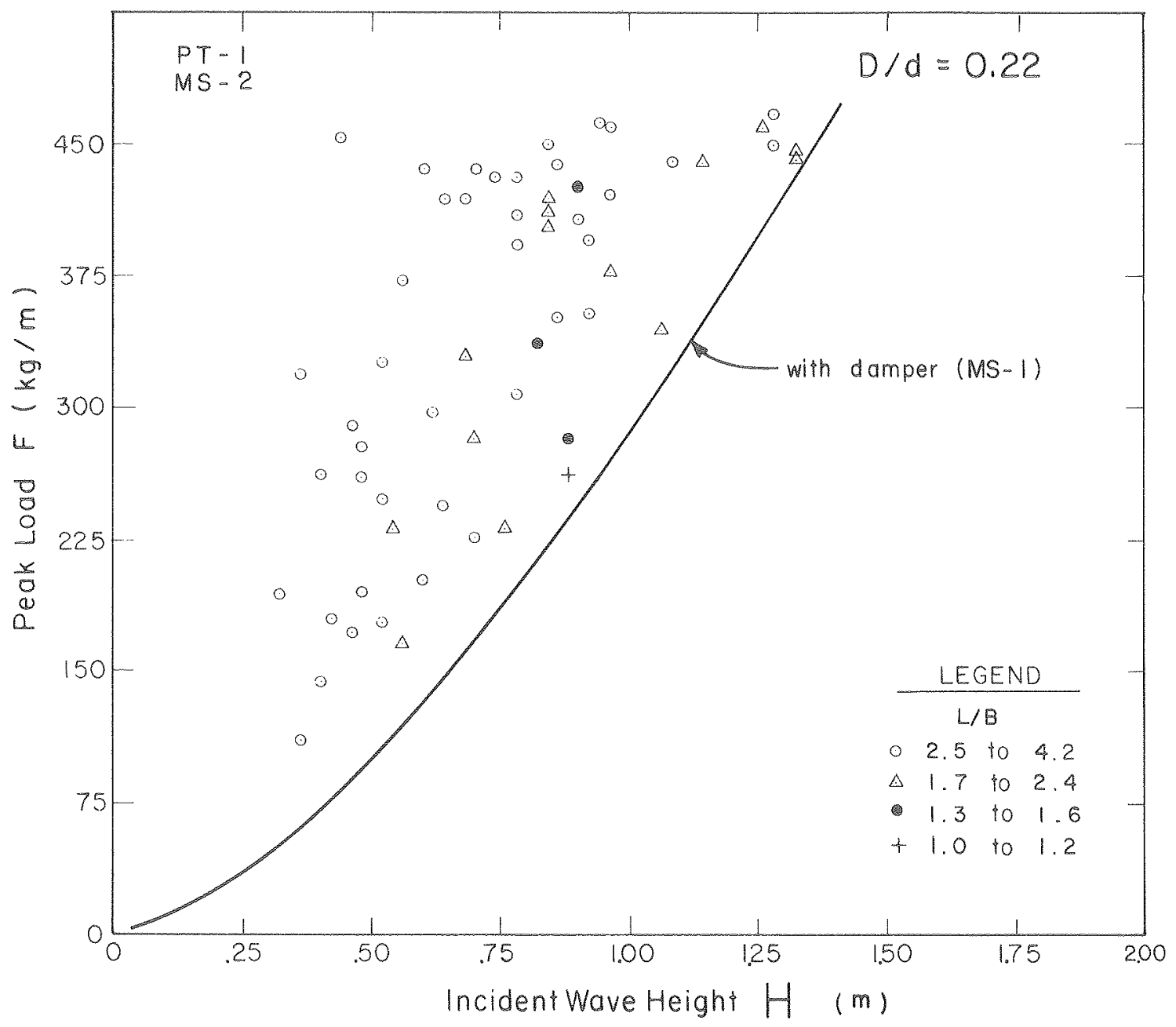

XBL $804-9302$ A

Fig. 47 Effect of Mooring-System Compliance on $\mathrm{F}(\mathrm{MS}-1$ and $\mathrm{MS}-2, \mathrm{~d}=4.7 \mathrm{~m})$ 


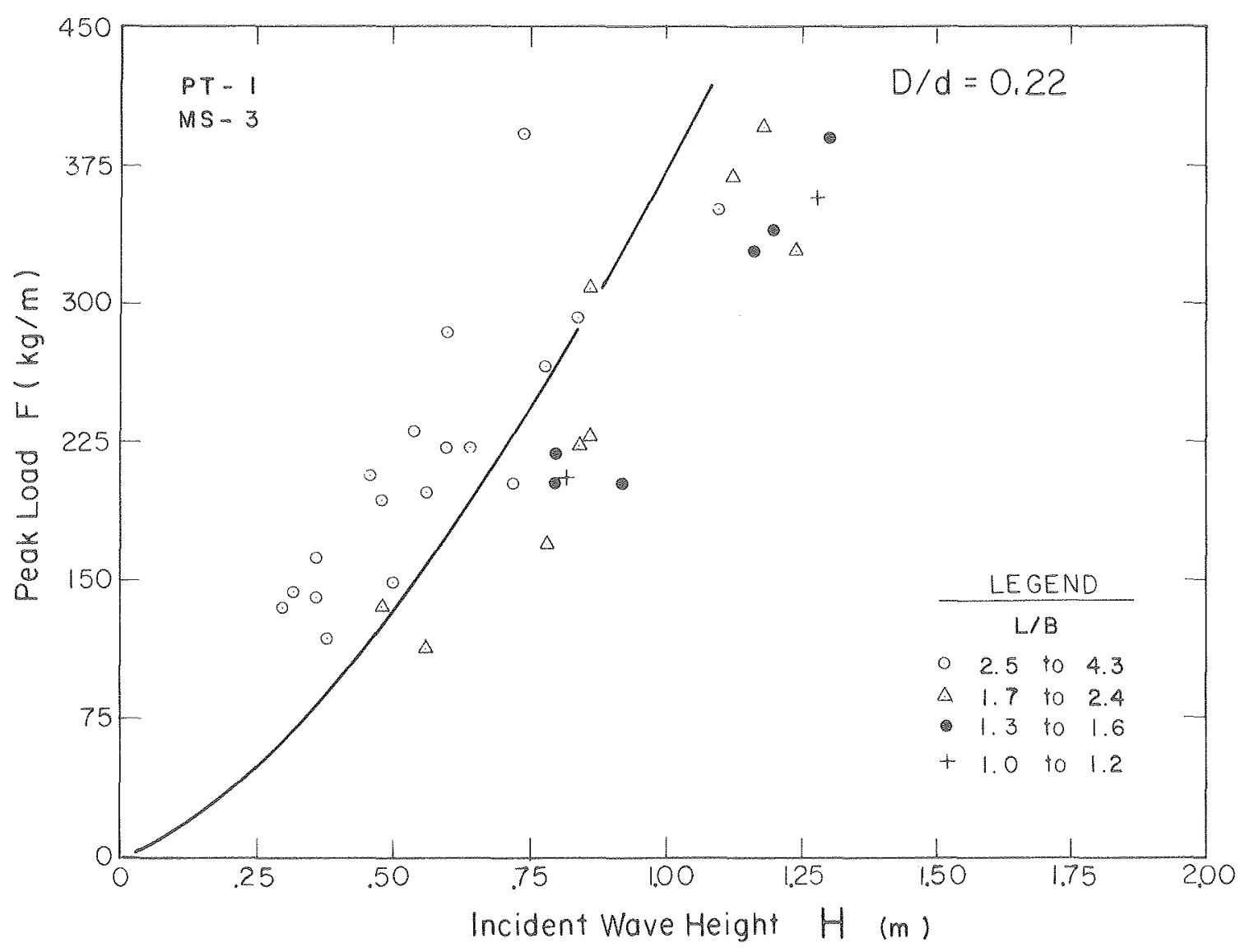

XBL $804-570$

Fig. 48 PT-1 Peak-Mooring-Force Data $(\mathrm{MS}-3, \mathrm{~d}=4.7 \mathrm{~m})$ 
b. PT- 2 Breakwater. The PT-2 module was tested only in the MS-3 mooxing configuration; the results are shown in Figs. 49 and 50. Again as for $\mathrm{PT}-1$, the force is proportional to $\mathrm{H}^{\mathrm{n}}$, but for $\mathrm{PT}-2$ the appropriate exponent is 2 , not $3 / 2$ as it was for $\mathrm{PT}-1$. The curves for $\mathrm{N}=2$ fitted by eye are shom in Figs. 49 and 50; the corresponding values of $K$ are listed in Table 4. Although PT-2 was tested with MS-3, and not the preferred MS-1 mooring system, the effect of a change from MS-3 to MS-1 may be estimated by assuming that the ratio of respective forces is the same as for the PT-1 module (for which such data exists and is conveniently summarized in Table 4). For PT-1 we note:

$$
\frac{\mathrm{K}(\mathrm{MS}-1)}{\mathrm{K}(\mathrm{MS}-3)}=\frac{280}{370}=0.76
$$

Assuming that this ratio holds for the PT-2 module as well, one obtains the estimated MS-1 values shown in parenthesis in Table 4. Although peak mooring forces for the PT-1 module are higher than for the PT-2 module for the same wave height and water depth, it should be noted that the transmitted wave is also smaller in the case of $\mathrm{PT}-1$. 


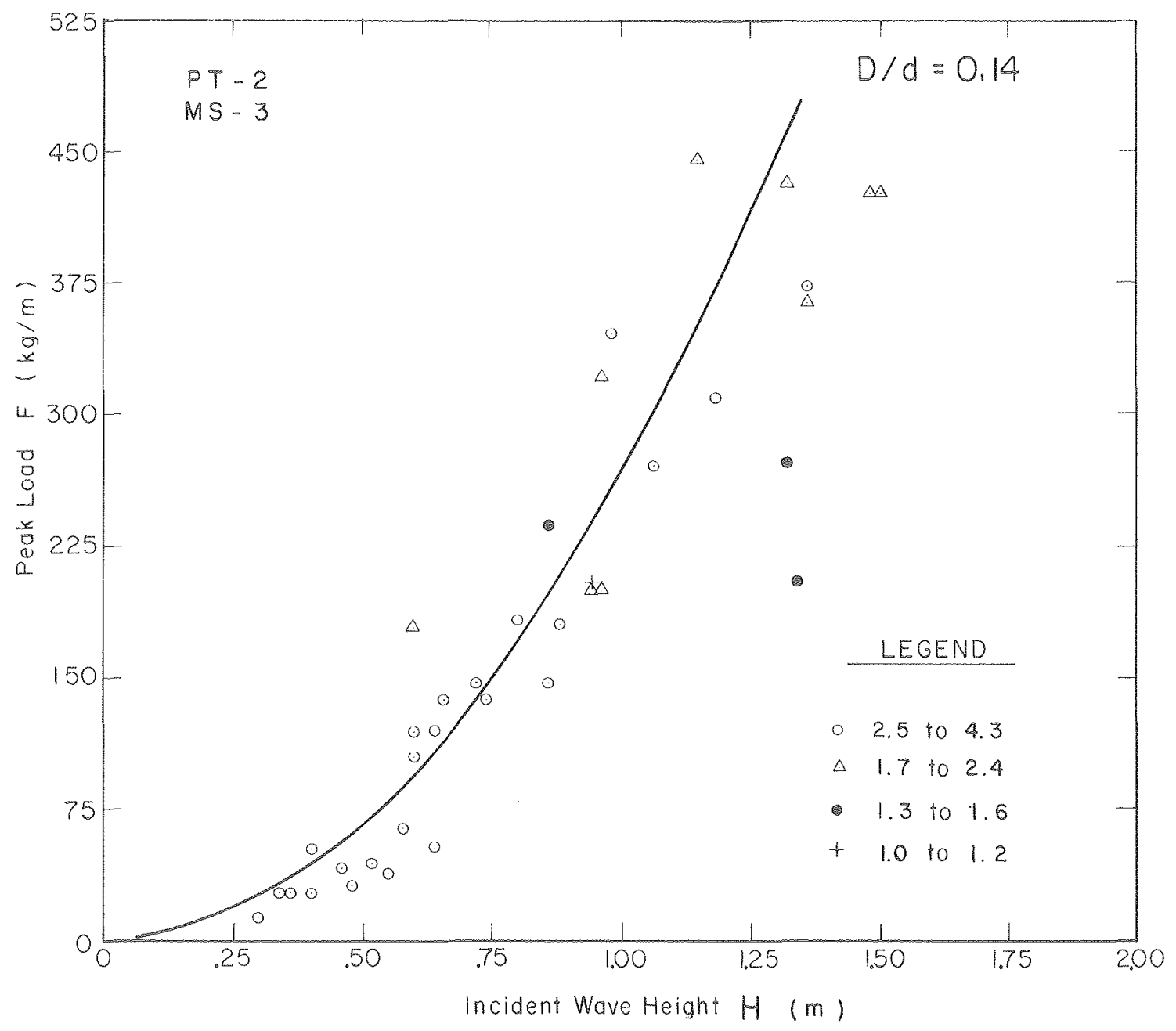

XBL $804-557$

Fig. 49 PT-2 Peak-Mooring-Force Data $(\mathrm{MS}-3, \mathrm{~d}=4.7 \mathrm{~m})$ 


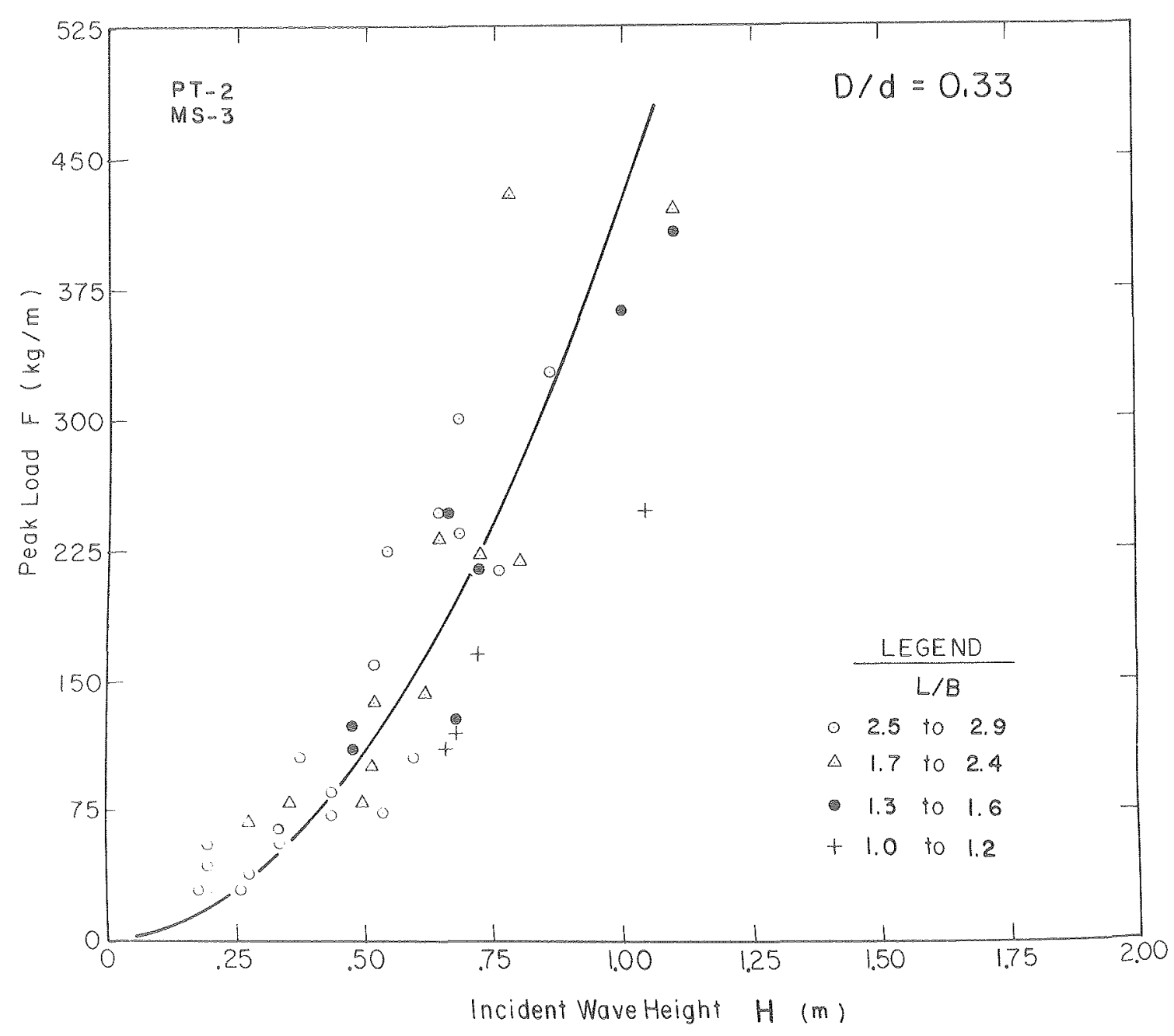

XBL $804-5668$

Fig. 50 PT-2 Peak-Mooring-Force Data $(M S-3, d=2.0 m)$ 
c. Goodyear Breakwater. The Goodyear-module tests by Giles and Sorensen also included evaluation of breakwater mooring loads. Data from those experiments has been plotted in Figs. 51 and 52 for the case corresponding most nearly to our conditions, i.e., for the 6-module-beam Goodyear breakwater that is also $12.2 \mathrm{~m}$ ( $40 \mathrm{feet}$ ) wide. The curves shown in Figs. 51 and 52 indicate that $F$ is proportional to $\mathrm{H}^{2}$ : the corresponding force coefficient $\mathrm{K}$ is listed in Table 4. The hyperbolic relationship between $F$ and $H$ evidently describes the data very adequately.

For a given wave height and length, mooring forces on the Goodyear breakwater are clearly much lower than for a PT-Breakwater of equal size. This finding is attributed principally to three factors whose relative importance cannot be quantified at this time:

a) The transmitted wave for the PT-Breakwater is smaller than that for the Goodyear breakwater, i.e., different levels of energy dissipation occur on each structure (wave breaking and impact, etc.).

b) Different mooring systems were utilized. The importance of this has already been demonstrated with regard to the PT-1 breakwater, see Table 4 .

c) The Goodyear breakwater stretches extensively under load, being very pliable throughout. This influences, perhaps dominates, mooxing dynamics and load-transmission characteristics. 


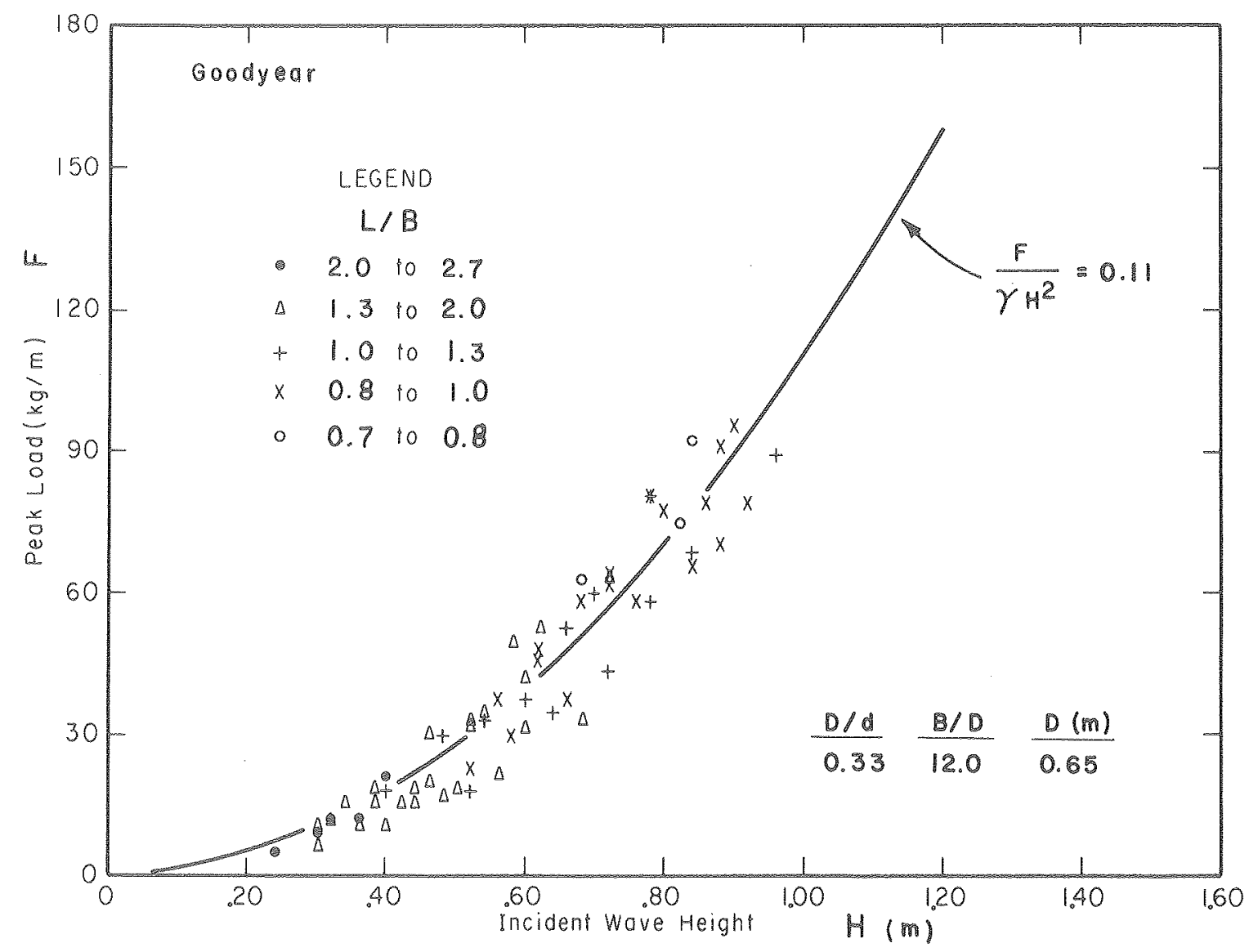

XBL $805-9705$

Fig. 51 Goodyear Peak-Mooring-Force Data

(ref. 3, $d=2.0 \mathrm{~m}$ ) 


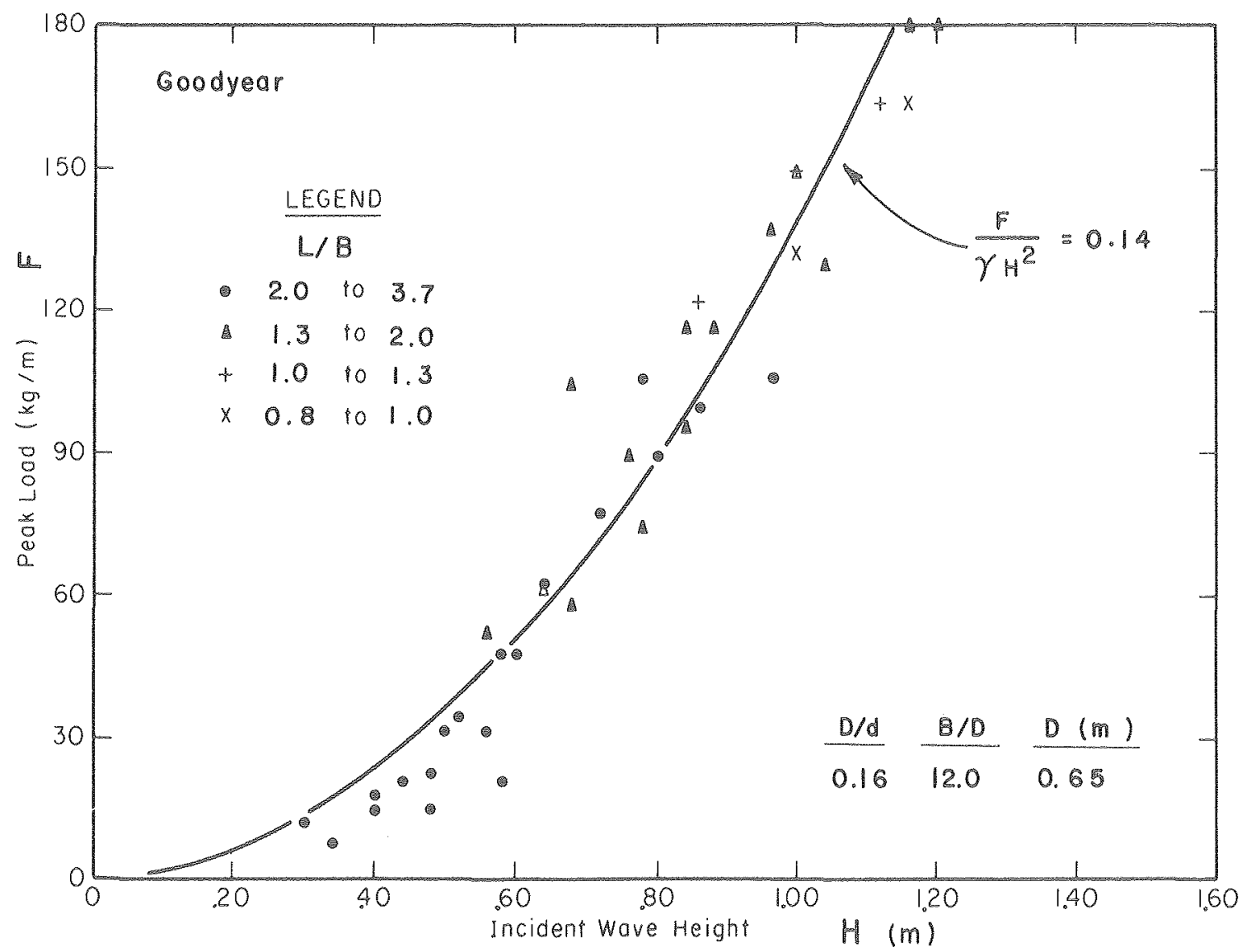

XBL 805-9706

Fig. 52 Goodyear Peak-Mooring-Force Data (ref. 3, d=4.0m) 
VI. SUMMARY AND CONCLUSTONS

Two prototype-scale PT-Breakwaters were tested in CERC's large wave tank using regular waves: the PT-1 module composed of truck tires and steel pipes in waves up to $1.8 \mathrm{~m}(5.8 \mathrm{ft})$ in height, and the smaller PT-2 module constructed from automobile tires and telephone poles, in waves up to $1.5 \mathrm{~m}(4.9 \mathrm{ft})$ in height. Wave-transmission and mooringload characteristics were established, based upon data from 402 separate runs in which incident and transmitted wave heights were recorded along with tension in the seaward mooring line.

In the course of the investigation, it became increasingly evident (during construction, crane operations and early experiments) that the PT-1 breakwater was inherenty rugged and could potentially function and survive under more severe wave conditions than those normally considered acceptable for floating tire breakwaters. For this reason, the PT-1 module was emphasized in the test program. Although structural failures were not experienced on either the PT-1 or the PT-2 breakwaters throughout the many weeks of testing, and post-test inspections did not reveal areas of imminent failure or excessive wear, it became clear that the PT-2 module is inherently more pliable than PT-1 because it is composed of automobile tires, not truck tires. Consequently, as waves break over the structure, greater compression and displacement of leading-edge tires occurs on the $\mathrm{PT}-2$ module than is true for the $\mathrm{PT}-1$ breakwater under the same conditions. Although PT-Breakwaters were designed to be pliable, with relative motion between individual components, under severe wave-induced loads the observed compression of leading-edge tires on $\mathrm{PT}-2$ was felt to be excessive for continuous 
operation. It is therefore suggested that the PT-2 breakwater be $1 \mathrm{im}^{-}$ ited to sites with significant wave heights of less than $0.9 \mathrm{~m}(3 \mathrm{ft})$; this condition is considered to be equally appropriate for Goodyear or Wave-Maze floating tire breakwaters that are composed of automobile tires as well. The value of $0.9 \mathrm{~m}(3 \mathrm{ft}$ ) was chosen by the researchers as representing the best, though inherently somewhat subjective estimate for the maximum acceptable significant wave height; it is based upon extensive laboratory observations and experience with a variety of field installations. The above rule is considered to be of practical importance because it reminds the designer that the environment is hostile and that PT-Breakwaters constructed from automobile tires are inherenty less rugged than those composed of truck tires, and both have survival Iimitations 。

The wave-attenuation performance of PT-Breakwaters improves as either wave length or water depth decrease, or the wave steepness increases (i.e. $C_{t}$ increases with $I / B$ and decreases with $D / d$ or $H / L$ ). The shelter afforded by a particular PT-Breakwater is strongly dependent upon the incident wave length: very substantial protection is provided from waves that are shorter than the breakwater is wide (i.e. $L<B$ ), but very little from waves longer than 3B. As the water depth decreases, the wave-attenuation performance improves: a breakwater that provides inadequate shelter at high tide may therefore be satisfactory at low tide. Wave attenuation generally improves with increasing wave steepness, especially for relatively long waves in shallow water (say $\mathrm{t}$ $>3 \mathrm{~B}$ and $\mathrm{d}>3 \mathrm{D})$. This behavior is atcributed principally to the inherent instability of water waves, which increases with wave steepness and, for waves near the breaking limit, is so great that only a small 
perturbation is required to "trigger" the breaking process. For very steep waves, breaking was observed to start just seaward of the breakwater, with large amounts of energy being dissipated as the wave rolled and surged over the breakwater. The wave-attenuation perfomance of $\mathrm{PT}-1$ was found to be superior to that of $\mathrm{PI}-2$ and the Goodyear breakwater: for $L / B=1$ (and deep water with $d>3 D$ and $H / L \simeq 0.04$ ), for example, the wave-height transmission ratio is approximately $C_{t}=0.6,0.4$ and 0.2 for the Goodyear, $\mathrm{PT}-2$ and $\mathrm{PT}-1$ breakwaters, respectively. Wave-transmission curves given in this report should not be used to design breakwaters that are less than $9 \mathrm{~m}$ (30 ft) or more than $15 \mathrm{~m}$ (50 ft) wide.

For a given breakwater, the peak mooring force $F$ (on the seaward mooring line, per unit length of breakwater) was found to depend primarily on the wave height $H$ and water depth $d$, with wave length $L$ apparently only of secondary importance. For the conditions investigated, Fincreases approximately with the square of the wave height; more specifically: $\mathrm{F} \propto \mathrm{H}^{\mathrm{n}}$ where $\mathrm{n}=1.5,2$ and 2 for the PT-1, $\mathrm{PT}-2$ and Goodyear breakwaters, respectively. For design purposes, and until results from ongoing experiments become available, it is suggested that the following formula be used to calculate anchor-requirements for breakwaters that range in width from 9 to 15 meters $(30-50$ ft):

$$
F=100\left(1+10 \mathrm{KH}^{\mathrm{n}}\right)
$$

where

$$
\begin{aligned}
& \mathrm{H}=\text { wave height in meters }(\mathrm{m}) \\
& \mathrm{F}=\text { restraining force }(\mathrm{kg} / \mathrm{m}) \text { to be provided by the } \\
& \text { anchor system for each meter of breakwater length, }
\end{aligned}
$$


$\mathrm{n}=3 / 2$ for the PT- 1 breakwater,

$\mathrm{n}=2$ for PT -2 and Goodyear breakwaters, and

$K=$ force coefficient from Table 4. 
Literature Cited

1. Candle, R.D., "Scrap Tire Shore Protection Structures" Engineering Research Department, Goodyear Tire and Rubber Co., Akron, Ohio, 1976.

2. Davis, A.P., Jr., "Evaluation of Tying Matexials for Floating Tixe Breakwaters," Marine Technical Report No. 54, University of Rhode Island, Kingston, R.I., April 1977.

3. Giles, M.L. and Sorenson, R.M., "Prototype Scale Mooring Load and Transmission Tests for a Floating Tire Breakwater", Technical Paper No. 78-3. U.S. Army Corps of Engineers, Coastal Engineering Research Center, Fort Belvoir, Virginia, April 1978.

4. Harms, V.W., "Design Criteria for Floating Tire Breakwaters", Proceedings, ASCE Journal of the Waterway, Port, Coastal and Ocean Division, Vol. 105, No. WW2, pp.149-170, March 1979.

5. Harms, V.W., "Data and Procedures for the Design of Floating Tire Breakwaters", Dept. of Civil Engineering, State University of New York, Buffalo, WREE Report No.7901, March 1979.

6. Harms, V.W. and Bender, T.J., "Preliminary Report on the Application of Floating Tire Breakwater Design Data", Water Resources \& Environmental Research Report No. 78-1, Dept. of Civil Engineering, State University of New York at Buffalo, April 1978. 
7. Kame1, A.M., and Davidson, D.D., Hydraulic Characteristics of Mobile Breakwaters Composed of Tires or Spheres", Technical Report No. H-68-2, United States Army Engineer Waterways Experiment Station, Vicksburg, Miss., 1968.

8. Kowalski, To, "Scrap Tire Floating Breakwaters," Marine Technical Report Series No. 24, 1974 Floating Breakwater Conference Papers, University of Rhode Island, Kingston, R.I., Apr., 1974. pp. 233-246.

9. Stitt, R.L., "Wave-Maze Floating Breakwater", Brochure, 10732 Freer St., Temple City, Calif., 1963 (revised 1977)。 
$-104-$

APPENDTX A 

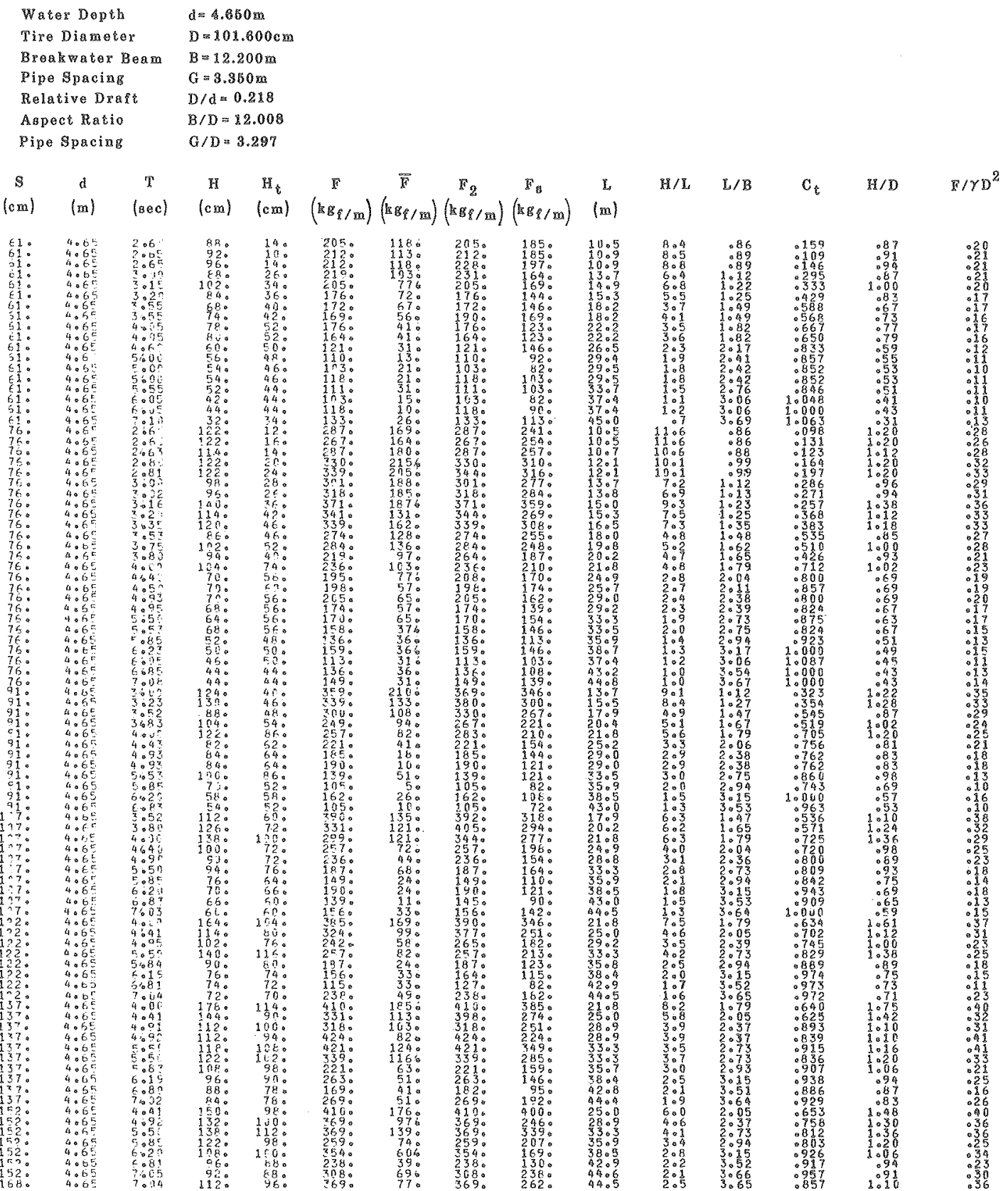
PT 1 BREAKWATER WITH MOORING TYPE I

Table A-2

$\begin{array}{ll}\text { Water Depth } & d=2.000 \mathrm{~m} \\ \text { Tire Diameter } & D=101.600 \mathrm{em} \\ \text { Breakater Beam } & B=12.200 \mathrm{~m} \\ \text { Pipe Spacing } & \mathrm{G}=3.350 \mathrm{~m} \\ \text { Relative Drafr } & D / d=0.608 \\ \text { Aapece Ratio } & B / D=12.008 \\ \text { Pipe Spacing } & G / D=8.287\end{array}$

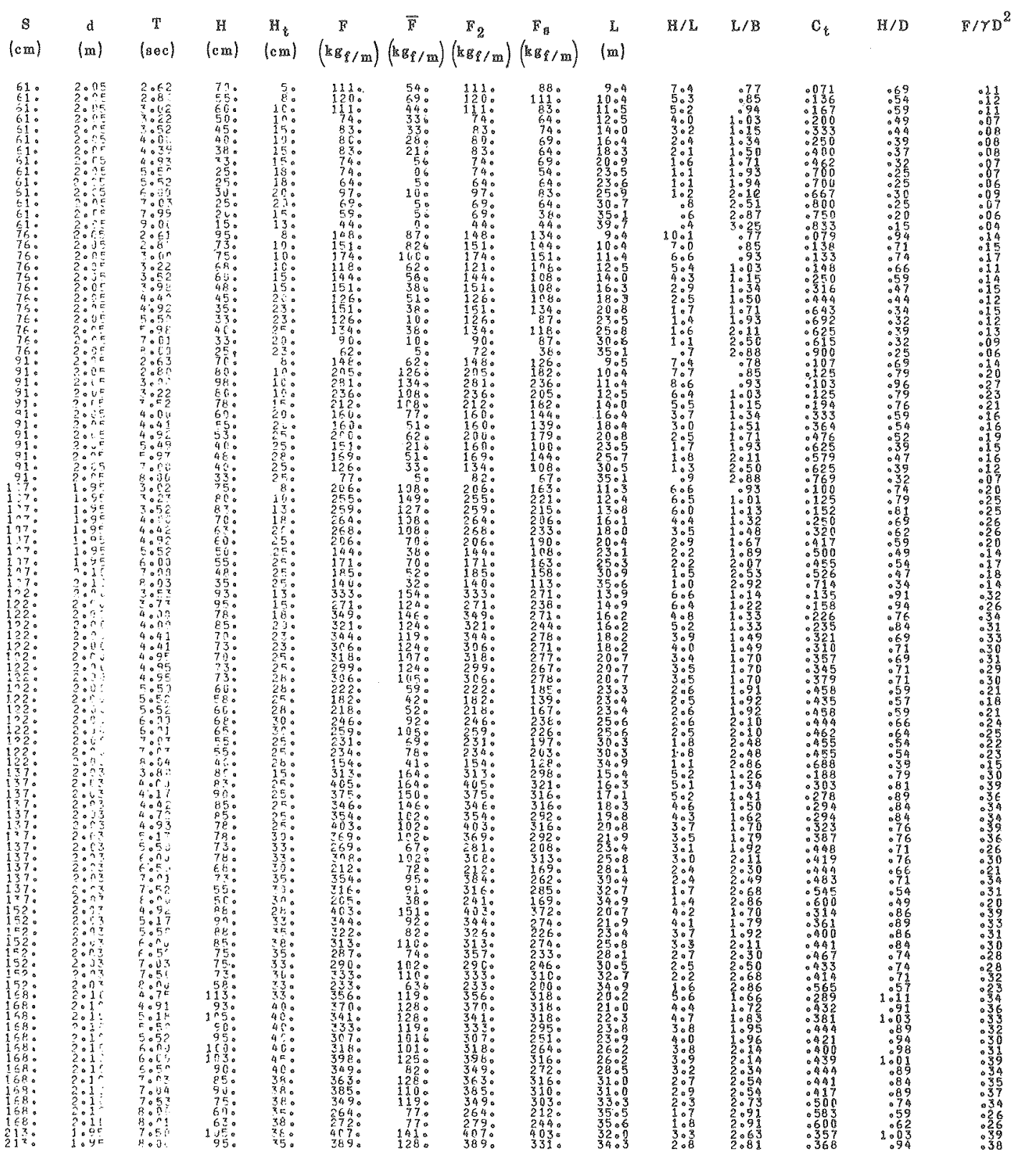


Water Dopth

Tire Diameter

Bred

Pipe Specing

Relative Drar

Aspect $\mathbb{R a t i o}$

$\mathbb{S}$ d

$1 D=3.207$

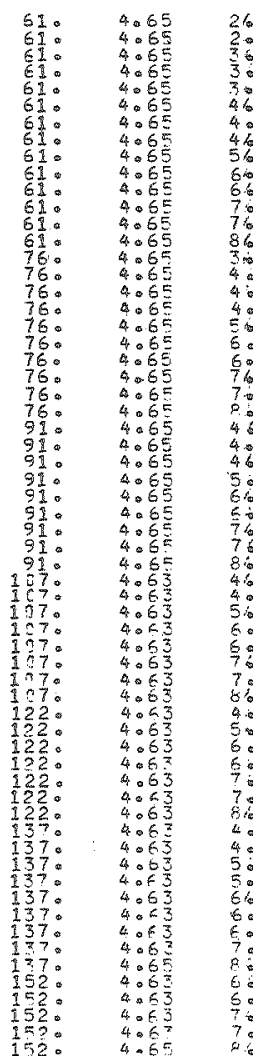

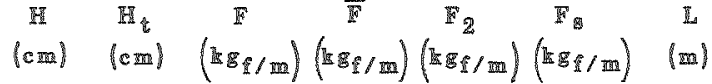

HII I

$\mathbb{L} / \mathbb{B}$

$\mathbb{C}_{\text {t }}$

理/D

$\mathbb{F} / Y \mathbb{D}^{2}$

(sec) (a

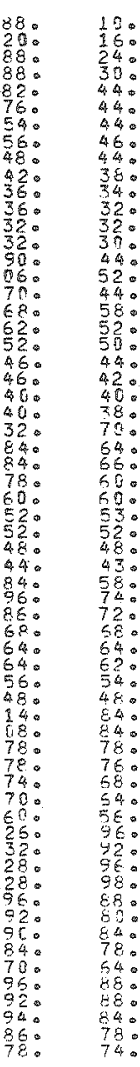
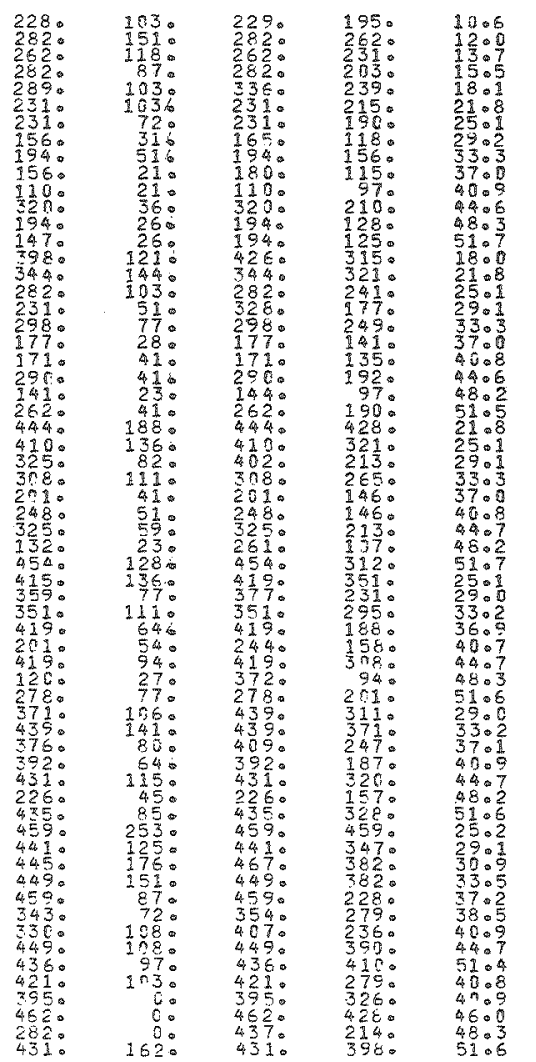

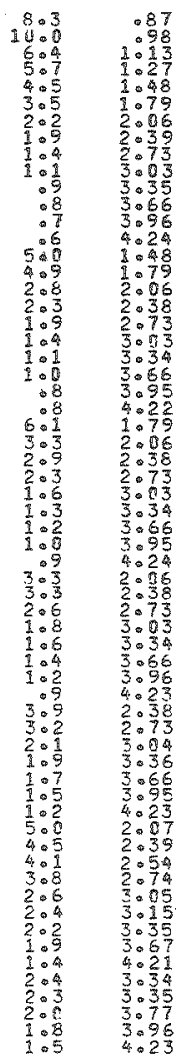

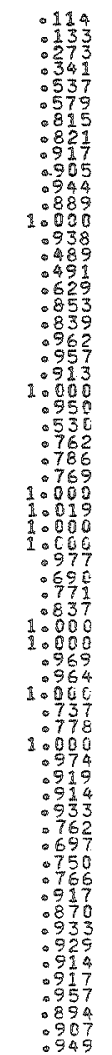

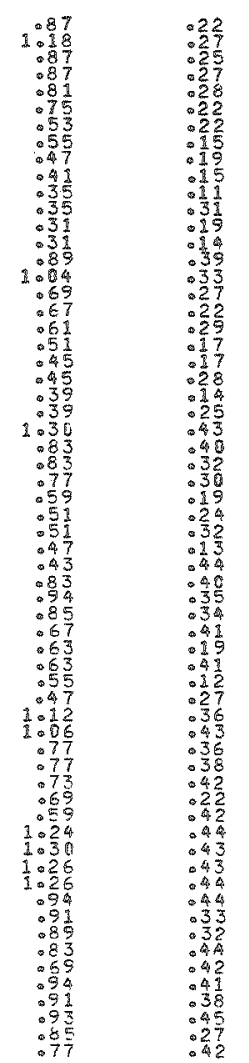


PT-I BREAKWATER WITH MOORINC TYPE 3

Table $A$
Weter Depth
di $=4.640 \mathrm{~m}$
Tire Diameter
$=101.600 \mathrm{~cm}$
Breanater Bew
$B=12.200 \mathrm{~m}$
Tipe Spring
$G=\$ 3.350 \mathrm{~m}$
Reldive Drat
$=0.219$
Aspect $\mathbb{R}$ atio
$B / D=12.008$
Pipe Spacing
$G / D=3.297$

\begin{tabular}{|c|c|c|c|c|c|c|c|c|c|c|c|c|c|c|}
\hline $\begin{array}{c}\mathbb{S} \\
(\mathrm{cm})\end{array}$ & $\stackrel{d}{m}$ & $\begin{array}{c}\mathrm{T} \\
(\mathrm{sec})\end{array}$ & $\begin{array}{c}\mathrm{H} \\
(\mathrm{cm})\end{array}$ & $\begin{array}{l}\mathbb{H}_{\hat{H}} \\
(\mathrm{~cm})\end{array}$ & $\begin{array}{c}\mathbb{F} \\
\left(\mathrm{kg}_{\mathrm{g}} / \mathrm{fm}\right)\end{array}$ & 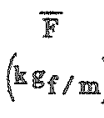 & $\begin{array}{c}F_{2} \\
\left(k g_{p} / m_{m}\right.\end{array}$ & 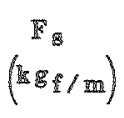 & $\stackrel{\mathbb{L}}{\mid \mathrm{mol}\}}$ & $\mathbb{H} / \mathbb{I}$ & $\mathbb{L} / \mathbb{B}$ & $\mathbb{C}_{t}$ & $\mathbb{H} / \mathbb{D}$ & $\mathbb{D} / \gamma \mathbb{D}^{2}$ \\
\hline 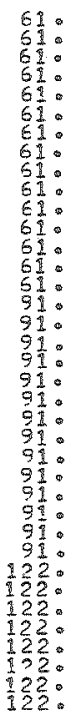 & 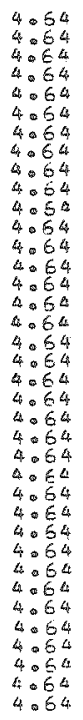 & 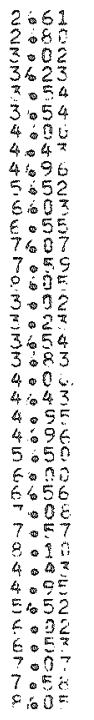 & 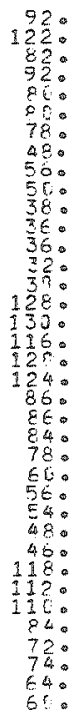 & 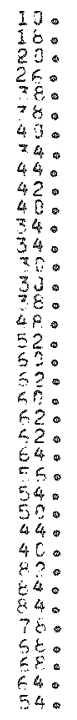 & 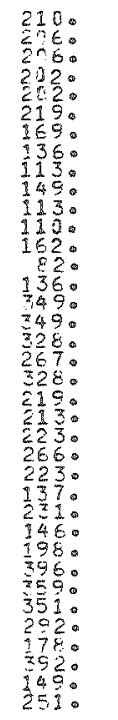 & 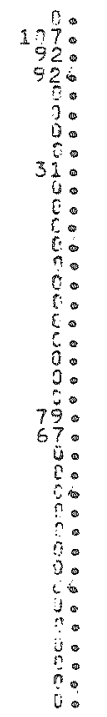 & 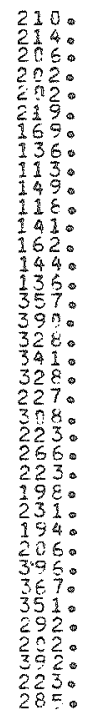 & 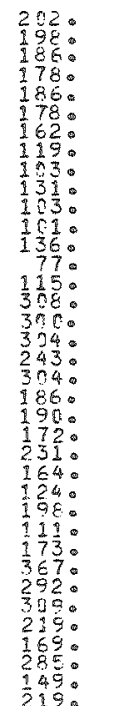 & 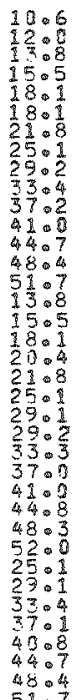 & 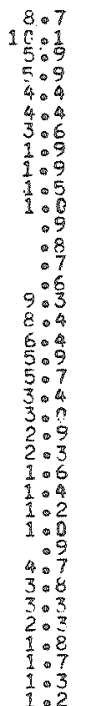 & 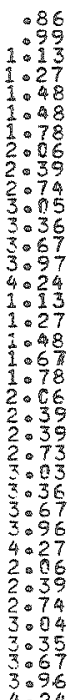 & 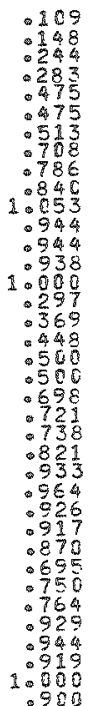 & 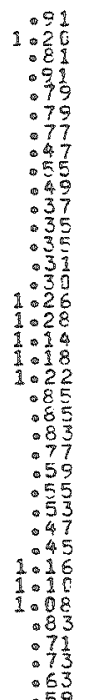 & 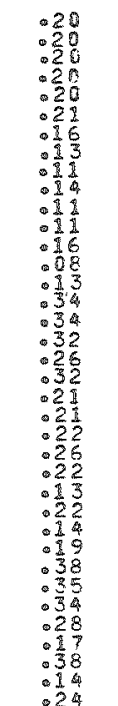 \\
\hline
\end{tabular}


PT-2 BREAKWATER WITH MOORING TYPE 3

Table A-5

Wher Depth

$d=4.7000 \mathrm{~m}$

Tire Diameter

$D=66.000 \mathrm{em}$

Brear water Beam

Pipe Spacing

$\mathbb{B}=12.200 \mathrm{~m}$

Relative Draft

$=3.660 \mathrm{~m}$

Aspect Ratio

$1 /=0.140$

Pipe Spreing

$B=18.48$

\begin{tabular}{|c|c|c|c|c|c|c|c|c|c|c|c|c|c|c|}
\hline$\stackrel{s}{(e m)}$ & $\frac{d}{d m}$ & $\begin{array}{c}\mathrm{T} \\
|\sec |\end{array}$ & $\begin{array}{c}\mathbb{P} 1 \\
\text { (erol }\end{array}$ & $\begin{array}{c}\mathrm{H}_{\hat{t}} \\
(\mathrm{~cm})\end{array}$ & $\begin{array}{c}\mathbb{F} \\
\left(\mathrm{F}_{\mathrm{s}} \mathrm{s}_{\mathrm{f} / \mathrm{m}}\right)\end{array}$ & $\begin{array}{c}\overline{\mathbb{E}} \\
\left(\mathrm{k}_{\mathrm{g}} \mathrm{g}_{\mathrm{f}} / \mathrm{m}\right.\end{array}$ & $\begin{array}{c}\mathbb{F}_{\mathbb{2}} \\
\left(\mathbb{F}_{\mathbb{R} / \pi}\right.\end{array}$ & $\begin{array}{c}\mathbb{F}_{\mathbb{B}} \\
\left(\mathrm{BS}_{\mathbb{P}} / \mathrm{m}\right)\end{array}$ & $\stackrel{\mathbb{L}}{(\mathrm{m})}$ & $\mathbb{R} / \mathbb{L}$ & $\mathbb{L} / \mathbb{B}$ & $\mathbb{C}_{t}$ & $\mathbb{H} / \mathbb{D}$ & $F / \gamma D^{2}$ \\
\hline 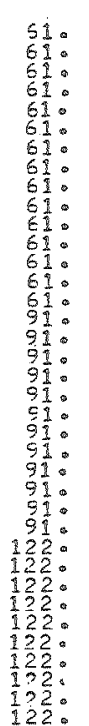 & 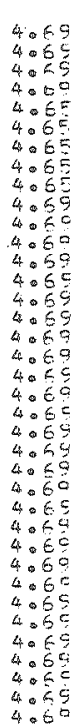 & 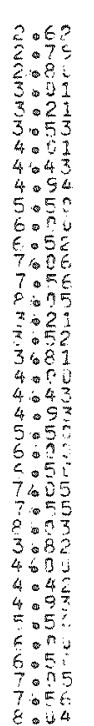 & 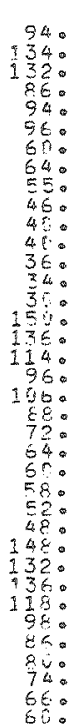 & 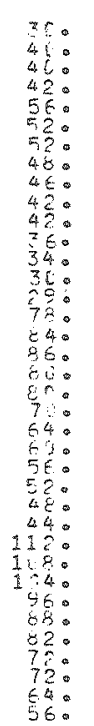 & 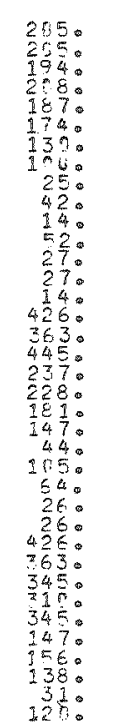 & 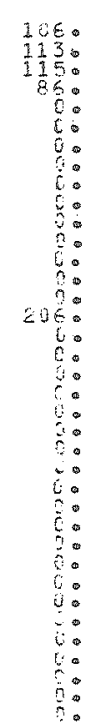 & 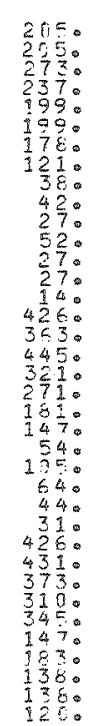 & 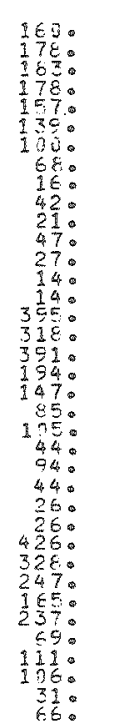 & 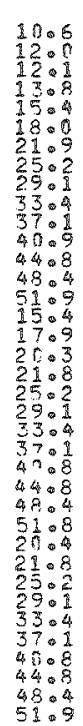 & 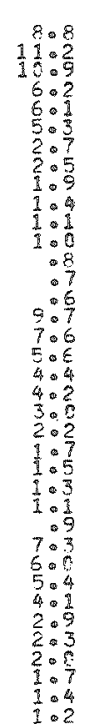 & 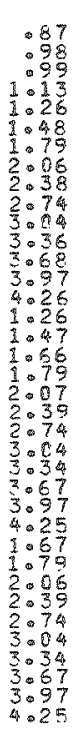 & 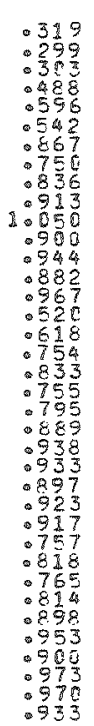 & 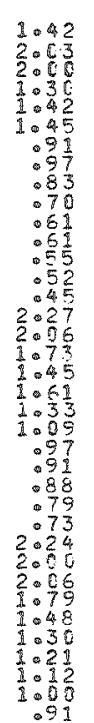 & 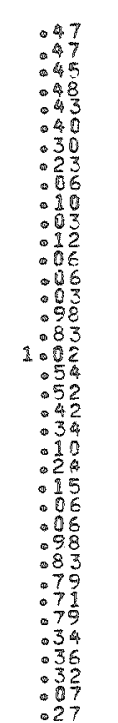 \\
\hline
\end{tabular}




\begin{abstract}
Water Dopth $\quad d=2.000$ m
wire Diameter $\quad \mathbb{D}=66.000$ m

Breakn 2 ter Beam $\quad B=12.200$ m

Pipe $B$ acing

Relative Draft $\quad D / d=0.330$

Aspect ratio

$\mathrm{B} / \mathrm{D}=18.485$

Pipe Spacing

$\mathbb{G} / D=3.5$
\end{abstract}

\begin{tabular}{|c|c|c|c|c|c|c|c|c|c|c|c|c|c|c|}
\hline $\begin{array}{c}8 \\
(\mathrm{~cm})\end{array}$ & $\stackrel{d}{(m)}$ & $\begin{array}{c}\mathbb{T} \\
(s \in \mathbb{C})\end{array}$ & $\begin{array}{c}\text { 酸 } \\
l \mathrm{em} /\end{array}$ & $\begin{array}{l}\mathrm{H}_{\text {t }} \\
\text { (ctin) }\end{array}$ & $\begin{array}{c}F \\
\left(\mathrm{~F}_{\mathrm{s}} \mathrm{g}_{\mathrm{f} / \mathrm{man}}\right)\end{array}$ & 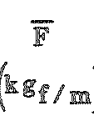 & $\begin{array}{l}F_{2} \\
F_{2}\end{array}$ & $\left(\begin{array}{c}\mathbb{F}_{\mathrm{g}} \\
\left(\mathrm{F}_{\mathrm{g}} / \mathrm{m}\right)\end{array}\right.$ & $\stackrel{\mathbb{L}}{|m|}$ & $\mathbb{P} / \mathbb{L}$ & $\mathbb{L} / \mathbb{B}$ & $\mathbb{C}_{\mathbb{t}}$ & $\mathbb{H} / \mathbb{D}$ & $F / \gamma D^{2}$ \\
\hline 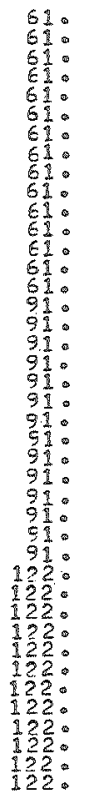 & 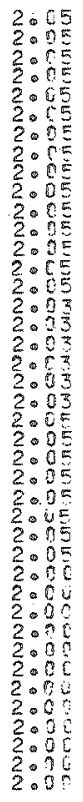 & 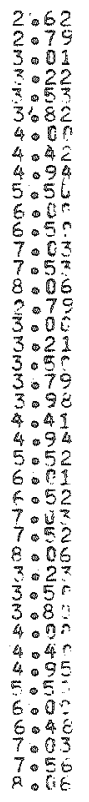 & 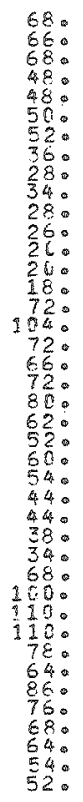 & 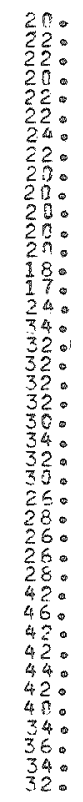 & 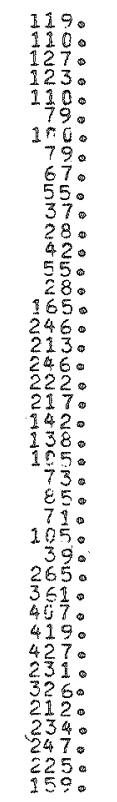 & 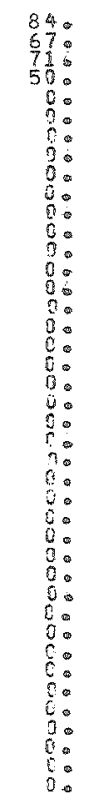 & 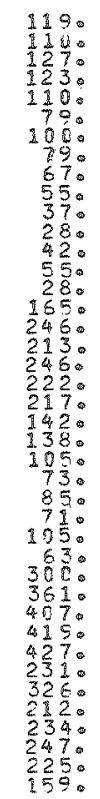 & 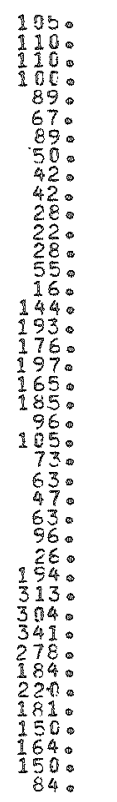 & 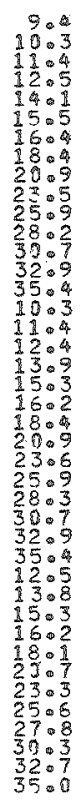 & 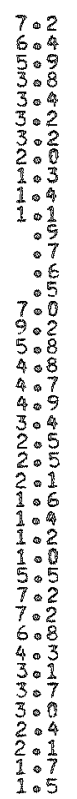 & 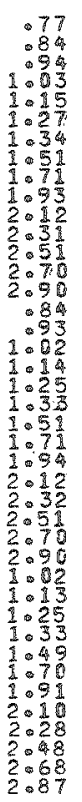 & 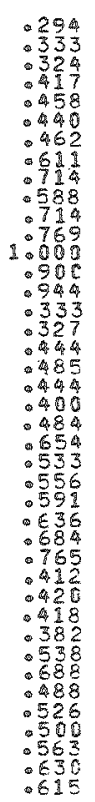 & 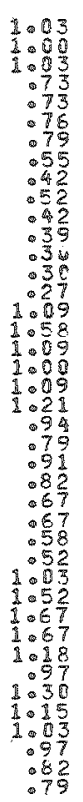 & 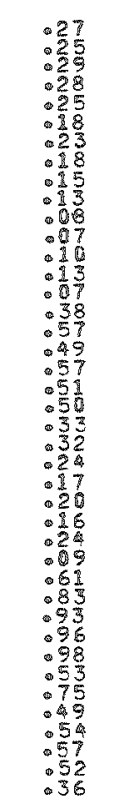 \\
\hline
\end{tabular}


PT-DB BREARWATER WITH MOORING TYPE 3

Table $A-7$

Wrer Depth

$d=4.650 \mathrm{~m}$

Tire Diameter $\quad D=101.6000$ m

Bromster Besm $B=25.900$ m

Pipe Sprecing $\mathrm{C}=3.350 \mathrm{~m}$

Relative Dratt $\quad \mathrm{D} / \mathrm{d}=0.218$

Aspect Ratio $\quad \mathbb{B} / \mathbb{D}=25.492$

Pipe Spacing $\quad G / D=3.297$

\begin{tabular}{|c|c|c|c|c|c|c|c|c|c|c|c|c|c|}
\hline$d$ & $\begin{array}{c}\mathbb{T} \\
|\sec |\end{array}$ & $\begin{array}{c}\mathrm{H} \\
(\mathrm{cm})\end{array}$ & $\begin{array}{l}\mathbb{H}_{\uparrow} \\
(\mathrm{c}+\mathrm{m})\end{array}$ & $\frac{F}{\left(\mathrm{Kg}_{\mathbb{1} / \mathrm{m}}\right.}$ & $\begin{array}{c}\overline{\mathbb{F}} \\
\mathrm{s} \mathbb{g}_{\mathfrak{H} / \mathfrak{n}}\end{array}$ & 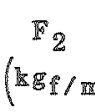 & $\begin{array}{c}\mathbb{F}_{\mathbb{B}} \\
\left(\mathrm{rg}_{\mathbb{I} / \mathrm{m}}\right)\end{array}$ & $\underset{1}{\mathbb{L}}$ & $\mathbb{H} / \mathbb{L}$ & $\mathbb{L} / \mathbb{B}$ & $\mathbb{C}_{\text {政 }}$ & $\mathbb{H} / \mathbb{D}$ & $\mathbb{F} / \gamma \mathbb{D}^{2}$ \\
\hline 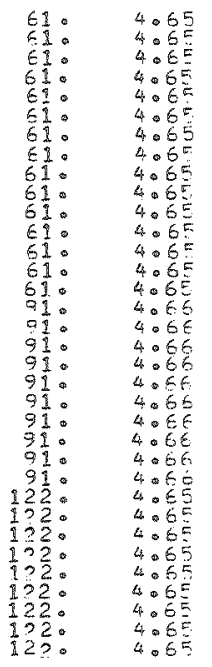 & 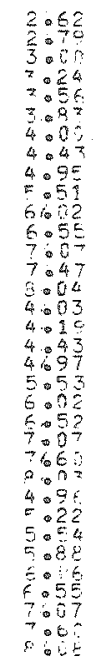 & 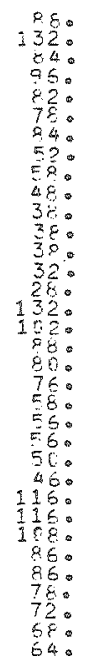 & 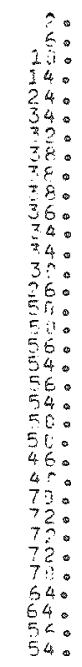 & 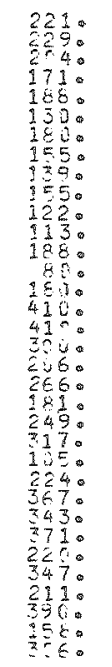 & 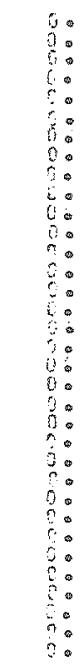 & 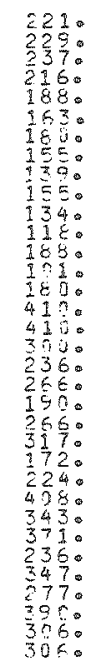 & 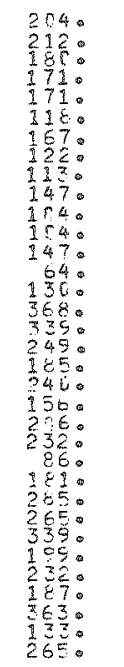 & 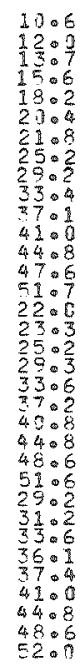 & 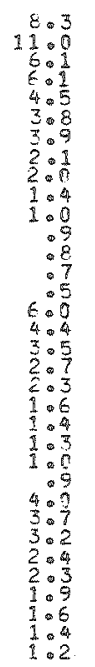 & 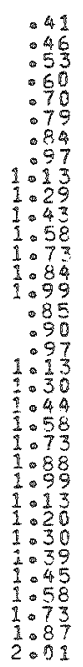 & 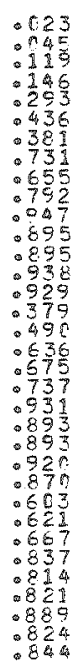 & 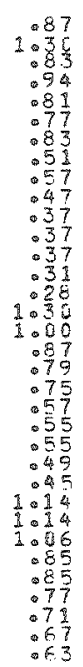 & 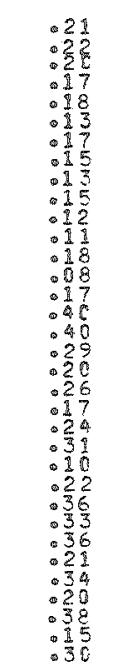 \\
\hline
\end{tabular}


- 112 -

APPENDTX B 


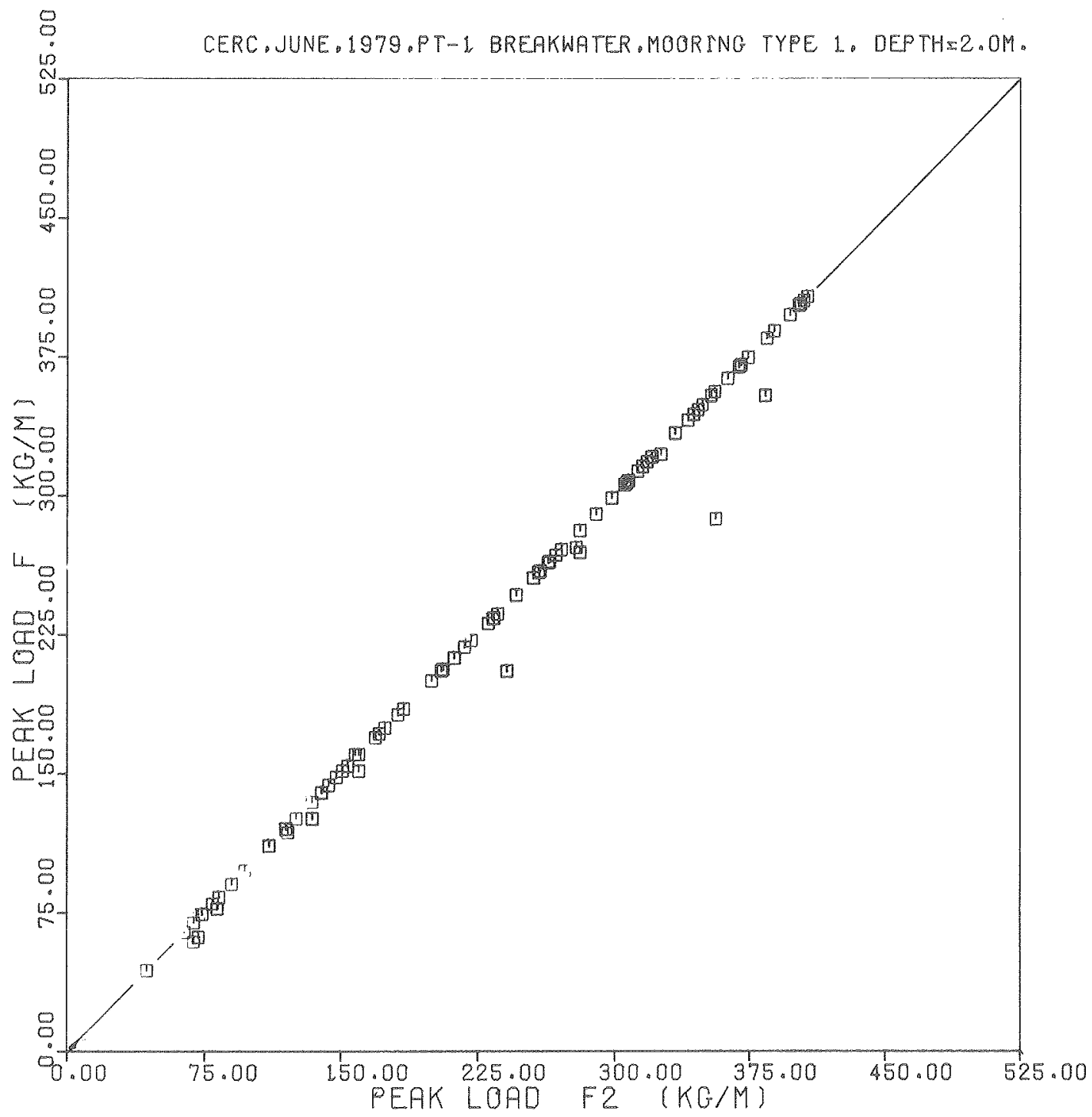

XBL $8010=12398$ Fig. $B-1 \quad \begin{aligned} & \text { Correlation of } F \text { and } F_{2} \\ & (M S-1, d=2.0 m)\end{aligned}$ 


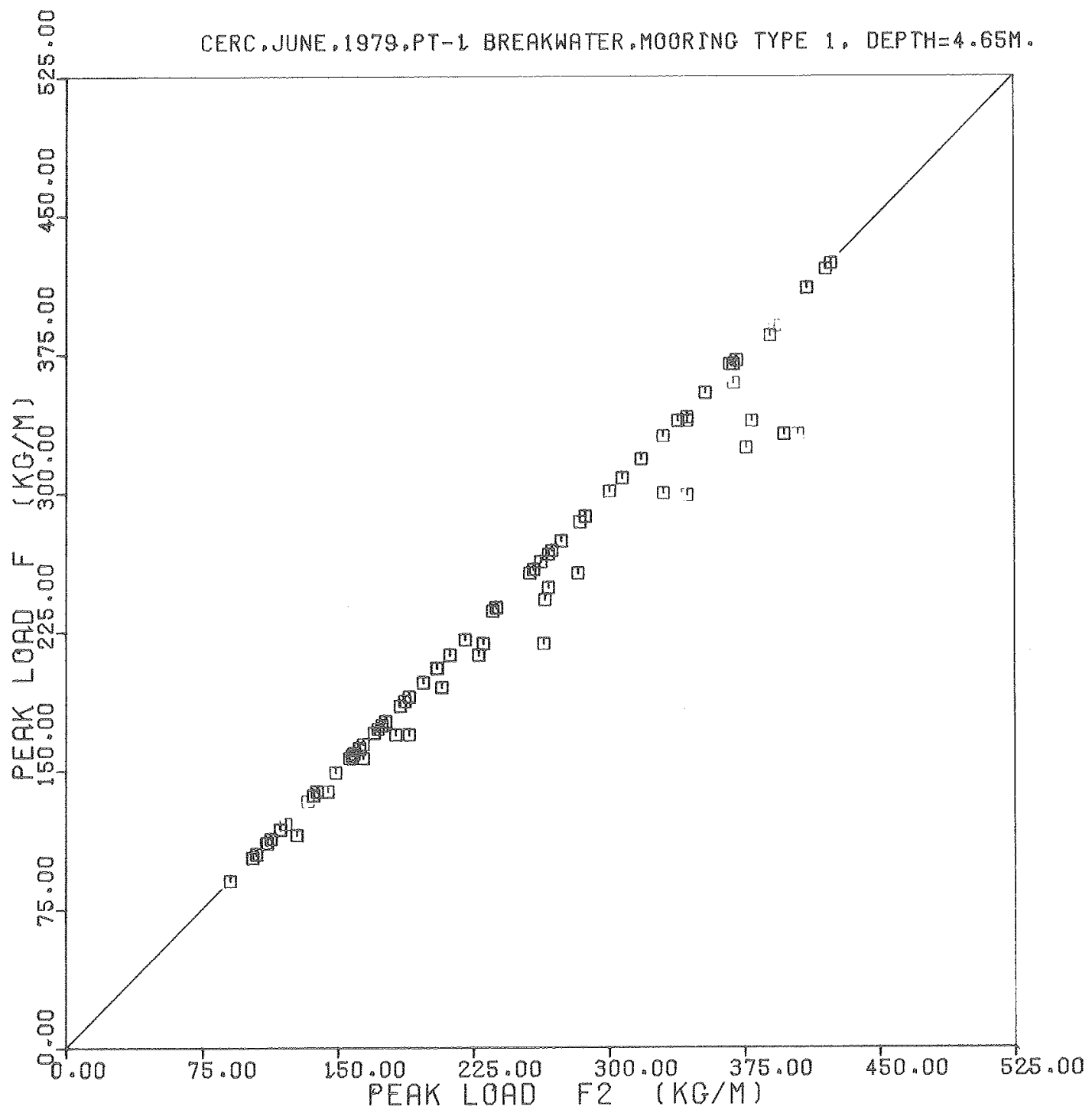

XBL $8010-12397$

$F i g \cdot B-2 \quad \begin{gathered}\text { Correlation of } \mathrm{F} \text { and } \mathrm{F}_{2} \\ (\mathrm{MS}-1, \mathrm{~d}=4.7 \mathrm{~m})\end{gathered}$ 


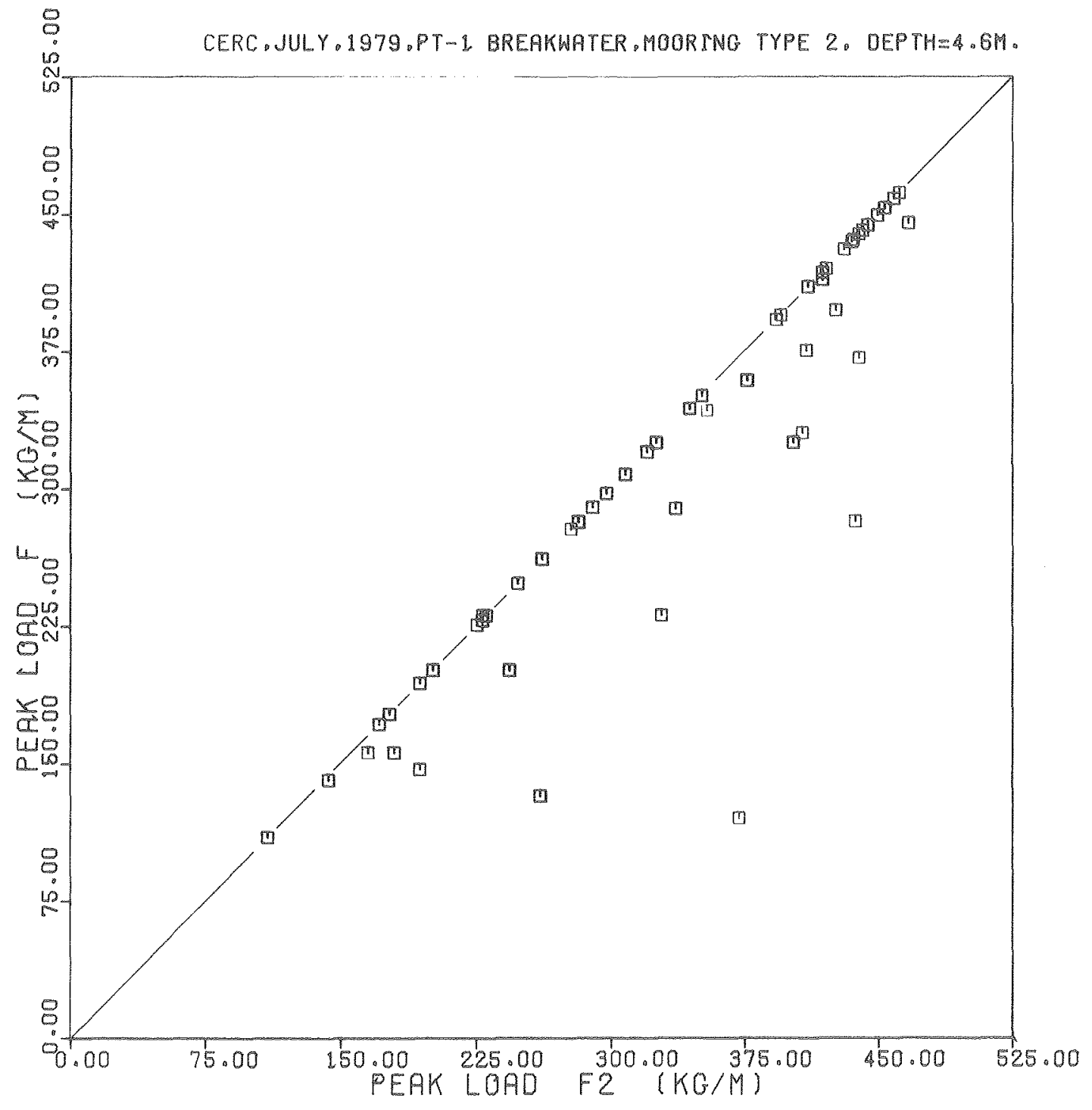

$X B L \quad 8010-12396$

Fig. $B-3 \quad \begin{aligned} & \text { Correlation of } F \text { and } F_{2} \\ & (M S-2, d=4.7 \mathrm{~m})\end{aligned}$ 


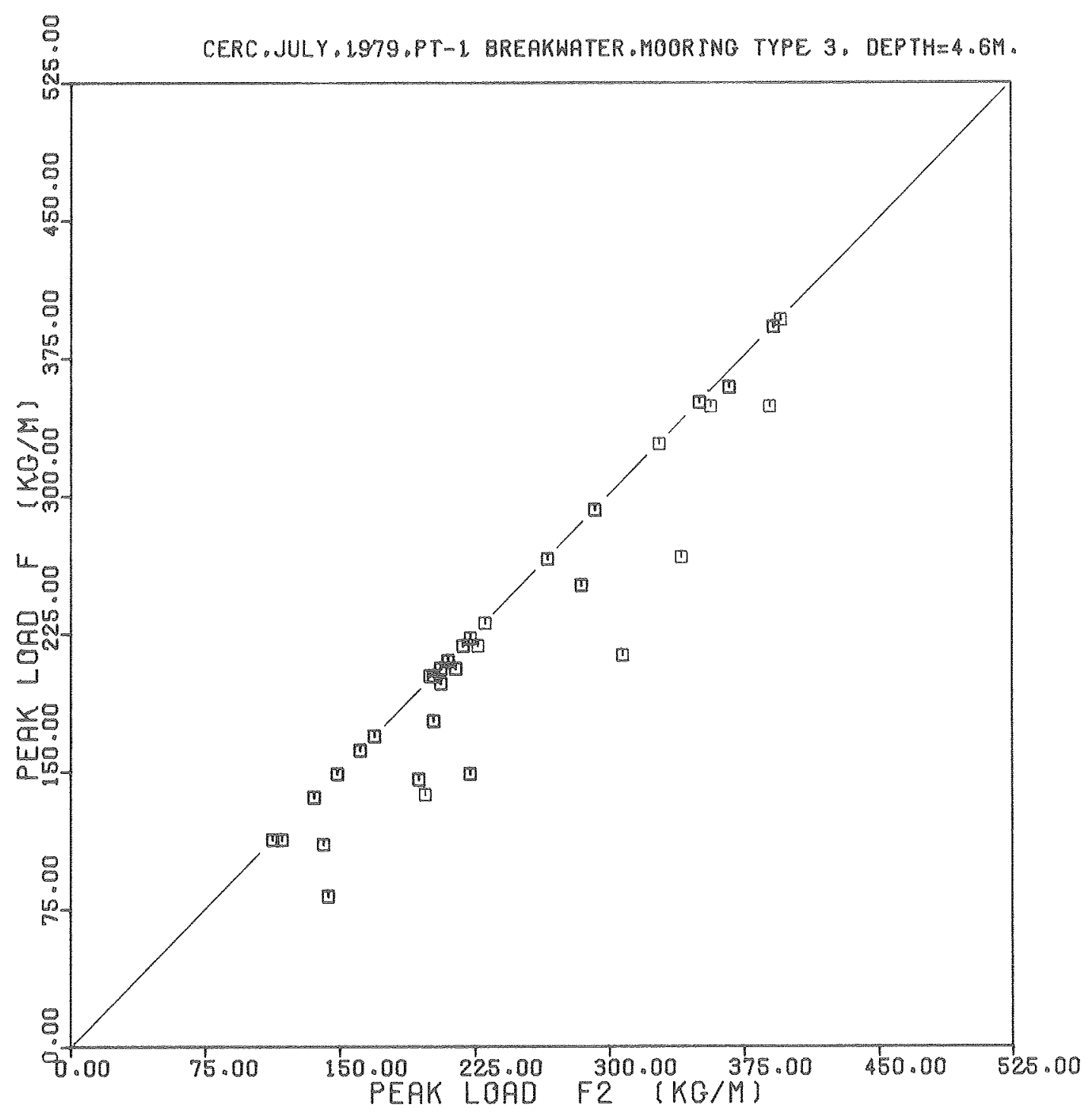

XBL $8010-12399$

Fig. B-4 Correlation of $\mathrm{F}$ and $\mathrm{F}_{2}$ 


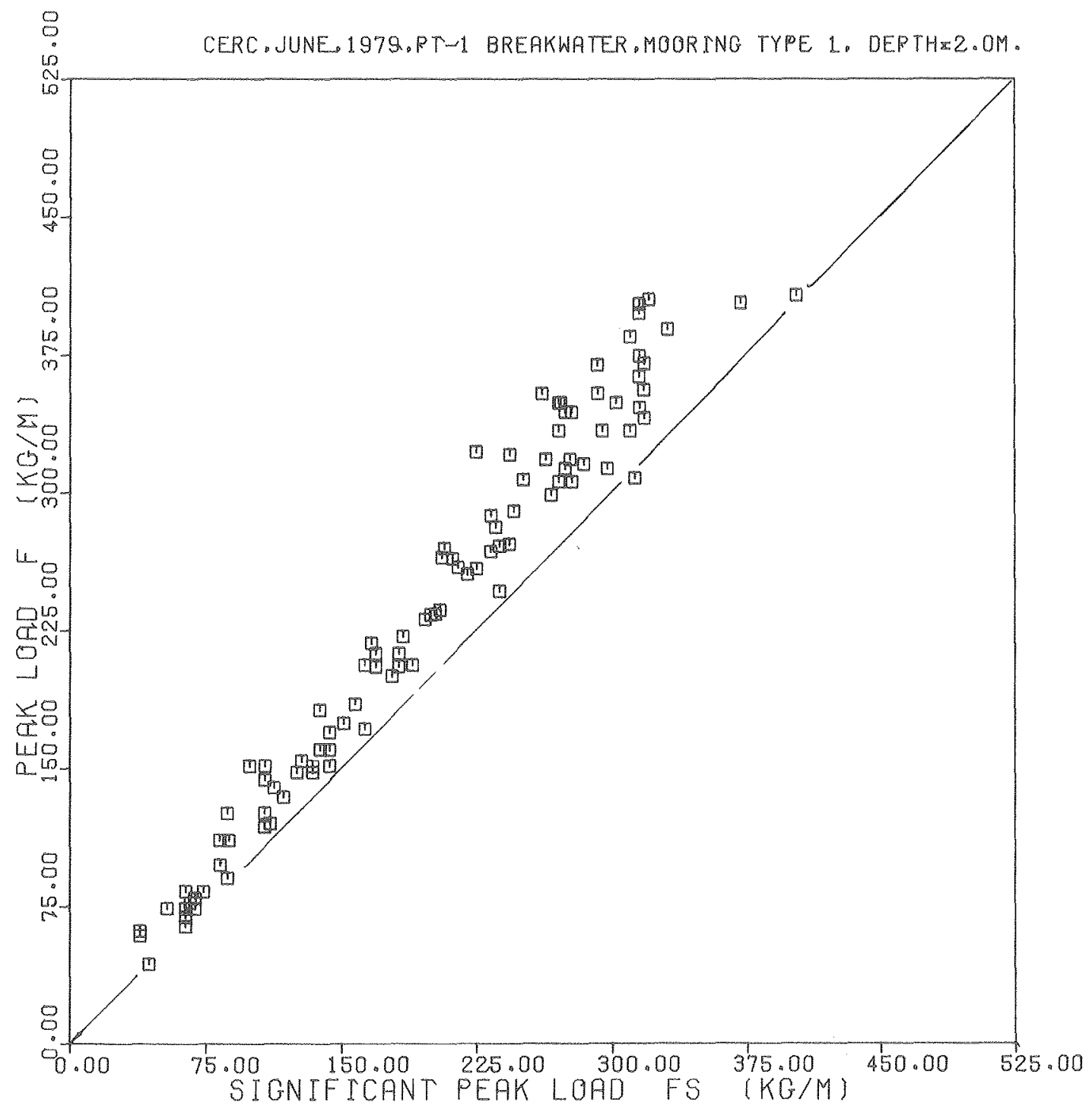

XBL 8010-12395

$\begin{aligned} \text { Fig. } B-5 \quad \begin{array}{l}\text { Correlation of } \mathrm{F} \text { and } \mathrm{F}_{\mathrm{S}} \\ (\mathrm{MS}-1, \mathrm{~d}=2.0 \mathrm{~m})\end{array} & \end{aligned}$ 


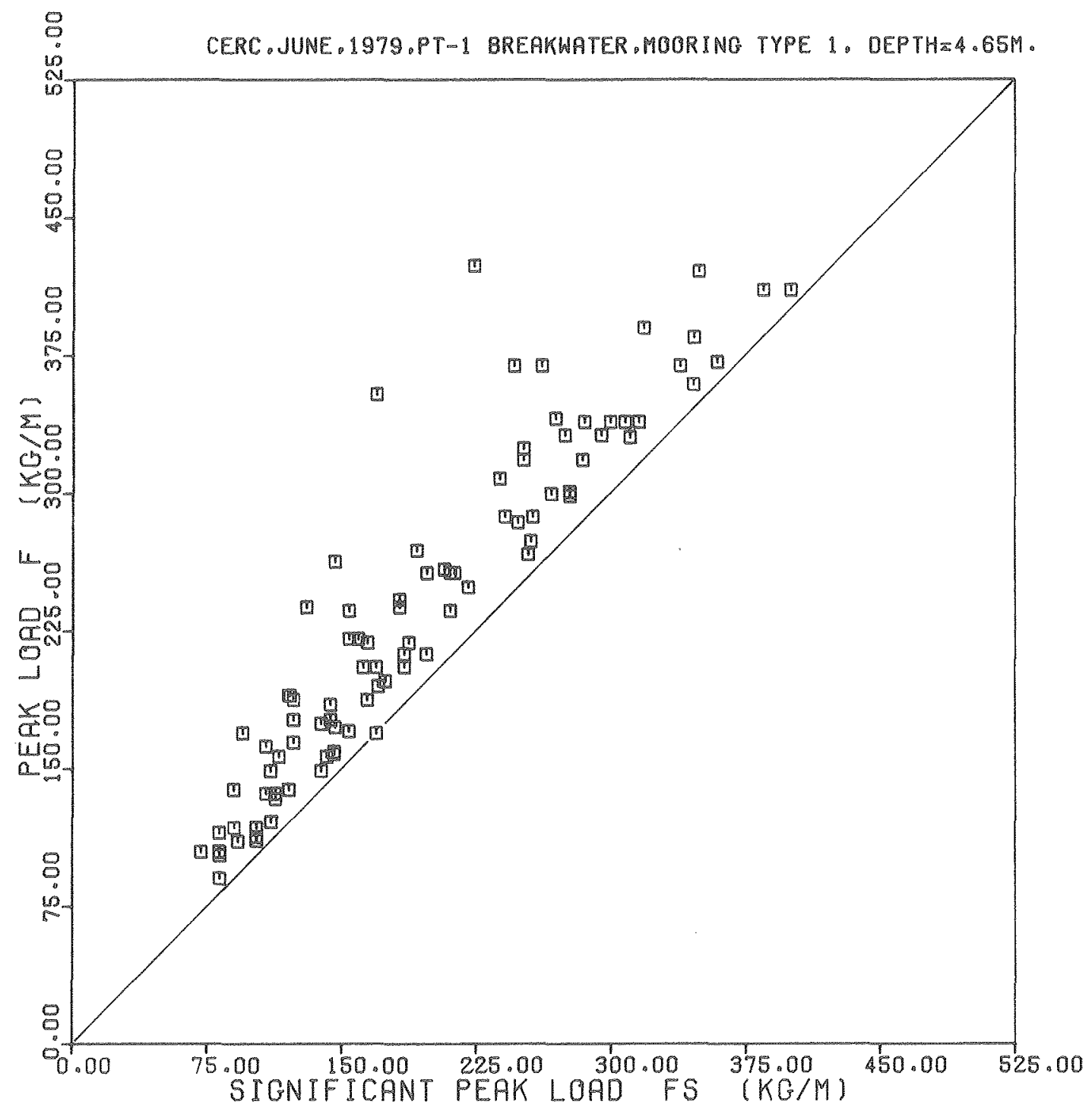

XBL $\quad 8010-12394$

Fig. B-6 Correlation of $\mathrm{F}$ and $\mathrm{F}_{\mathrm{S}}$ $(M S-1, d=4.7 m)$ 


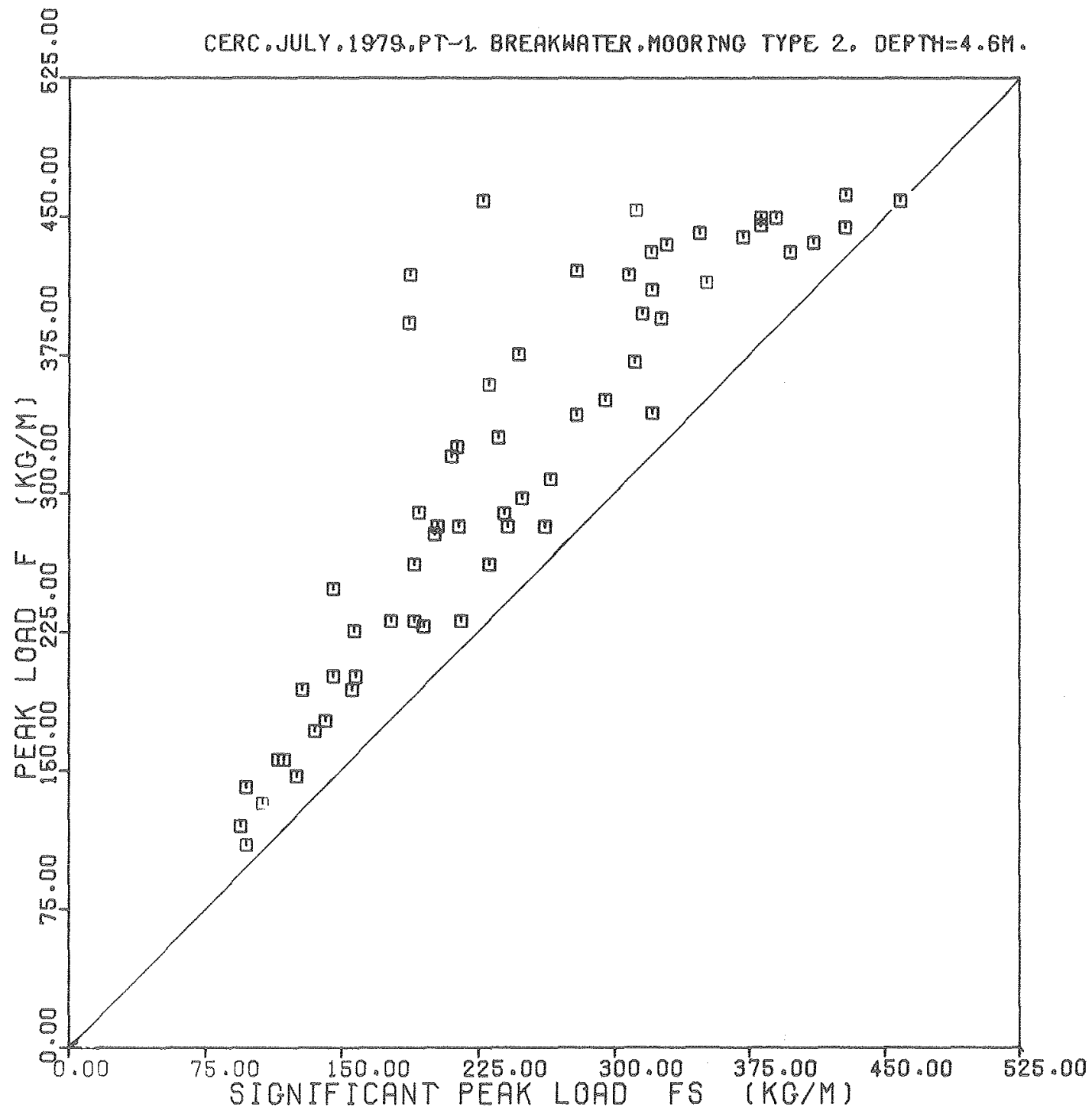

XBL 8010-12393

Fig. $\mathrm{B}-7 \quad \begin{aligned} & \text { Correlation of } \mathrm{F} \text { and } \mathrm{F}_{\mathrm{S}} \\ & (\mathrm{MS}-2, \mathrm{~d}=4.7 \mathrm{~m})\end{aligned}$ 


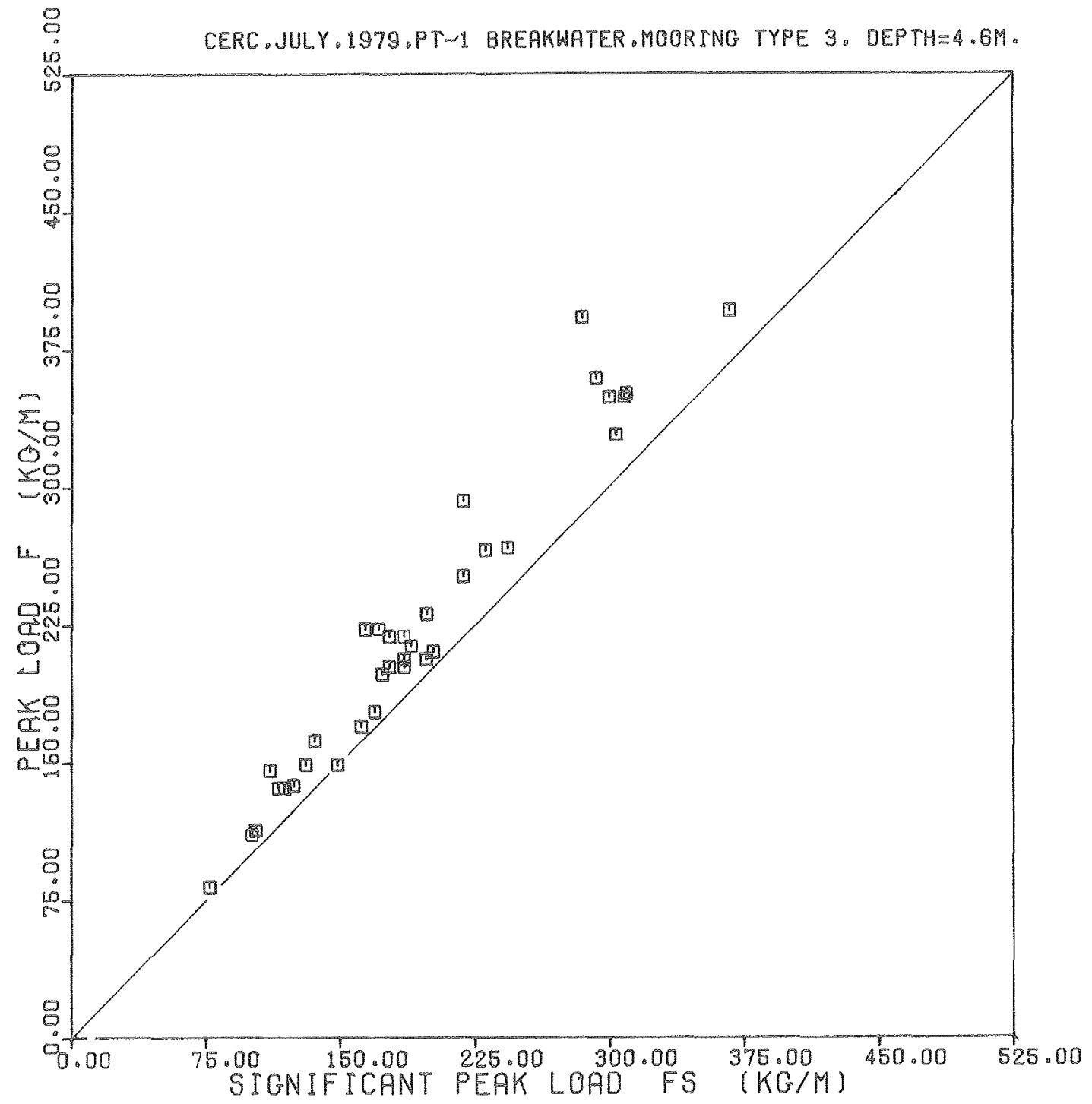

XBL $8010-12392$

Fig. B-8 Correlation of $\mathrm{F}$ and $\mathrm{F}_{\mathrm{S}}$ 
APPENDIX C 


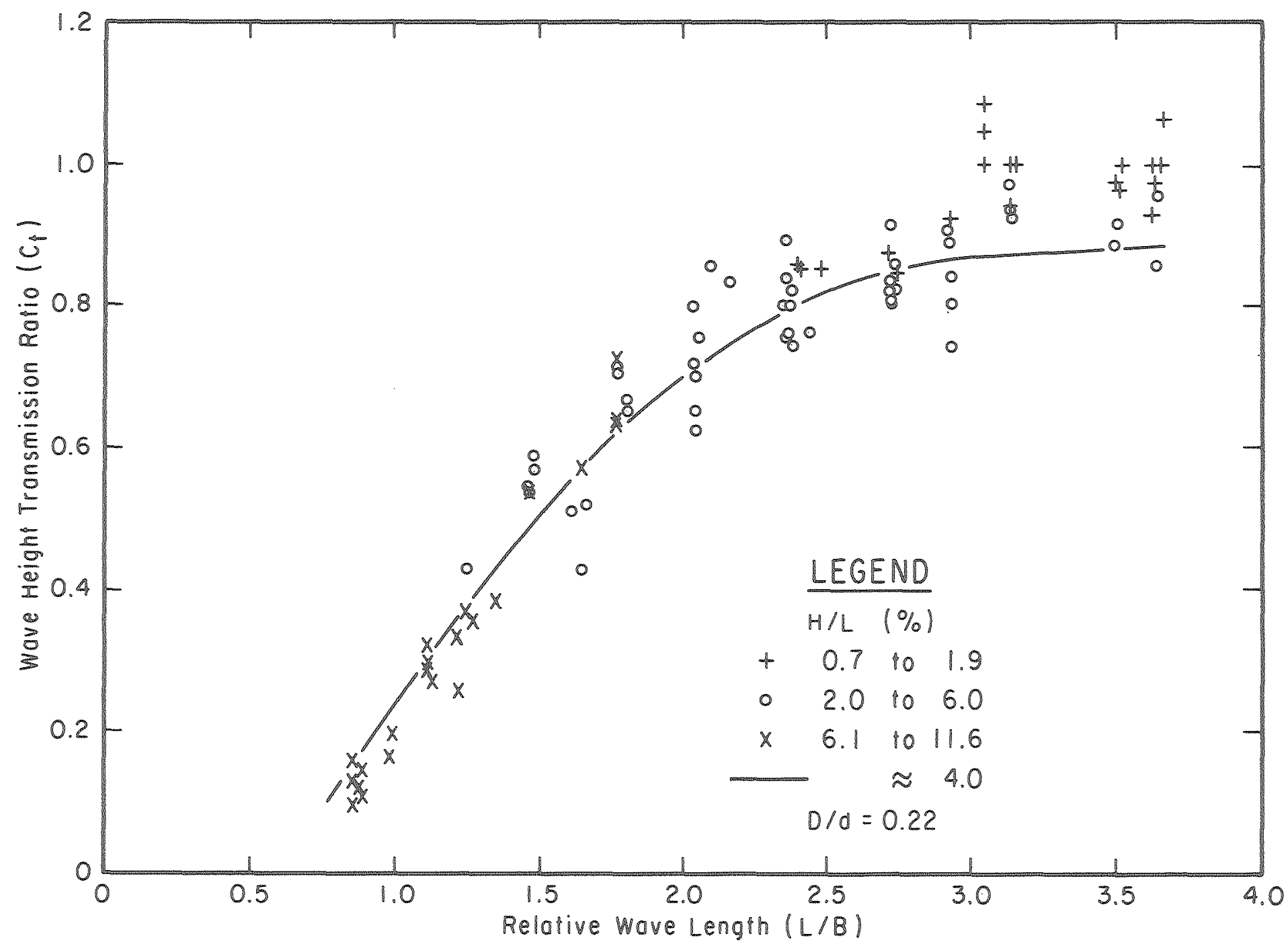

XBL $804-9227$

Fig. C-1 PT-1 Wave-Transmission Data for MS-I 


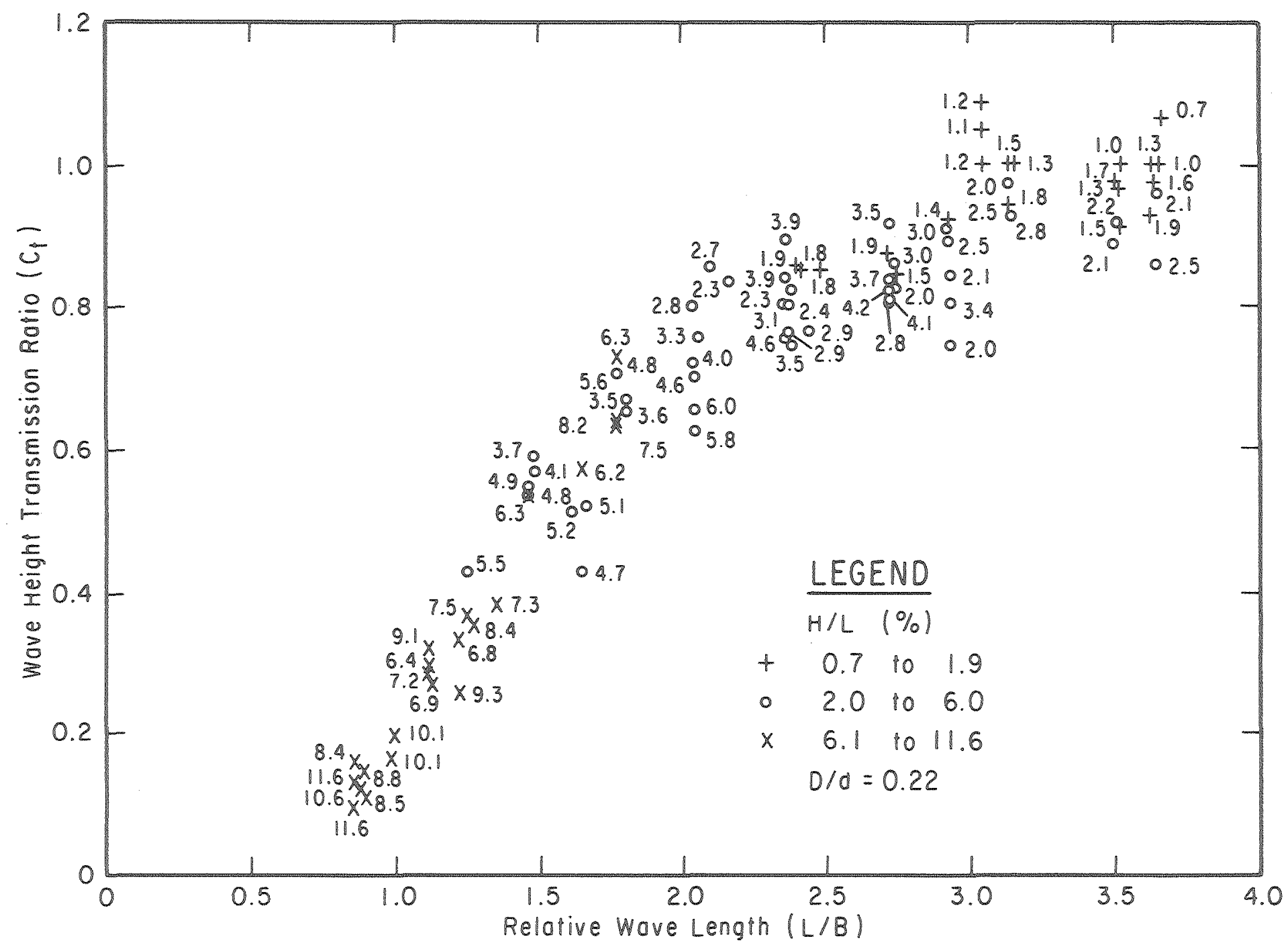

XBL $804-9226$

Fig. C-2 PT-1 Wave-Transmission Data for MS-1 (discrete $H / L$ ) 


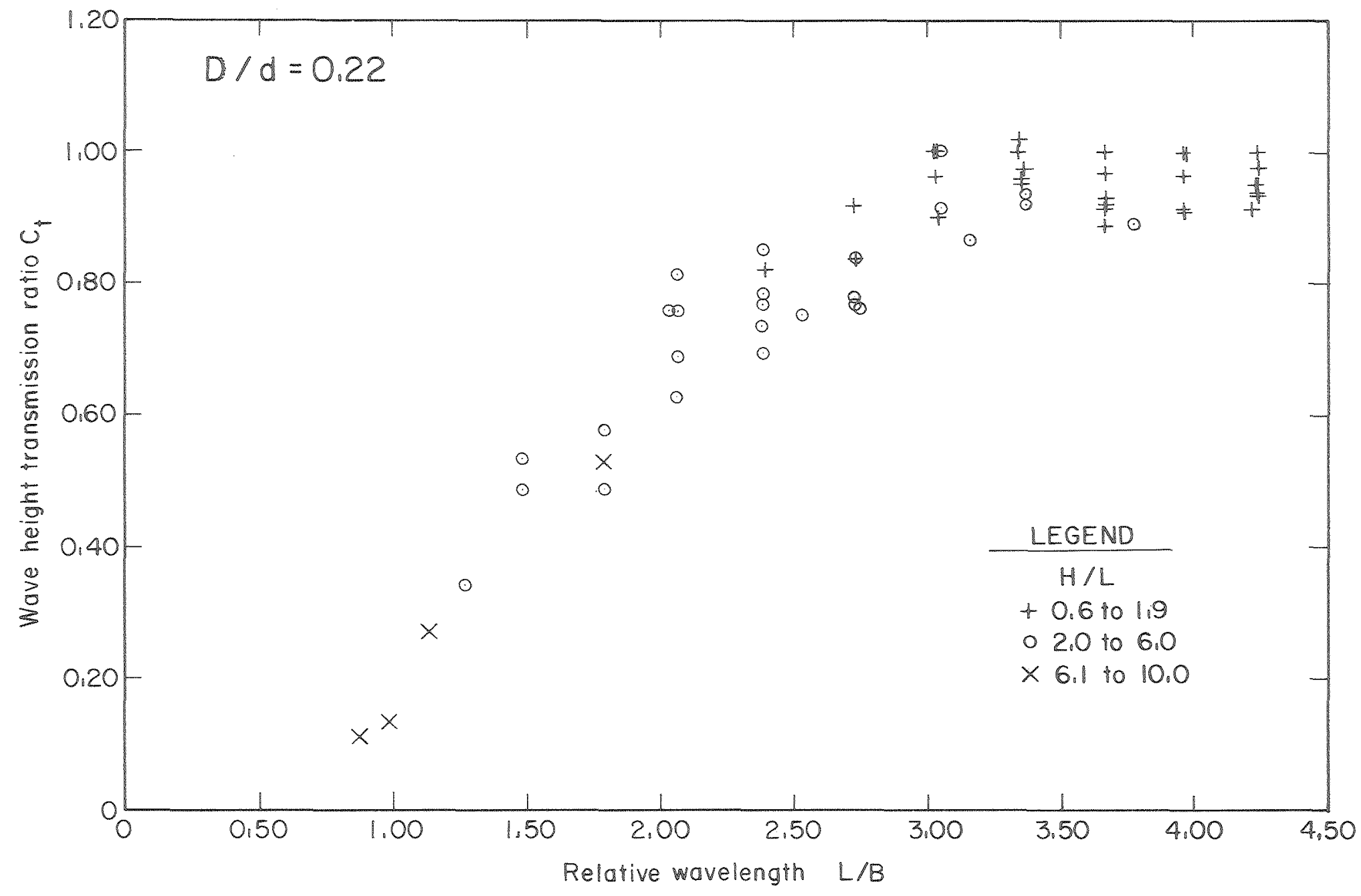

XBL $804-555$

Fig. C-3 PT-1 Wave-Transmission Data for MS-2 


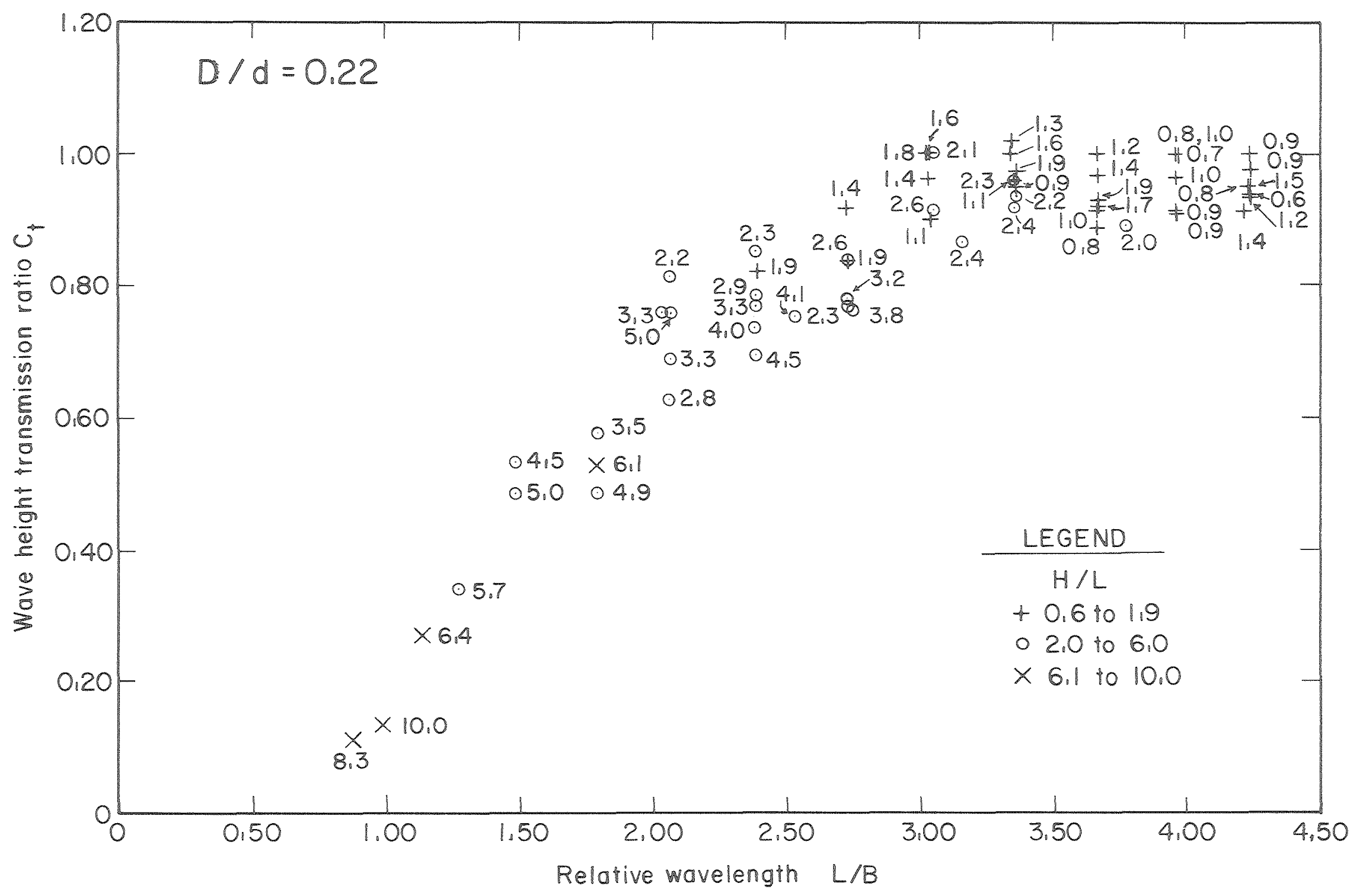




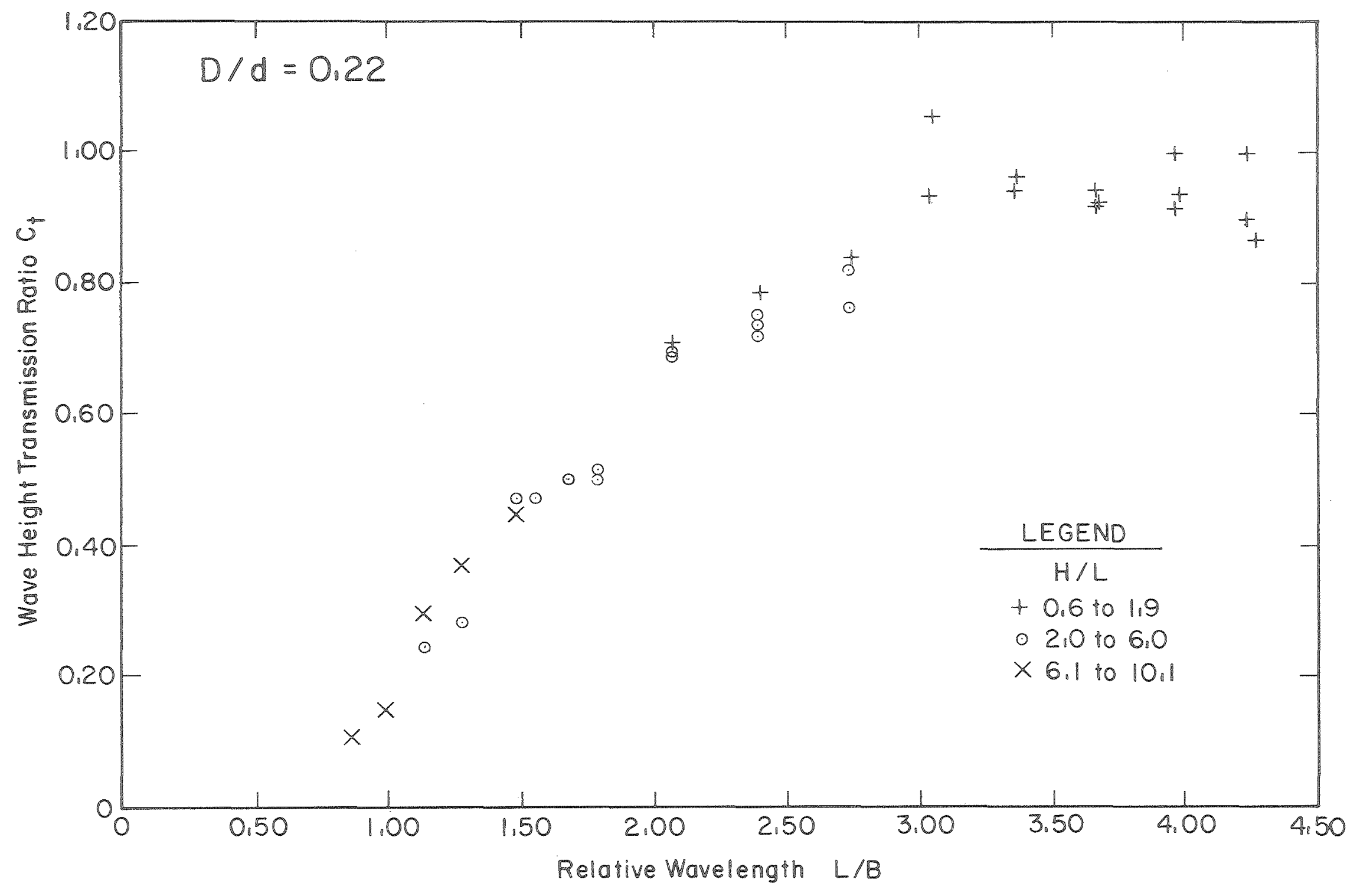

Fig. C-5 PT-1 Wave-Transmission Data for MS-3 


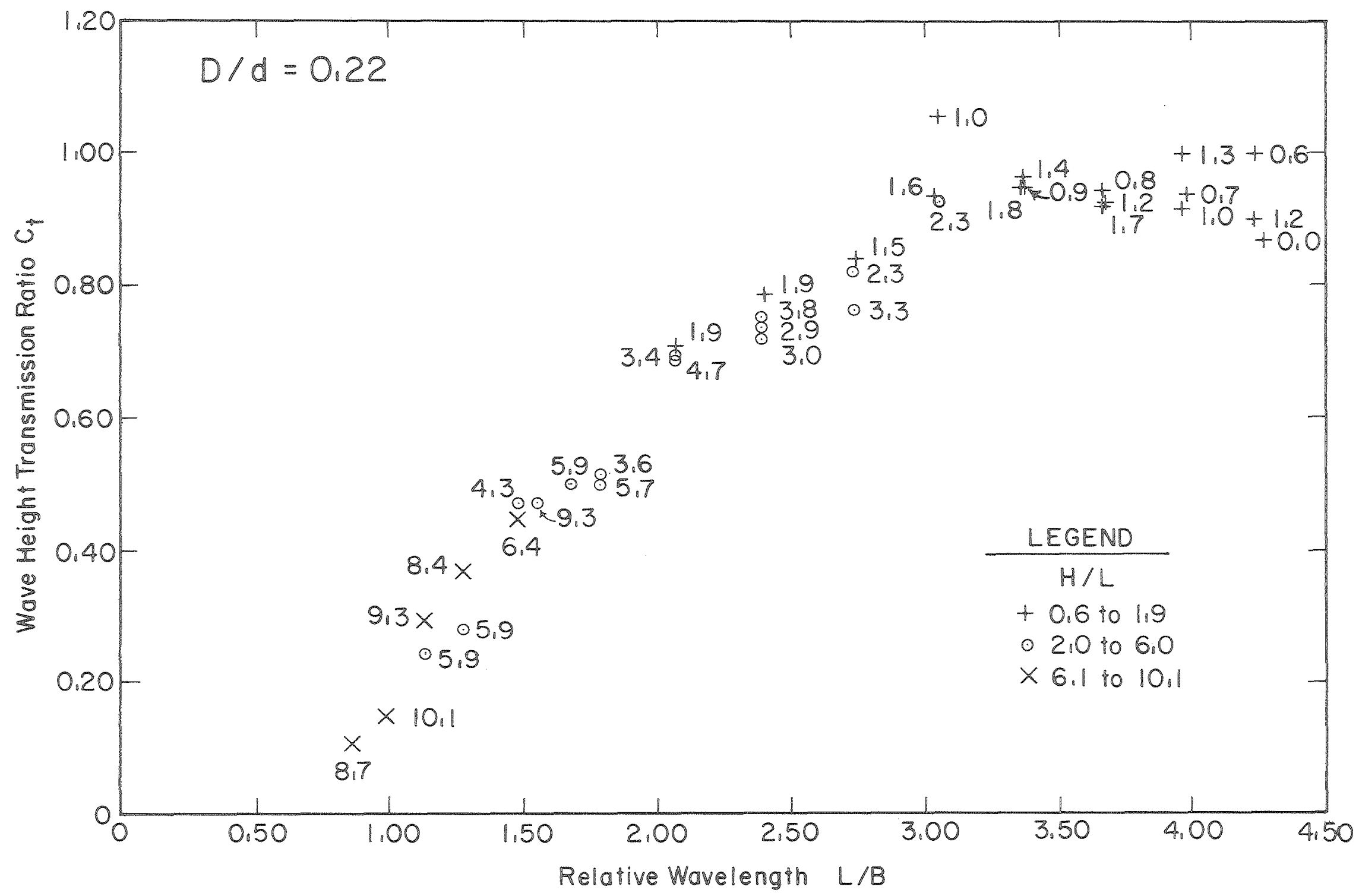

Fig. C-6 PT-1 Wave-Transmission Data for MS-3

XBL 804-553 (discrete $H / L$ ) 


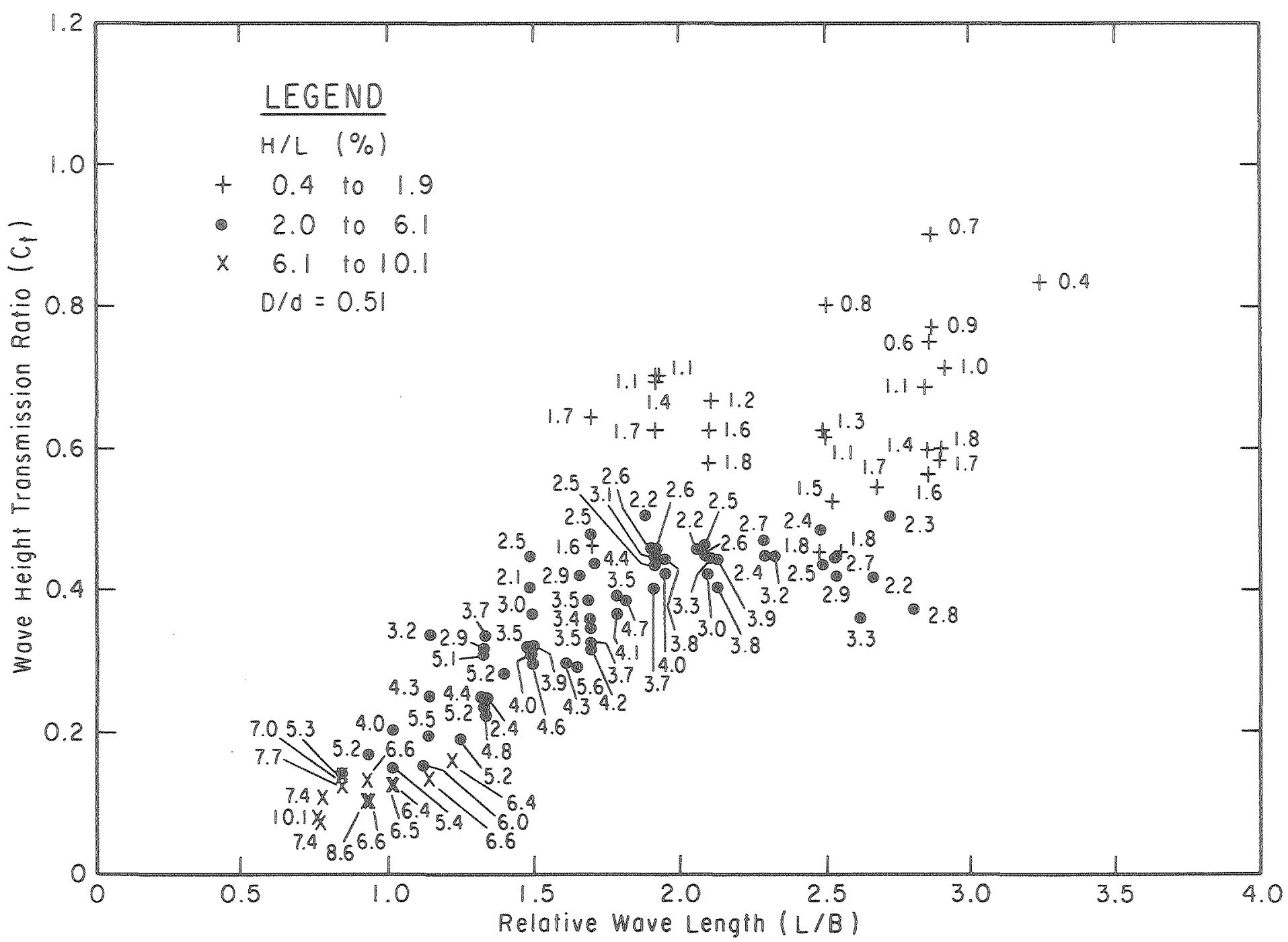

XBL $804-9225$

Fig. C-7 PT-1 Wave-Transmission Data for MS-3 (d=2.0m, discrete $\mathrm{H} / \mathrm{L}$ ) 


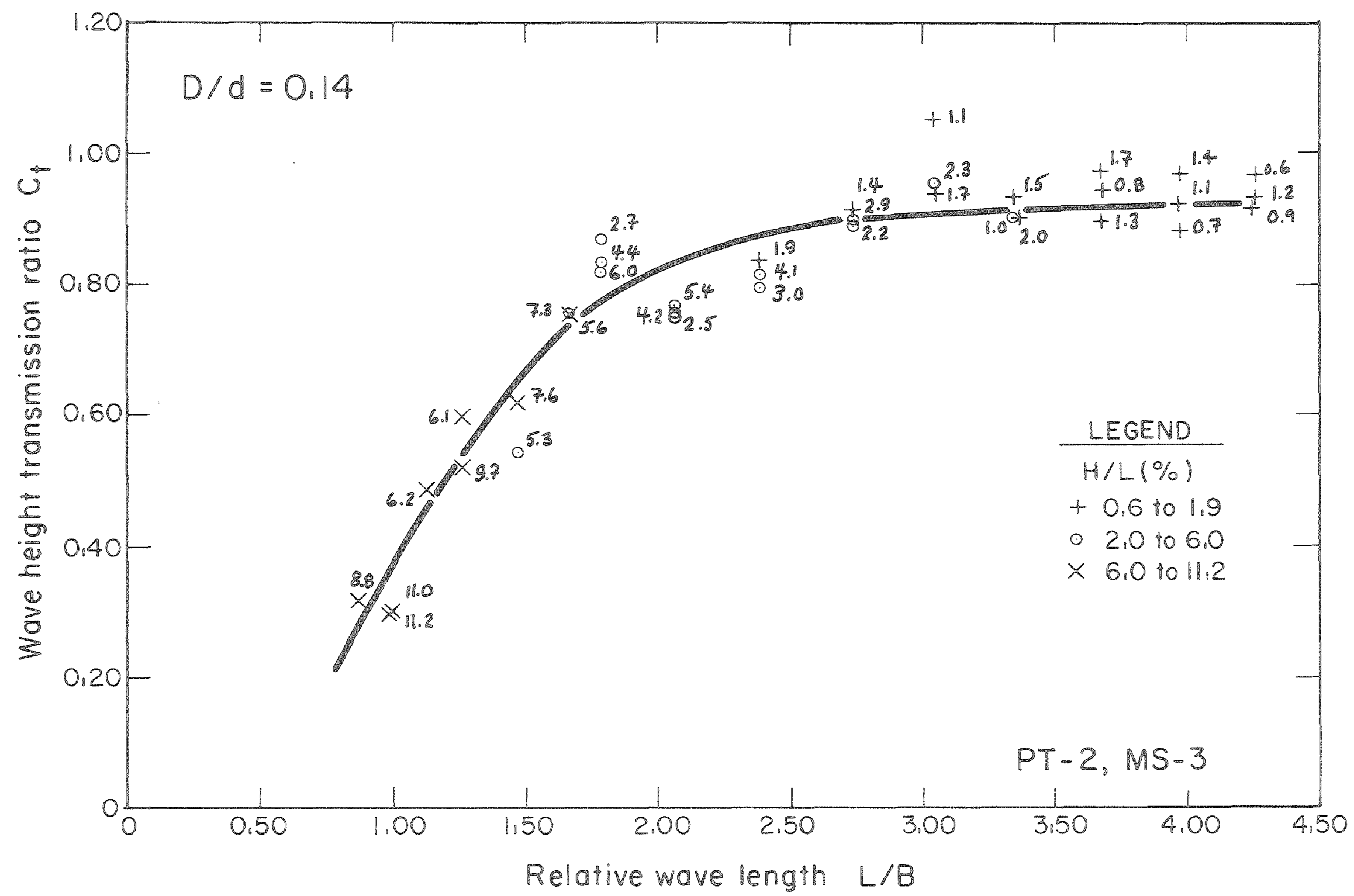

XBL $804-566 C$

Fig. C-8 PT-2 Wave-Transmission Data for MS-3

(discrete H/L) 


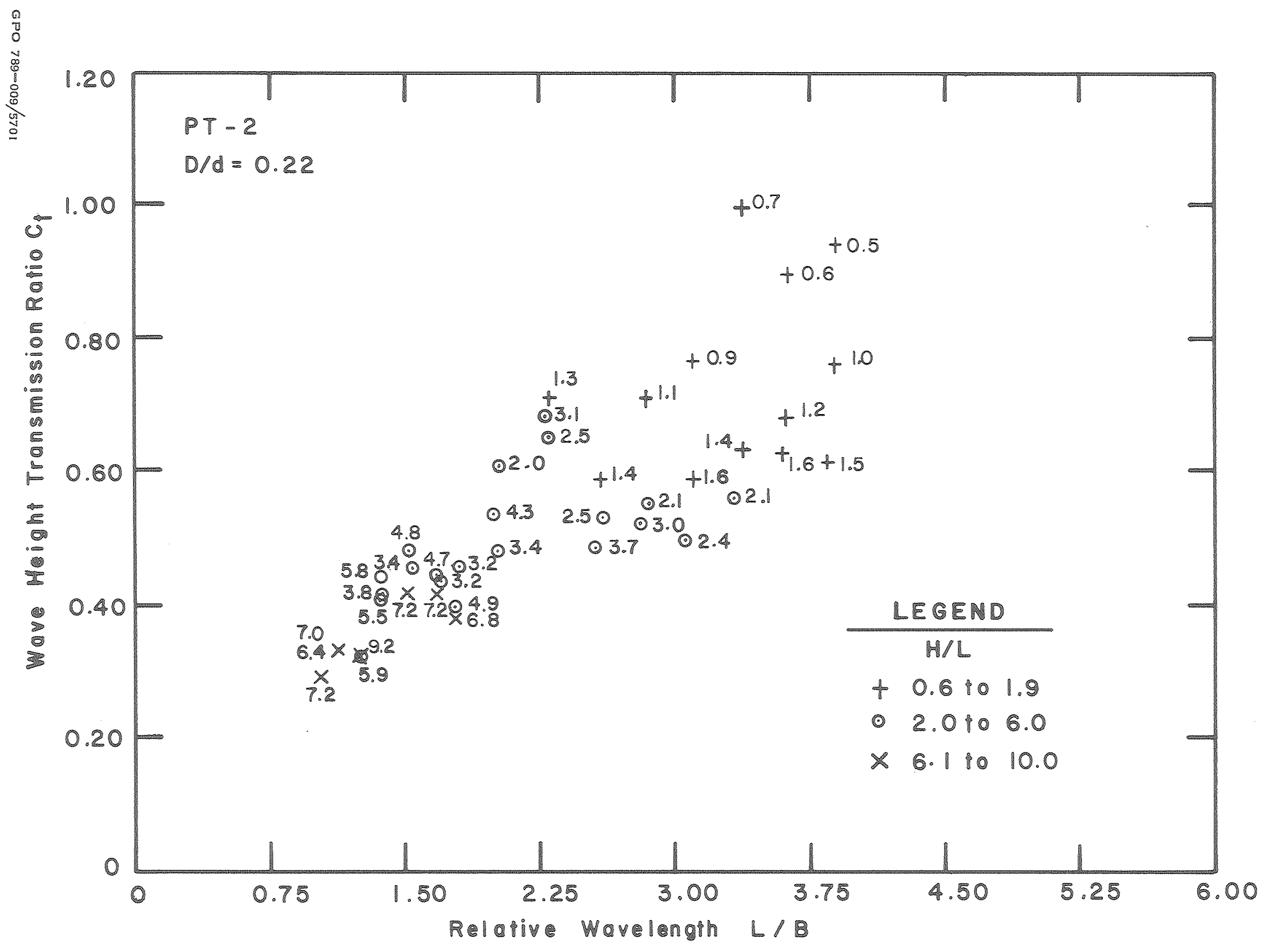

Fig. C-9 PT-2 Wave-Transmission Data for MS-3

XBL $8010-12389$ ( $d=2.0 \mathrm{~m}$. discrete $\mathrm{H} / \mathrm{T}$.) 

